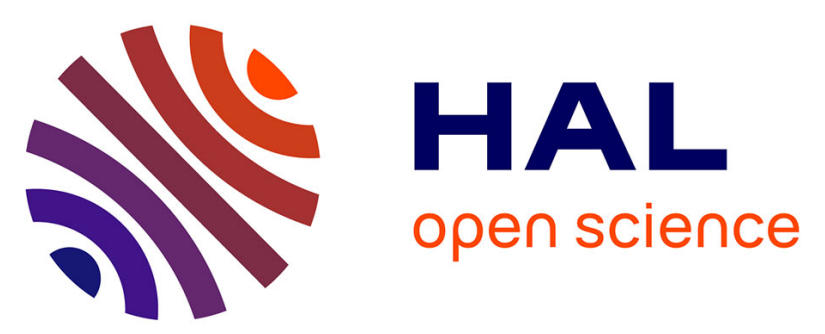

\title{
Current understanding of the growth of carbon nanotubes in catalytic chemical vapour deposition
}

Vincent Jourdain, Christophe Bichara

\section{To cite this version:}

Vincent Jourdain, Christophe Bichara. Current understanding of the growth of carbon nanotubes in catalytic chemical vapour deposition. Carbon, 2013, 58, pp.2-39. 10.1016/j.carbon.2013.02.046 . hal-01067024

\section{HAL Id: hal-01067024 \\ https://hal.science/hal-01067024}

Submitted on 22 Sep 2014

HAL is a multi-disciplinary open access archive for the deposit and dissemination of scientific research documents, whether they are published or not. The documents may come from teaching and research institutions in France or abroad, or from public or private research centers.
L'archive ouverte pluridisciplinaire HAL, est destinée au dépôt et à la diffusion de documents scientifiques de niveau recherche, publiés ou non, émanant des établissements d'enseignement et de recherche français ou étrangers, des laboratoires publics ou privés. 


\title{
Current understanding of the growth of carbon
}

\section{nanotubes in catalytic chemical vapour deposition}

\author{
Vincent Jourdain $^{1,2, *}$, Christophe Bichara ${ }^{3}$ \\ ${ }^{1}$ Université Montpellier 2, Laboratoire Charles Coulomb UMR 5221, F-34095, Montpellier,
} France.

${ }^{2}$ CNRS, Laboratoire Charles Coulomb UMR 5221, F-34095, Montpellier, France

${ }^{3}$ CINAM, CNRS and Aix Marseille Université, Campus de Luminy, Case 913, 13288

Marseille Cedex 9, France.

\section{Table of contents}

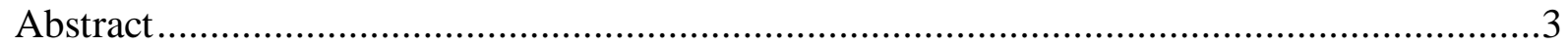

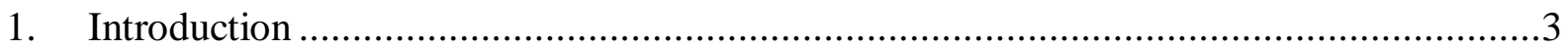

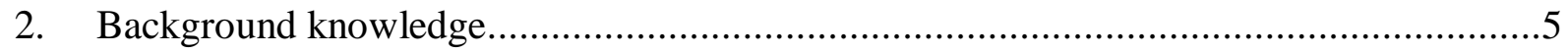

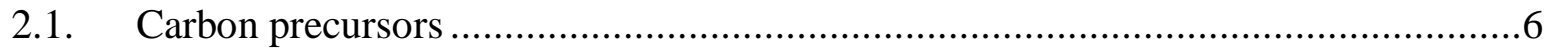

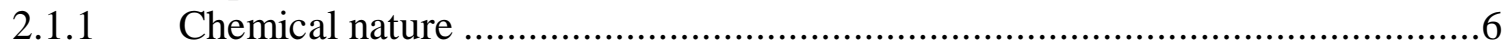

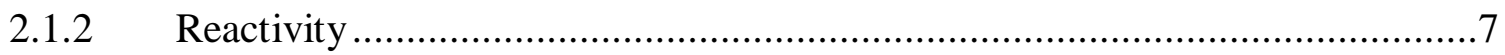

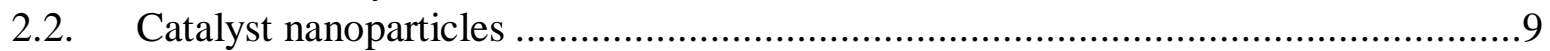

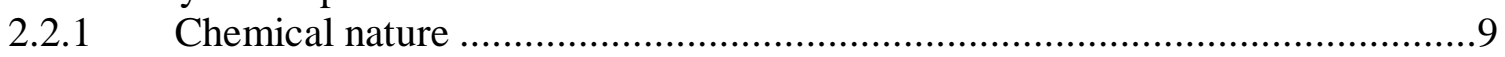

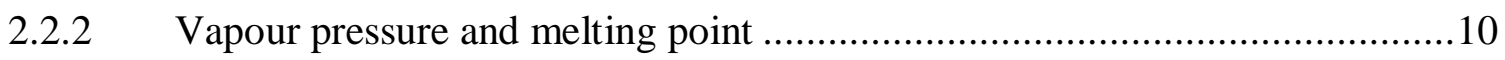

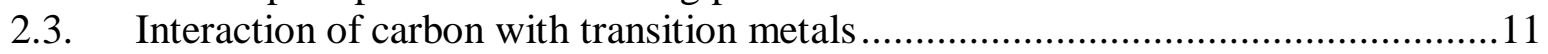

2.3.1 Affinity for carbon: carbon solubility and formation of carbides ...................11

2.3.2 Carbon diffusion: bulk, surface and subsurface ........................................... 14

2.3.3 Theoretical aspects of carbon structures interactions with metal surfaces.......17

2.4. Catalytic activity of transition metal nanoparticles ........................................20

2.4.1 Dissociative adsorption on transition metal surfaces ....................................2. 20

2.4.2 Catalytic activity of transition metal carbides ..............................................21

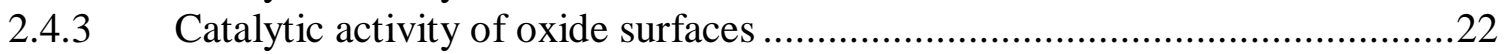

2.4.4 Nanometric size effects on catalytic activity ............................................2.

2.5. Interactions of metal nanoparticles with their environment .................................24

2.5.1 Redox interactions between metal nanoparticles and gas species ...................24

2.5.2 Interactions of metal nanoparticles with oxide supports ..............................25

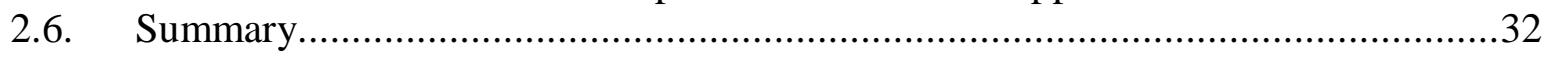

3. Synthesis-structure relationship in carbon nanotubes grown by catalytic chemical vapour

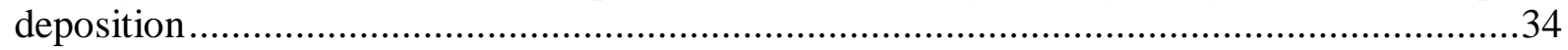

\footnotetext{
* Corresponding author. Tel/Fax: +33 467144778. E-mail address: vincent.jourdain@ univ-montp2.fr (V. Jourdain)
} 


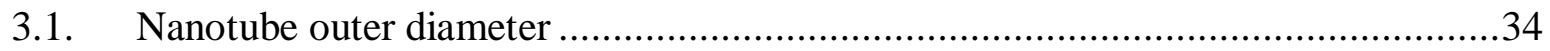

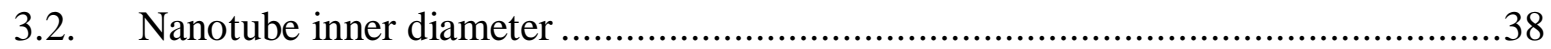

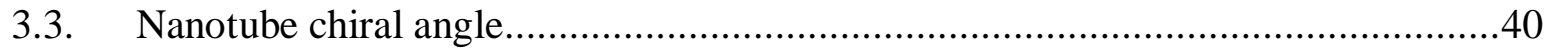

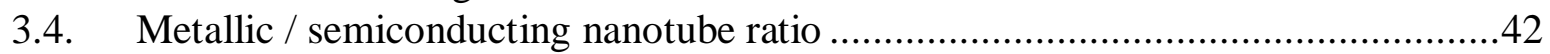

3.5. Defect density and carbonaceous impurities ...................................................44

3.6. Proportion of catalyst particles active for nanotube growth.................................46

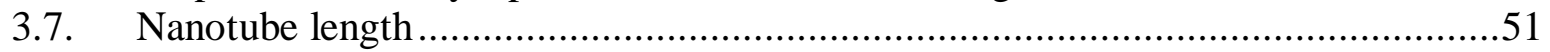

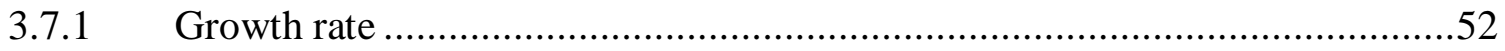

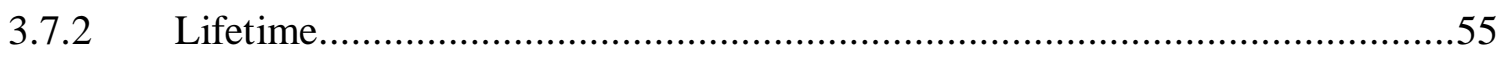

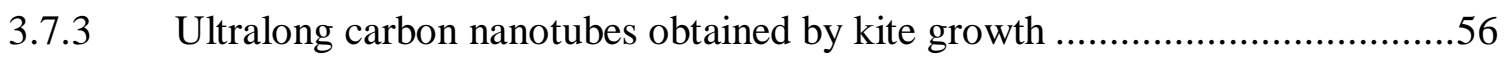

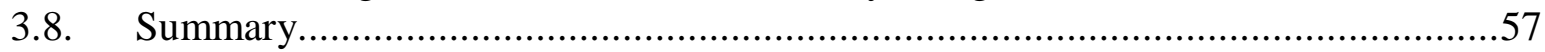

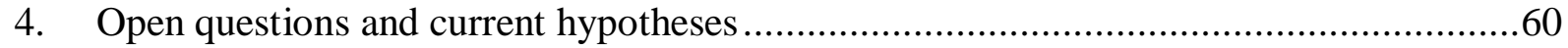

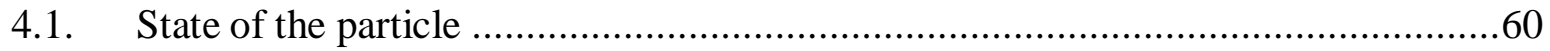

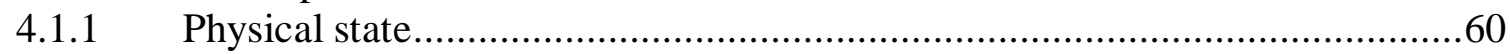

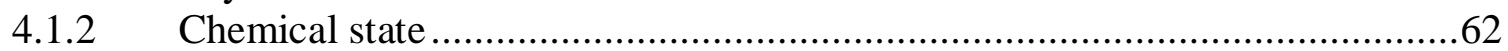

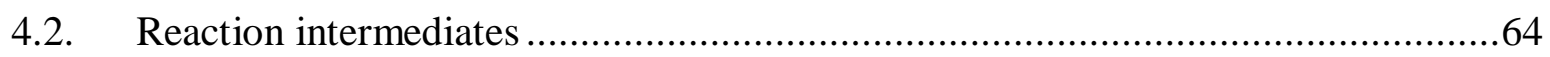

4.3. Mechanism of nanotube nucleation and growth................................................66

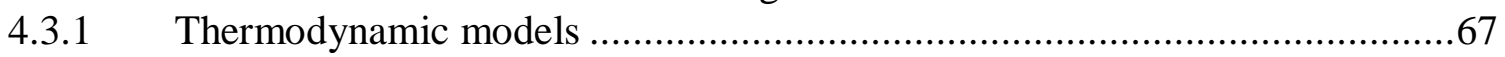

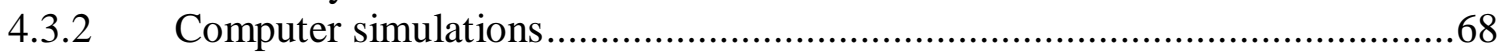

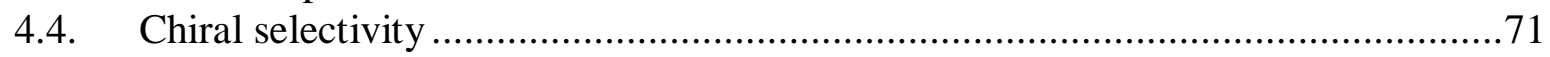

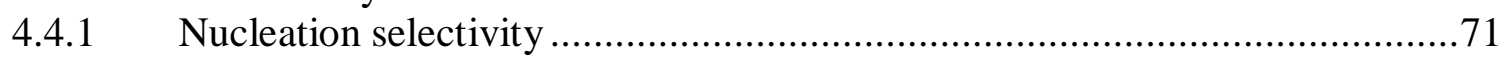

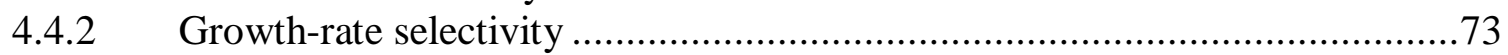

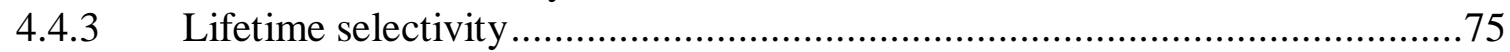

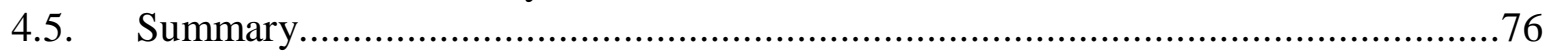

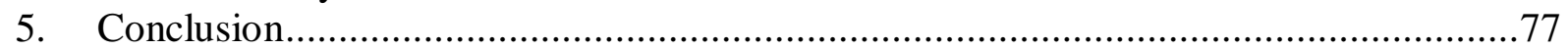

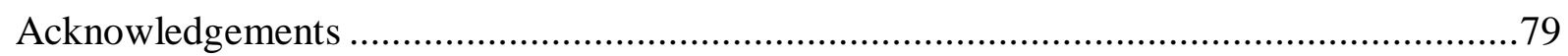

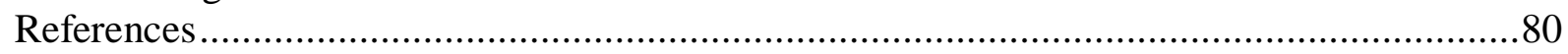




\section{Abstract}

Due to its higher degree of control and its scalability, catalytic chemical vapour deposition is now the prevailing synthesis method of carbon nanotubes. Catalytic chemical vapour deposition implies the catalytic conversion of a gaseous precursor into a solid material at the surface of reactive particles or of a continuous catalyst film acting as a template for the growing material. Significant progress has been made in the field of nanotube synthesis by this method although nanotube samples still generally suffer from a lack of structural control. This illustrates the fact that numerous aspects of the growth mechanism remain ill-understood. The first part of this review is dedicated to a summary of the general background useful for beginners in the field. This background relates to the carbon precursors, the catalyst nanoparticles, their interaction with carbonaceous compounds and their environment. The second part provides an updated review of the influence of the synthesis parameters on the features of nanotube samples: diameters, chirality, metal/semiconductor ratio, length, defect density and catalyst yield. The third part is devoted to important and still open questions, such as the mechanism of nanotube nucleation and the chiral selectivity, and to the hypotheses currently proposed to answer them.

\section{Introduction}

The last two decades have seen a burst of synthetic nanomaterials stimulated by the prediction of novel properties stemming from their nanoscale dimensions. Among them, carbon nanotubes (CNTs) are particularly attractive nano-objects notably because of the strong influence of their structural features on their electrical and optical properties. However, controlling these structural features soon appeared to be a particularly challenging task. Various synthesis approaches, such as arc discharge and laser ablation, were developed aiming at producing pure and well-controlled CNT samples in large quantity. Due to its 
higher degree of control and its scalability, Catalytic Chemical Vapour Deposition (CCVD) is now the standard synthesis method of CNTs. CCVD is at the crossing of two important chemical methods: thin-film growth by Chemical Vapour Deposition (CVD) and chemical conversion by Gas-Solid Heterogeneous Catalysis (GSHC). CCVD consists in the catalytic conversion of a gaseous precursor into a solid material at the surface of catalyst particles or of a continuous catalyst film. Novel aspects specific to CCVD arise from the combination of CVD and GSHC. For instance, the template effect of the catalyst surface on the shape of the growing material is central in CCVD: in the case of catalyst nanoparticles, one-dimensional objects such as CNTs and semiconducting nanowires can be grown; if the catalyst is in the form of a continuous film, two-dimensional materials such as graphene can be prepared. Compared with GSHC, the catalyst in CCVD is not only in contact with the gas phase (and sometimes a support), but presents an additional interface with the growing material. This imposes a supplementary difficulty because both interfaces have to be preserved in order to continuously grow nanotubes/nanowires without disrupting the gaseous precursor supply.

Since the first reports of the catalytic formation of nanotubular carbon filaments in the 1950s [1,2] and 1970s [3-7] and the seminal papers of Sumio Iijima in the early 1990s [8,9], significant progress has been made in terms of synthesis yield, nanotube alignment and sample purity. However, CCVD-grown synthesis of nanotubes still generally suffers from a lack of structural control over the nanotube chirality, the semiconducting/ metallic ratio, and the nature and density of defects, highlighting that numerous aspects of the growth mechanism remain ill-understood. The scope of this paper is to present a review of the current understanding of the growth mechanism of CNTs by CCVD. There have been previous reviews in this field [10-16], with different objectives (e.g. chronological description of the evolution of the methods and achievements, focus on simulation works, on the role of the catalyst particles or on a particular type of CCVD such as plasma-enhanced). Compared with 
them, the present review primarily focuses on the fundamental aspects of the CNT growth by CCVD. It first aims at summarizing background knowledge derived from neighbouring fields and that is relevant to the understanding of CNT growth by CCVD. The first tutorial part is therefore primarily aimed at beginners in the field. Beginners may also rapidly realize the difficulty arising from the huge number of publications in the field and the variety of studied systems. The second part of this review aims at providing a synthesis of the most relevant works addressing the experimental dependence of CNT features on CCVD conditions. Finally, the third part is devoted to describe important questions that are still open and discuss the hypotheses proposed to account for these experimental dependences and that currently participates to the building of a general growth mechanism of CNTs in CCVD.

\section{Background knowledge}

The simplest system to grow CNTs by CCVD consists of catalyst nanoparticles brought to high temperature in presence of gaseous carbon-containing molecules. The nanoparticles are commonly made of a transition metal such as $\mathrm{Fe}$, $\mathrm{Ni}$ or $\mathrm{Co}$, but other elements and compounds have recently proven to be efficient catalyst as well. In many cases, the catalyst particles are deposited on a support material such as $\mathrm{SiO}_{2}$ or $\mathrm{Al}_{2} \mathrm{O}_{3}$. It is apparent from the beginning that the size and shape of the catalyst particle and its interactions with the other components of the system play central roles in CCVD. Generally speaking, it is commonly accepted that CCVD catalyst particles should fulfil the following functions [10-13].

1) Catalyze the dissociation of the gaseous carbon-containing molecules.

2) Allow diffusion of carbon intermediates and their chemical interaction.

3) Provide a nanoscale template for the nucleation and growth of a nanotube.

4) Keep a reactive nanotube rim. 
Functions 1 and 2 are also found in heterogeneous catalysis and justify the use of the term catalyst particle, i.e. a particle that helps in rapidly achieving the chemical equilibrium between the carbon-containing molecules and a graphene-type material. Functions 3 and 4 are unique to CCVD catalysts and impose additional or somehow different constraints compared with GSHC catalysts, which justifies the use of the alternative term seed particle.

In this chapter, we aim at providing some background knowledge useful for understanding the catalytic growth of CNTs. This knowledge is mostly derived from chemical vapour deposition, heterogeneous catalysis and metallurgy. The chapter is divided in five parts: i) nature of the most common carbon precursors used for CNT growth and their chemical reactivity, ii) nature of the nanoparticles used to grow CNTs in CCVD and influence of their nanometric size on some of their physical properties, iii) interactions of transition metals with carbon, iv) catalytic activity of transition metals, v) interactions of transition metal nanoparticles with the environment (reactive atmosphere, oxide support).

\subsection{Carbon precursors}

\subsubsection{Chemical nature}

A large number of carbon-containing molecules can be used as a carbon source to grow CNTs in CCVD: hydrocarbons (gaseous [17] or liquid [18]), alcohols [19], aromatic compounds [20] or even naturally-occurring carbon resources [20]. Ethylene, acetylene, methane, carbon monoxide and ethanol are presently the most frequent precursors of CNTs in CCVD (Figure 1). It is important to keep in mind that such gaseous carbon precursors not only bear carbon but also other elements such as hydrogen and/or oxygen. These elements are not compulsory since CNTs can be grown from pure carbon [21,22] as commonly achieved in arc discharge and laser ablation syntheses by sublimation of graphite [23]. However, the byproduction of hydrogen- and oxygen-bearing molecules such as $\mathrm{H}_{2}$ and $\mathrm{H}_{2} \mathrm{O}$ may impact the 
formation of CNTs. $\mathrm{H}_{2}$ and $\mathrm{H}_{2} \mathrm{O}$ are actually common additives in CCVD with recognized influence on CNT growth as discussed hereafter. Nitrogen- [24], phosphorus- [25] and boronbearing [26] precursors are known to form substitutionally doped CNTs. However, the influence of oxygen and hydrogen on the defects of CCVD-grown CNTs is still poorly known.
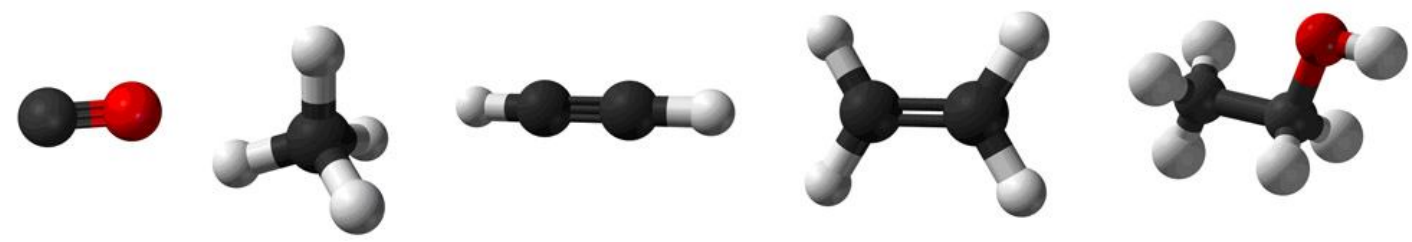

Figure 1. Common carbon precursors of CNTs in CCVD: carbon monoxide, methane, acetylene, ethylene and ethanol from left to right (black: carbon, red: oxygen, white: hydrogen).

\subsubsection{Reactivity}

Thermodynamic stability is an important feature of a precursor. Figure 2 shows the standard Gibbs energy of formation for different carbon precursors as a function of temperature in the Ellingham approximation (data from [27]). Except for methane, all precursors decompose exothermally. It is seen that methane is more stable than graphite for temperatures lower than $600-700^{\circ} \mathrm{C}$. At atmospheric pressure, acetylene, ethylene and ethanol are less stable than graphite at all temperatures while carbon monoxide is more stable than graphite at temperatures higher than about $700^{\circ} \mathrm{C}$. It is important to remember that the conversion equilibriums and the inversion temperatures will vary with the partial pressures of the involved gaseous species.

This being said, some general comments can still be drawn. The pyrolysis of methane requires high temperatures to become thermodynamically allowed. Its conversion into higher organic compounds is thermodynamically restricted: experimentally, the main products of methane decomposition are simply carbon and dihydrogen [28]. If coupled with oxygen, methane can form other compounds such as $\mathrm{CO}_{2}, \mathrm{CO}$ [28], $\mathrm{C}_{2} \mathrm{H}_{4}$ and $\mathrm{C}_{2} \mathrm{H}_{6}[29,30]$. At the 
opposite, the decomposition of acetylene, ethylene and ethanol is thermodynamically allowed at all temperatures and occurs readily provided a sufficient activation. Due to their high Gibbs energies of formation, these latter compounds can self-decompose into carbon, dihydrogen and a large variety of volatile organic compounds and polycyclic aromatic hydrocarbons [3134]. The disproportionation of $\mathrm{CO}$ into carbon and $\mathrm{CO}_{2}$ (i.e. the Boudouard reaction) is the main reaction path in the absence of other reactants (e.g. $\mathrm{H}_{2}$ [35]). The reaction being highly exothermic, the reaction equilibrium shifts toward the reactants when increasing the temperature. Since the number of gaseous molecules decreases in the Boudouard reaction, the equilibrium conversion also increases with increasing pressure.

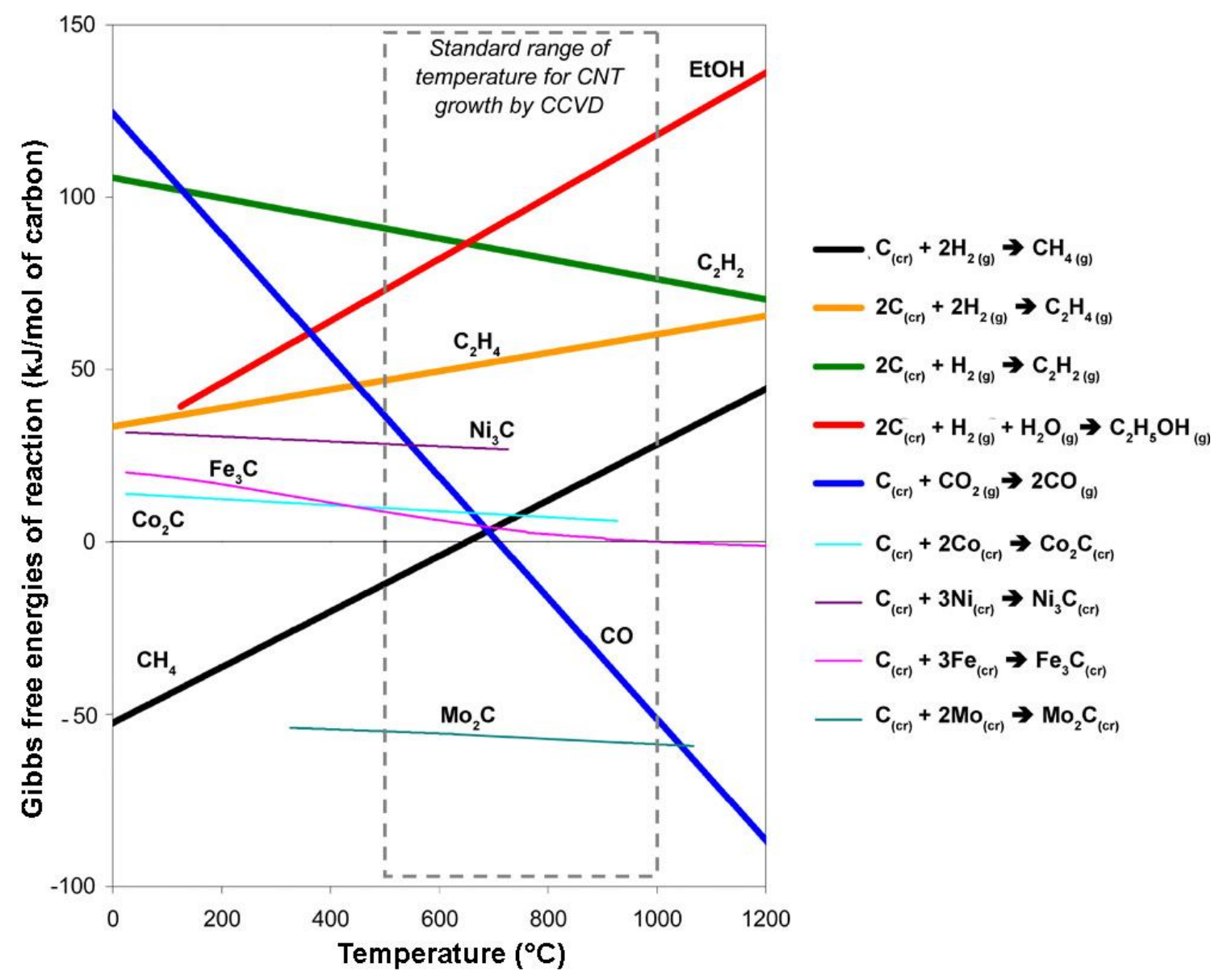

Figure 2. Gibbs free energies of reaction per mole of carbon for the formation of common metal carbides and carbon feedstocks. "cr" and "g" respectively stand for crystalline and gaseous. Data from [27,36].

The stability of a carbon precursor is also illustrated by the strength of its chemical bonds. Table 1 presents the dissociation energy of the weakest $\mathrm{C}-\mathrm{H}$ bond of different hydrocarbons. 
It is apparent that the strength of the $\mathrm{C}-\mathrm{H}$ bond decreases with increasing the number of carbon neighbours. A similar trend is observed in the case of a carbon-metal bond as described in $\S 2.3 .3$.

\begin{tabular}{|cccc|}
\hline Hydrocarbon & Weakest $\mathrm{C}-\mathrm{H}$ bond & $\begin{array}{c}\text { C-H bond dissociation energy } \\
(\mathrm{kJ} / \mathrm{mol})\end{array}$ & Atomic charge on $H$ \\
\hline Methane & Primary & 440 & +0.087 \\
Ethane & Primary & 420 & +0.002 \\
Propane & Secondary & 401 & -0.051 \\
Isobutane & Tertiary & 390 & -0.088 \\
\hline
\end{tabular}

Table 1. Dissociation energies of $\mathrm{C}-\mathrm{H}$ bonds and charge on $\mathrm{H}$ of some light hydrocarbons. From [37].

\subsection{Catalyst nanoparticles}

\subsubsection{Chemical nature}

Nickel, iron and cobalt are the most common catalysts for CNT growth by CCVD. Over the years, many other elements have been proven suitable. Beside $\mathrm{Fe}$, Ni and $\mathrm{Co}$, MWCNT growth have been reported using nanoparticles of Pd [38], Pt [38], Au [39], Mn [38], W [38], $\mathrm{Ti}$ [38], TiC [40], Mg [38], $\mathrm{Al}$ [38], In [38], $\mathrm{Na}$ [38], $\mathrm{K}$ [38] and Cs [38]. These nanoparticles were usually larger than $3 \mathrm{~nm}$. Beside $\mathrm{Fe}, \mathrm{Ni}$ and Co, SWCNT growth was reported using nanoparticles of other late transition metals (Pd [41], Pt [41], $\mathrm{Ru}$ [42]), noble metals ( $\mathrm{Cu}$ [41,43], Ag [41], Au [41,44]), early transition metals (Mn [45], Cr [46], Mo [47]), elements of the carbon family (diamond [48], Si [49], Ge [49], Sn [46], Pb [46]), lanthanides (Gd [50], Eu [50]) and other mixed compounds ( $\mathrm{FeSi}_{2}$ [51], $\mathrm{SiC}$ [49,52], $\mathrm{SiO}_{2}$ [53,54], $\mathrm{Al}_{2} \mathrm{O}_{3}$ [54], $\mathrm{TiO}_{2}$ [54], $\mathrm{Er}_{2} \mathrm{O}_{3}$ [54], $\mathrm{ZnO}$ [55]). These nanoparticles were usually less than $3 \mathrm{~nm}$.

Binary mixtures of active catalysts such as $\mathrm{Ni}, \mathrm{Fe}$ and $\mathrm{Co}$ are frequently used and often observed to display a higher activity than individual elements [56]. Non- or weakly active 
elements are also frequently mixed as co-catalysts, notably to prevent or control the coarsening of the catalyst. They notably include Mo [57,58] and Mg [59] mixed with Fe or Co.

Considering this wide variety of active elements and compounds, one may wonder which properties are actually required to promote the growth of CNTs. Hereafter are summarized some important physical and chemical properties of the nanoparticles used to grow carbon nanotubes.

\subsubsection{Vapour pressure and melting point}

The physical state of the catalyst during CNT growth (i.e. solid or liquid) is important because it influences several properties of the catalyst such as the solubility of carbon and its diffusion rate. It is still a highly debated issue (see §4.1) whose resolution is complicated by three effects.

First, in the presence of carbon, the melting point can be decreased by up to a few hundred degrees for the elements displaying a eutectic point in their phase diagram with carbon $(e . g$. $\mathrm{Fe}, \mathrm{Co}, \mathrm{Ni}, \mathrm{Pt}, \mathrm{Pd}, \mathrm{Rh}, \mathrm{Ru}, \mathrm{Ir}, \mathrm{Re})$. Second, for particles in the range of $1-10 \mathrm{~nm}$, the equilibrium vapour pressure is significantly increased which is usually approximated by the Kelvin or Gibbs-Thomson equation. The equilibrium vapour pressure of a particle of radius $r$ in contact with a vapour phase can be written as:

$$
p=p_{0} \exp \left(\frac{2 \sigma_{s g} V}{k T r}\right)
$$

where $p$ and $p_{0}$ are the equilibrium vapor pressures over curved and flat surfaces, respectively; $\sigma_{s g}$ is the surface tension at the particle-gas interface, $V$ is the volume of an atom in the particle, $k$ is the Boltzmann constant and $T$ is the temperature. The relation reflects the fact that particles with a higher surface/volume ratio are less stable. A practical consequence is that particles tend to evolve toward larger sizes as first described by W. Ostwald (see Ostwald 
ripening in $\$ 2.5 .2 .2$ ). In the case of a liquid or solid environment, an analogous equation can be written to express the equilibrium concentration in the outer environment surrounding the nanoparticle. Another consequence is that the melting point of nanoparticles is significantly depressed. The melting point of a nanoparticle in its own liquid can be approximated by:

$$
T_{m}(r)=T_{m}^{b u l k}\left(1-\frac{4 \sigma_{s l}}{H_{f} \rho r}\right)
$$

where $T_{m}(r)$ and $T_{m}^{b u l k}$ are, respectively, the particle and bulk melting points, $\sigma_{s l}$ is the surface tension at the solid-liquid interface, $H_{f}$ is the bulk latent heat of fusion per volume unit and $\rho$ is the density of the particle. All these effects originate from the large contribution of surface atoms to the total energy of the system. If the nanoparticles are deposited on a substrate, the interaction is therefore also expected to modify their melting point, which is the third effect to consider. As an example, Shibuta et al. [60] calculated that the melting point of a nickel cluster increased by up to $200^{\circ} \mathrm{C}$ with increasing catalyst-substrate interaction.

\subsection{Interaction of carbon with transition metals}

\subsubsection{Affinity for carbon: carbon solubility and formation of carbides}

In general, the ability of transition metals to bond with carbon atoms increases with the number of unfilled d-orbitals. Metals without d-vacancies in their electron configuration, such as $\mathrm{Zn}$ or $\mathrm{Cu}$, display a negligible affinity for carbon. Metals with few d-vacancies such as $\mathrm{Ni}$, Fe and Co exhibit a finite carbon solubility. Transition metals with many d-vacancies such as Ti and Mo can form strong chemical bonds with carbon and highly stable carbide compounds. For transition metals, the affinity for carbon therefore increases from the right to the left of the periodic table [61-63]. For example, the solubility of carbon at $700^{\circ} \mathrm{C}$ (a typical synthesis temperature for CNTs) is below detection limit in $\mathrm{Zn}, 0.01 \%$ at. in $\mathrm{Cu}, 0.3-0.5 \%$ at. in $\mathrm{Ni}$ and $1.2 \%$ at. in fcc-Co. Elements from $\mathrm{Mn}$ to $\mathrm{Ti}$ form carbides of increasing stability and 
increasing carbon share (Figure 3). Fe is an intermediate case: Fe forms a metastable carbide $\left(\mathrm{Fe}_{3} \mathrm{C}\right)$, the solubility of carbon is relatively low in $\alpha-\mathrm{Fe}\left(\sim 0.1 \%\right.$ at. at $\left.700^{\circ} \mathrm{C}\right)$ but substantial in $\gamma$-Fe $\left(\sim 4 \%\right.$ at. at $\left.800^{\circ} \mathrm{C}\right)$. The solubility of carbon in metals generally increases with temperature.

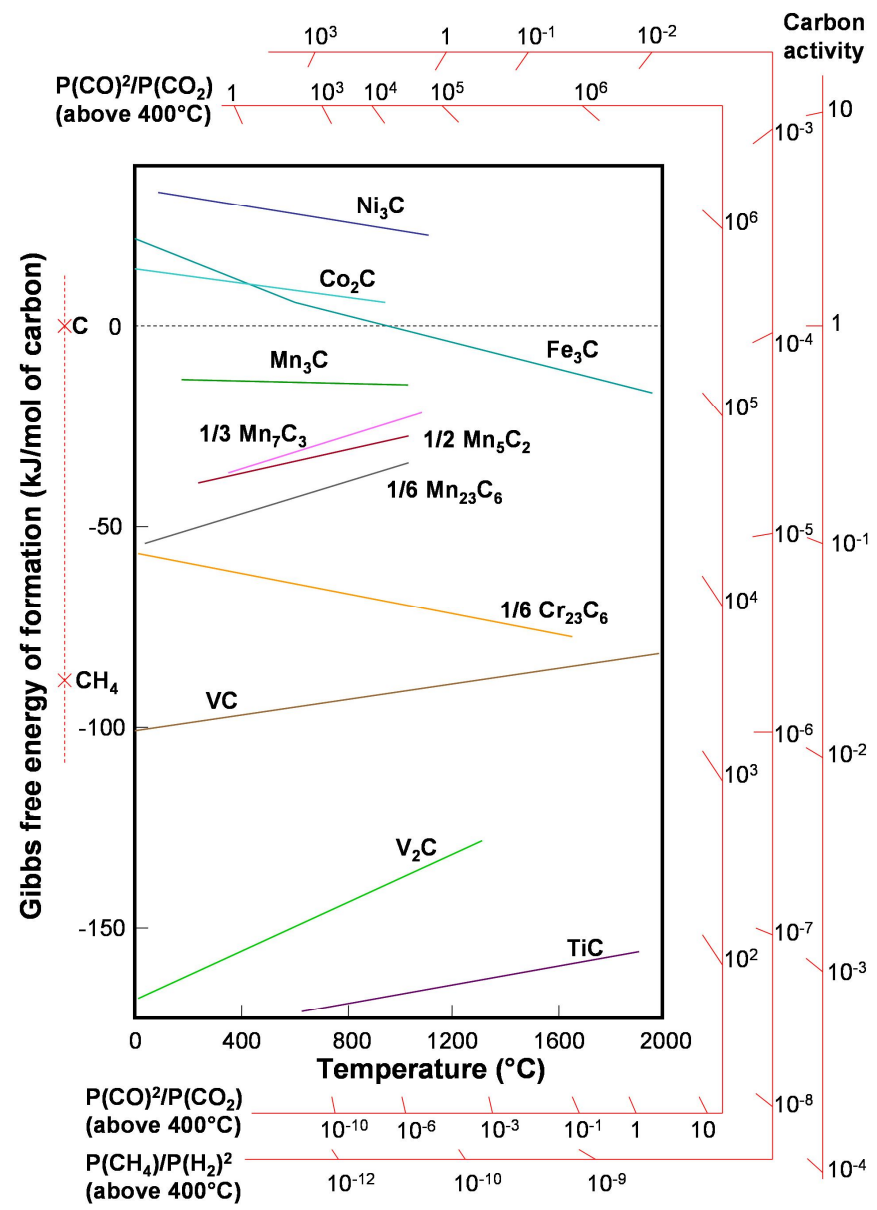

Figure 3. Ellingham diagram for carbides of 3d transition metals. Adapted from [36].

Graphitic carbon will be allowed to form if the carbon concentration overcomes the solubility of carbon in the catalyst particle. For elements that do not form stable carbides $(e . g$. $\mathrm{Cu}, \mathrm{Ni}, \mathrm{Co}, \mathrm{Pb}, \mathrm{Sn}, \mathrm{Au}, \mathrm{Ag}, \mathrm{Zn}, \mathrm{Cd}, \mathrm{Pd}, \mathrm{Pt}$ ) [64], the critical concentration for the segregation of graphitic carbon is therefore the solubility limit of carbon in the metal. For carbide-forming elements, the carbon concentration must exceed the carbon content of the highest stable carbide (e.g. $\mathrm{Mn}_{3} \mathrm{C}$ for $\mathrm{Mn}, \mathrm{TiC}$ for $\mathrm{Ti}$ ) for graphitic carbon to form. 
A complicating factor is the influence of the particle size on the solid solubility of impurities such as carbon and the stability of mixed compounds (i.e. carbides) [65-67]. The solubility of carbon in nanoparticles is not well established and is still a subject of controversy. Experimentally, there are many reports of increased solubilities inside nanoparticles [66-70], including a giant increase of carbon solubility in $\mathrm{Au}$ nanoparticles [71]. A Kelvin-type relation has sometimes been used to explain the experimental observations although this relation actually describes the solubility in the medium around the nanoparticle as already stressed by A. Harutyanyan [13] and not the solubility inside the nanoparticle. Over the last years, thermodynamic models specifically addressing the solid solubility of impurities inside nanoparticles have been devised based on different assumptions: size-dependent entropy [72], regular solution theory [73], quantum confinement of elementary excitations [74], sizedependent melting enthalpy, entropy and atomic interaction energy [75] or linear concentration dependence of the surface energy [76]. In general, these thermodynamic models predict an increase of the solubility of impurities inside nanoparticles of decreasing size. In certain models, however, both solubility increase and decrease are possible depending on the relative binding strengths between atoms in the system. The matter is therefore not well established yet in both the general case and the particular case of carbon dissolution inside metal nanoparticles. Recently, Diarra et al. [77] reported Grand Canonical Monte Carlo simulations to calculate the adsorption isotherms of carbon on nickel nanoparticles of varying size: they found that at a given carbon chemical potential and temperature, smaller nickel nanoparticles dissolve a larger fraction of carbon than larger ones due to the larger carbon solubility in subsurface than in the bulk.

Experimental observations long supported that catalysts having intermediate carbon solubilities (between 0.5 and 1.5 wt.\%) and not forming stable carbides were required to promote CNT growth [40] although the reason for that was unclear. The reports of novel 
catalysts displaying both low (e.g. $\mathrm{Cu})$ and high (e.g. Ti) affinities for carbon probably should lead to reconsider this conclusion.

\subsubsection{Carbon diffusion: bulk, surface and subsurface}

The diffusion mode of carbon atoms during CNT growth (bulk versus surface diffusion) has long been and still is a highly debated issue. The solid-state diffusion of impurities (such as carbon) has been studied for many years, notably for metallurgy purposes. Figure 4 shows the solid-state diffusion constants of carbon in various bulk metals and metal carbides as a function of temperature. Despite the absence of a simple rule, some general trends can be given [78].

i) The bulk diffusion of carbon atoms is much faster than that of the atoms of the solid metal host since the former ones diffuse interstitially while the latter ones diffuse substitutionally.

ii) Interstitial diffusion depends on the geometry of the host lattice and is faster in more open structures. For instance, the activation energy for carbon diffusion is $1.53-1.57 \mathrm{eV}$ in closepacked fcc Fe while only $0.83 \mathrm{eV}$ in bcc Fe [79,80].

iii) The higher the melting-point of the host, the smaller the diffusion constant of the solute atoms. For instance, in the case of $\alpha-\mathrm{Fe}, \mathrm{V}$ and Mo that are all bcc metals, but with significantly different melting points, the diffusion constants inversely follow the order of melting points, that is $\mathrm{Fe}\left(\mathrm{T}_{\mathrm{m}}=1808 \mathrm{~K}\right)>\mathrm{V}\left(\mathrm{T}_{\mathrm{m}}=2160 \mathrm{~K}\right)>\mathrm{Mo}\left(\mathrm{T}_{\mathrm{m}}=2890 \mathrm{~K}\right)$.

iv) The diffusion constant depends inversely upon the solid solubility, being least for metals which form a continuous series of compounds (i.e. carbides in the case of carbon diffusion). For instance, in the case of $\mathrm{Pd}, \mathrm{Ni}$ and $\gamma$-Fe that are all fcc metals with close melting points, the diffusion constants inversely follow the order of carbon affinity, that is $\mathrm{Pd}>\mathrm{Ni}>\mathrm{Fe}$. 


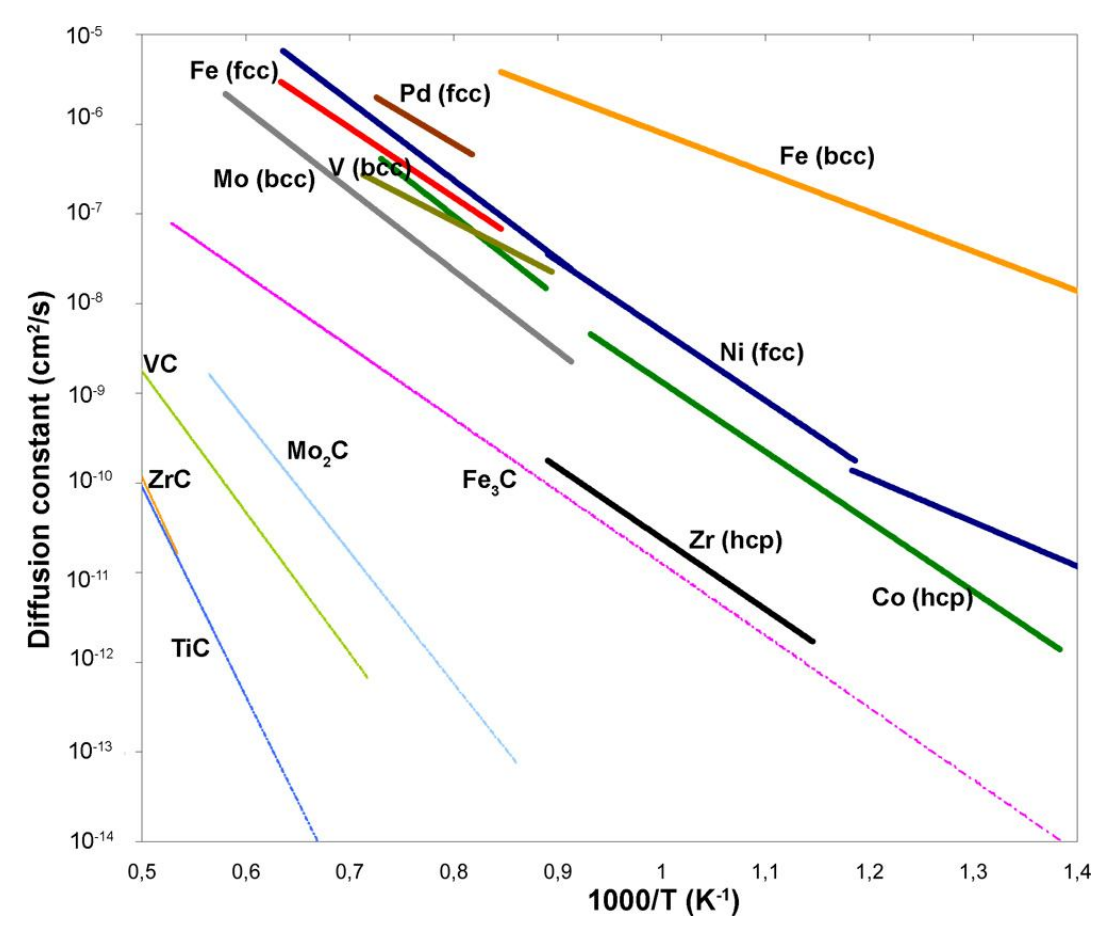

Figure 4. Bulk diffusion constants of carbon in various metals and metal carbides as a function of temperature. The activation energies for bulk diffusion of carbon was measured to be $1.44-1.74 \mathrm{eV}$ in $\mathrm{Ni}$ (fcc) [80-83] (at the exception of Massaro et al. [84] who found $0.87 \mathrm{eV}$ in the range $350-700^{\circ} \mathrm{C}$ ), $1.50-1.68$ $\mathrm{eV}$ in $\mathrm{Co}$ (hcp) $[80,85], 1.53-1.57 \mathrm{eV}$ in fec Fe $[79,80], 0.83 \mathrm{eV}$ in bec Fe $[79,80], 1.20 \mathrm{eV}$ in $\mathrm{V}[80,86,87]$, $1.37 \mathrm{eV}$ in $\mathrm{Pd}[88,89], 1.44-1.78 \mathrm{eV}$ in $\mathrm{Mo}[80,90]$ and $1.58 \mathrm{eV}$ in $\mathrm{Zr}[91]$.

Studies on the diffusion of carbon have revealed a strong dependence of the diffusion coefficients on the carbon concentration [78,92,93]. For instance, the activation energy for bulk diffusion of carbon in fcc-Fe decreases from $1.55 \mathrm{eV}$ to $1.24 \mathrm{eV}$ if the amount of dissolved carbon is increased by 6 at. \% [94]. In $\mathrm{Ni}$, calculations predict that for carbon concentrations above 50 at. \% in the first subsurface layer, the carbon diffusion barrier would decrease from $1.6 \mathrm{eV}$ to below $1.0 \mathrm{eV}$ [82]. This effect is usually explained by the lattice expansion caused by the addition of carbon. It has also been proposed that the repulsion between carbon atoms at close distance could enhance the diffusivity of interstitial carbons [95].

However, for very high carbon contents as encountered in carbides, it is commonly observed that the activation energies for carbon diffusion are much higher than in the 
corresponding metals (see Figure 4). This is tentatively explained by the fact that carbon diffusion in carbides is no longer interstitial but mediated by thermal vacancies in the metal and carbon sub-lattices [96]. For instance, the activation barrier is $1.60-1.92 \mathrm{eV}$ in $\mathrm{Fe}_{3} \mathrm{C}$ [9799], $3.4 \mathrm{eV}$ in TiC [100], 3.1 eV in $\mathrm{VC}$ [101] and 2.9-3.6 eV in $\mathrm{Mo}_{2} \mathrm{C}$ [102] and $2.6 \mathrm{eV}$ in $\mathrm{WC}$ [101]. As a consequence, the bulk diffusion constants of carbon in metal carbides are usually much lower than in the corresponding metals as visible in Figure 4. It is worth noting that the diffusional mobility of the metal atoms in carbides is still several orders lower than that of carbon atoms [103].

Addition of other elements also influences the diffusion rate of carbon. For instance, the diffusion constant of $\mathrm{C}$ in fcc-Fe increases with the concentration of $\mathrm{Ni}$ and $\mathrm{Cu}$, but decreases in the presence of carbide-forming elements such as Cr, W, Mo and others [92]. Other elements like Si and Co raise or lower the diffusion coefficient of carbon, depending on the temperature and their concentration $[92,104]$. In agreement with these measurements, calculations predict that the addition of small amounts of $\mathrm{Au}$ would reduce the activation barrier from $1.6 \mathrm{eV}$ for pure $\mathrm{Ni}$ to $0.07 \mathrm{eV}$ for $\mathrm{Ni}$ with 6 at. \% of $\mathrm{Au}$ [81].

Much less data are available concerning the surface diffusion of carbon. In general, the activation barriers are found to be significantly lower than for bulk diffusion. For instance, calculations on the surface diffusion on $\mathrm{Ni}(111)$ and $\mathrm{Ni}(110)$ yielded a barrier of $0.4-0.5 \mathrm{eV}$ [105] in good agreement with the experimental value of $0.3 \mathrm{eV}$ measured on a polycrystalline Ni surface [106]. First-principles calculations by Yazyev and Pasquarello [62] on Ni, Pd, Pt, $\mathrm{Cu}, \mathrm{Ag}$ and $\mathrm{Au}$ yielded that bulk diffusion has systematically a higher activation barrier than surface and subsurface diffusions. Surface-to-subsurface diffusion is another interesting case to consider: $\mathrm{Xu}$ and Saeys [82] calculated an activation barrier for carbon on $\mathrm{Ni}(111)$ of 0.7 $\mathrm{eV}$ at low carbon coverages, a value that is intermediate between surface and bulk diffusion. 
Like solubility, the diffusion rate of carbon in nanoparticles may be dependent on the particle size. Despite some experimental observations [107], such a possible effect is still insufficiently documented.

\subsubsection{Theoretical aspects of carbon structures interactions with metal}

\section{surfaces}

For the CCVD growth of CNTs, a key aspect is the carbon-metal interaction that obviously depends on the nature of the catalyst considered. A large number of papers have been devoted to the theoretical study of this metal carbon interaction, mostly using quantum chemistry (QC) or Density Functional Theory (DFT) based calculations. As usual in such an instance, the general trends are rather robust (e.g. early TMs tend to make too stable carbides, late TMs are better for catalytic purposes) but differences exist in the details. The problem is indeed complex, especially because of the unique ability of carbon to form various structures with different bonding characters. As described hereafter, we can qualitatively consider that the interaction of carbon with a metal surface is stronger for isolated atoms and decreases when C-C bonds with neighboring carbon atoms, corresponding to strong lateral interaction, are formed. The ultimate limit is the formation of a full graphene layer of a flat metal surface that has weak adhesion energy.

The interaction of atomic carbon with different metallic surfaces or bulk metals has been extensively studied. A thorough study of the applicability of DFT for computing key quantities such as the heat of solution of $\mathrm{C}$ in $\mathrm{Ni}$ is reported by Siegel and Hamilton [108]. A useful reference state is the stability of the ideal $\mathrm{C} \mathrm{sp}^{2}$ structure such as graphene. Referred to it, and neglecting the energy difference due to the finite diameter of a tube and its curvature, the adsorption or solution energy of a carbon atom directly tells us whether a $\mathrm{C}$ atom will prefer binding to the tube or to the metal. The adsorption energy depends on the different 
surface sites available on different structures (flat surface with different orientations, steps, clusters ...). Interstitial subsurface and bulk sites have been considered, too, as well as carbon dimers. For $\mathrm{Ni}, \mathrm{Pd}, \mathrm{Pt}, \mathrm{Cu}, \mathrm{Ag}$ and $\mathrm{Au}[62,82,109-111]$, the adsorption of a single $\mathrm{C}$ atom is less stable than its incorporation in a graphene layer, with energy differences of the order of 1 eV/carbon atom for Ni, Pd, Pt and 2-4 eV/carbon atom for noble metals. Subsurface sites are more favorable than bulk incorporation or adsorption on various surface sites. For Ni and Co hollow (100) semi-octahedral sites are more favorable than compact facets [112,113]. When suitable surface coverage is reached, this leads to the $(2 \times 2) \mathrm{P} 4 \mathrm{~g}$ "clock" surface reconstruction observed on $\mathrm{Ni}(100)[114,115]$. Complex behavior is also predicted on different facets of $\mathrm{Fe}$, an important catalyst for NT growth. Carbon adsorption on the different facets of bcc Fe has be shown [116-118] to substantially modify their surface energies, thus potentially explaining changes of the nanoparticle shape observed during growth. At low surface coverage, $\mathrm{C}$ atoms are separated from each other and their binding on late transition metal surfaces is stronger on open sites than on compact facets. On a bcc Fe (100) facet with a somewhat larger (2/3) surface coverage, carbon chain structures have been experimentally evidenced and found to be strongly interacting with the surface $[119,120]$.

Carbon dimers are found to be the most stable adsorbed species on noble metals, and close to it on $\mathrm{Ni}$ [108]. More precisely, acetylene which can be consider as a prototype of carbon dimer is more strongly adsorbed on Ni than on Pd, Pt and Rh (111) surfaces [121] in agreement with the chemisorption model of Nørskov (see 2.4.1). Tight binding calculations, allowing the relaxation of large simulation boxes, indicate, in agreement with experiments, that dimers can be stabilized in subsurface, involving strong local distortions [122].

During nanotube growth, carbon does not interact with a flat surface but rather with a cluster. Attempts have been made $[123,124]$ to take this finite size effect into account, but one rapidly faces difficult challenges. DFT based calculations are better suited to deal with 
periodic systems and calculations of interaction energies of carbon with metallic clusters are therefore limited to small cluster sizes, below 100 atoms. In addition, the stability of these small size clusters results from a balance between bulk and surface energies, leading to magic numbers sizes, for which calculations have been done. However, the strong chemisorption of carbon that can modify the surface energy contribution and the presence of a substrate that also strongly interacts with the clusters cast some doubts on the relevance of this approach.

Starting from individual atoms, dimers and chains on the metal surface, the next step is the study of the interaction of caps or tubes with flat surfaces or metal nanoparticles. In this case, carbon atoms have already formed bonds with other neighboring carbons, and, as consequence, the interaction with the metallic surface is weaker. This kind of calculations is in principle more relevant to the experimental nanotube growth situation, but still rely on some assumptions, concerning, in particular, the structure of the metal catalyst, generally taken as pure (no carbon dissolved in) and crystalline. Ding et al. have underlined the importance of a strong carbon metal interaction [125], to sustain a continuous growth by preventing the closure and detachment of the tube: they show that $\mathrm{Fe}, \mathrm{Co}$ and $\mathrm{Ni}$ bind stronger to the tube, and hence perform better than $\mathrm{Pd}, \mathrm{Cu}$ and $\mathrm{Au}$. Larsson et al. [126] calculated that the adhesion energy between metal clusters and SWCNT caps follows the order Fe $\sim \mathrm{Co}>\mathrm{Ni}$. Depending on the tube chirality, bond strengths are in the $(-2.5 ;-1.5) \mathrm{eV} / \mathrm{bond}$ range for the former. In the context of trying to explain chiral selectivity, Reich et al. [127] calculated the interaction of caps with different chiralities on a flat Ni (111) surface, showing small energy differences between them.

Much weaker interaction energies are expected for carbon structures (flakes, flat caps...) lying almost flat on the surface. Fan et al. [128] calculated the adhesion energy and stability of small $\mathrm{C}$ flakes on $\mathrm{Ni}$ to propose a model for the cap nucleation. Lacovig et al. [129] studied the evolution of the binding energy of carbon flakes on $\operatorname{Ir}(111)$ as a function of 
the flake size, starting from almost zero (graphene layer) to $-1.2 \mathrm{eV} / \mathrm{C}$ atom for a $\mathrm{C}_{6}$ ring, emphasizing the role of the edge atoms contribution in the binding.

When the flakes grow larger, we tend towards a graphene structure that generally interacts weakly with metal surfaces. This pushes DFT calculations to their limits, since Local Density Approximation results in an overestimation of the adhesion energy, while Generalized Gradient Approximations result in near zero adhesion energies. Recent developments try and include non-local corrections to the DFT approximations [130-132]. It may be expected that the adhesion strength of the graphene sheet also depends on the amount of carbon dissolved in the metal particle although this dependence is rarely addressed in the literature.

\subsection{Catalytic activity of transition metal nanoparticles}

\subsubsection{Dissociative adsorption on transition metal surfaces}

The role of a catalyst is to accelerate a thermodynamically-allowed chemical process (e.g. the decomposition of carbon-containing molecules) by creating a transition state of lower energy [133]. The corresponding decrease of activation energy depends on the strength of the adsorbate-substrate bond which experimentally reflects in the heat of adsorption. There is a general trend for the heats of adsorption to decrease from the left to the right of the periodic table. For instance, the heat of adsorption of $\mathrm{CO}$ on polycrystalline $\mathrm{Ti}$ is $6.5 \mathrm{eV}$, but only 0.9 $\mathrm{eV}$ on polycrystalline $\mathrm{Cu}$ [133]. This trend can be explained by the chemisorption model developed by Nørskov [134] stipulating that molecules adsorbing on transition metals preferentially interact with the d-states near the Fermi level that give rise to bonding and antibonding levels. The d-electron contribution to the bonding is therefore proportional to (1$f_{d}$ ) where $f_{d}$ is the degree of filling of the d-band. 
When a molecule is adsorbed on a metal surface, the activation barrier for its dissociation is lowered. For instance, the activation barrier for the dissociation of acetylene was measured to be $1.4 \mathrm{eV}$ on $\mathrm{Ni}(111)$ instead of $5.58 \mathrm{eV}$ for self-decomposition [105]. If the surface bonds are too strong, the reaction intermediates will remain on the surface and block the adsorption of new reactant molecules. Forming adsorbate-substrate bonds of intermediate strength is an important property of a good catalyst. The catalytic activity of transition metals for a given reaction often displays a volcano-shaped pattern across the periodic table [135]. For instance, acetylene and ethylene are observed to be very weakly adsorbed on noble metals such as $\mathrm{Au}$, $\mathrm{Ag}$ and $\mathrm{Cu}[133]$ while, on other transition metals, the adsorption of unsaturated hydrocarbons is generally strong and dissociative. When one adsorbs an unsaturated hydrocarbon onto a transition-metal surface at low temperature and then heats the surface, the molecule decomposes and leaves the surface covered with partially dehydrogenated fragments (e.g. ethylidyne) or carbon, rather than desorb from the surface. At higher temperatures, polymeric carbon chains with the general formula $\mathrm{C}_{\mathrm{x}} \mathrm{H}$ are formed, which eventually results in a graphitic monolayer [133].

It was also demonstrated that dissociative adsorption of hydrocarbons often leads to the population of subsurface sites even in metals having low carbon solubility. For instance, Teschner et al. reported a carbon content of 35 to 45 at \% in the three top layers of Pd under alkyne exposure at $350 \mathrm{~K}$ while the bulk solubility of carbon in $\mathrm{Pd}$ is less than 1 at. \% at this temperature. The surface carbide was found to be stable only in the reaction ambient. Interestingly, the degree of subsurface population by carbon was found to strongly influence the catalytic activity and the conversion selectivity [136].

\subsubsection{Catalytic activity of transition metal carbides}

Many metal surfaces will form carbides when exposed to carbon-bearing molecules at high temperatures (see Figure 2 for examples). It is important to judge their catalytic activity 
since nanoparticles of carbides (e.g. TiC) or of carbide-forming metals (e.g. Ti, Mn, W, Cr, $\mathrm{Mo}, \mathrm{Fe}$ ) were reported to be active for CNT growth in CCVD (see 2.2.1). Compared with pure metals, carbides generally display lower adsorbate-surface bonds [137-139] and are therefore often considered as having no or weak catalytic activity. Carbides of the group 4-6 metals have been studied for their catalytic activity in oxidation, hydrogenation/dehydrogenation, isomerisation and hydrogenolysis, and in many cases have been found to rival the performance of metals of the Fe-group [140,141]. While refractory carbides do not display high activity for oxidation reactions, they are often as active as transition metals for hydrogenation and dehydrogenation reactions. As a consequence, carbide surfaces are used for catalysis in extreme conditions due to their remarkably high hardness and melting points, as compared to transition metals.

\subsubsection{Catalytic activity of oxide surfaces}

Nanoparticles of different oxide compounds (e.g. $\mathrm{SiO}_{2}$ [53,54], $\mathrm{Al}_{2} \mathrm{O}_{3}$ [54], $\mathrm{TiO}_{2}$ [54], $\mathrm{Er}_{2} \mathrm{O}_{3}$ [54], $\mathrm{ZnO}$ [55]) have been recently shown to be efficient catalysts of SWCNT growth. In addition, many oxides that are commonly used as catalyst supports in CCVD display catalytic activity. For instance, Yoshihara et al. [142] observed that $\mathrm{Al}_{2} \mathrm{O}_{3}$ and $\mathrm{TiO}_{2}$ could catalyze the decomposition of acetylene (but not that of methane). Although heterogeneous catalysis mostly involves metal catalysts, many processes make use of oxides $[133,143]$ such as zeolites (cracking of crude oil), chromium oxide (polyethylene synthesis), vanadium oxide $\left(\mathrm{NO}_{\mathrm{x}}\right.$ reduction), copper oxide, zinc oxide (water-gas shift reaction), and molybdenum oxide (acrylonitrile synthesis). Overall, oxides have lower heats of adsorption than the corresponding metals [144,145], but polar oxide surfaces $\left(e . g . \mathrm{Cr}_{2} \mathrm{O}_{3}(0001), \mathrm{NiO}(111)\right)$ display higher adsorption energies than non-polar ones (e.g. $\mathrm{MgO}(100), \mathrm{NiO}(100))$ [146]. An oxide catalyst is often referred to as acidic or basic according to the propensity of the metal ions to donate or accept electrons (Lewis acidity) or protons (Brønsted acidity) [133]. In the field of 
CNT growth by CCVD, Magrez et al. [147] notably observed that the growth was dramatically activated when the surface of the support is made basic or when the acidity of the support is modified from Lewis to Brønsted using water molecules.

\subsubsection{Nanometric size effects on catalytic activity}

It has long been recognized that the size and the surface structure of the catalyst can influence the catalytic activity. A catalytic reaction is defined as structure-sensitive if its conversion rate changes markedly as the size of the catalyst particles is changed. For instance, while bulk gold has no catalytic activity, Haruta et al. reported that gold nanoparticles can catalyze the oxidation of carbon monoxide [148]. Using size-controlled gold nanoparticles, Tsunoyama et al. observed a relationship between the particle size and the catalytic activity for the oxidation of alcohol, the smaller nanoparticles being more active [149]. This is correlated by the observations that Pd nanoclusters of decreasing size display larger heats of adsorption [150].

The reactivity of a metal surface is generally associated to both its geometric features and its electronic structure. Classically, the structure sensitivity of a catalytic reaction is associated to a modification of the population of reactive sites (terrace, steps, kinks, surface defects) with decreasing particle size. For instance, the probability of $\mathrm{H}_{2}$ dissociation decreases from 0.9 on a stepped $\operatorname{Pt}(332)$ surface to less than $10^{-3}$ on a defect-free $\operatorname{Pt}(111)$ surface [151]. Several authors reported that reducing the nanoparticle size modifies their electronic structure (i.e. decrease of the density of states at the Fermi level, modification of the shape and position of the valence band) [150]. The decrease of the density of states at the Fermi level has sometimes been proposed to explain size effects in catalysis. In the case of very small particles of a few tens of atoms, the electronic properties can be dramatically changed relatively to bulk material due to quantum confinement effects. Meier et al. notably proposed 
that the increase in heat of adsorption and the onset of catalytic activity coincide with the metal to non-metal transition that occurs in gold clusters of approximately $3 \mathrm{~nm}$ in size [146].

Small catalyst particles are also in closer interaction with their environment and are therefore more sensitive to support effects as detailed below.

\subsection{Interactions of metal nanoparticles with their environment}

\subsubsection{Redox interactions between metal nanoparticles and gas species}

Aging of nickel, cobalt and iron thin films in air results in oxide and hydroxide formation accompanied by a modification of the surface morphology $[152,153]$. Frequently, catalysts are subjected to an oxidative pre-treatment (i.e. calcination) to remove carbon contaminants or to reduce the surface mobility and the coarsening of catalyst particles.

The propensity of an element to be oxidized or reduced as a function of the gaseous atmosphere is apparent in an Ellingham diagram for oxides (Figure 5). Oxides and hydroxides of iron, cobalt and nickel are generally reduced under hydrogen [154], ammoniac [155] or hydrocarbon [156] atmospheres. It is apparent from Figure 5 that oxides commonly used as supports $\left(\mathrm{SiO}_{2}, \mathrm{Al}_{2} \mathrm{O}_{3}, \mathrm{MgO}\right)$ are extremely stable and are not expected to be reduced in standard growth conditions. Other oxides such as $\mathrm{TiO}_{2}, \mathrm{MnO}, \mathrm{Cr}_{2} \mathrm{O}_{3}$ and $\mathrm{ZnO}$ are also very stable. At some exceptions, the affinity for oxygen among transition metals generally increases from the right to the left of the periodic table, like the affinity for carbon. $\mathrm{FeO}$, for instance, is more difficult to reduce than $\mathrm{NiO}$ and $\mathrm{CuO}$. Ellingham diagrams based on bulk thermodynamic values are often useful to predict the stability of oxides at a given temperature and in a given atmosphere.

However, when dealing with nanoparticles, surface and interface effects come into play. The chemical stability of nanoparticles can be modified by the interaction with a support. For 
instance, an XPS analysis by J. Lu [157] indicated that under similar reducing conditions, $\mathrm{Fe}(\mathrm{III})$ nanoparticles on silicon oxide were substantially reduced to $\mathrm{Fe}(0)$, but failed to do so when supported on silicon nitride. The different interactions of metal nanoparticles with oxide substrates are discussed in more detail in the following part.

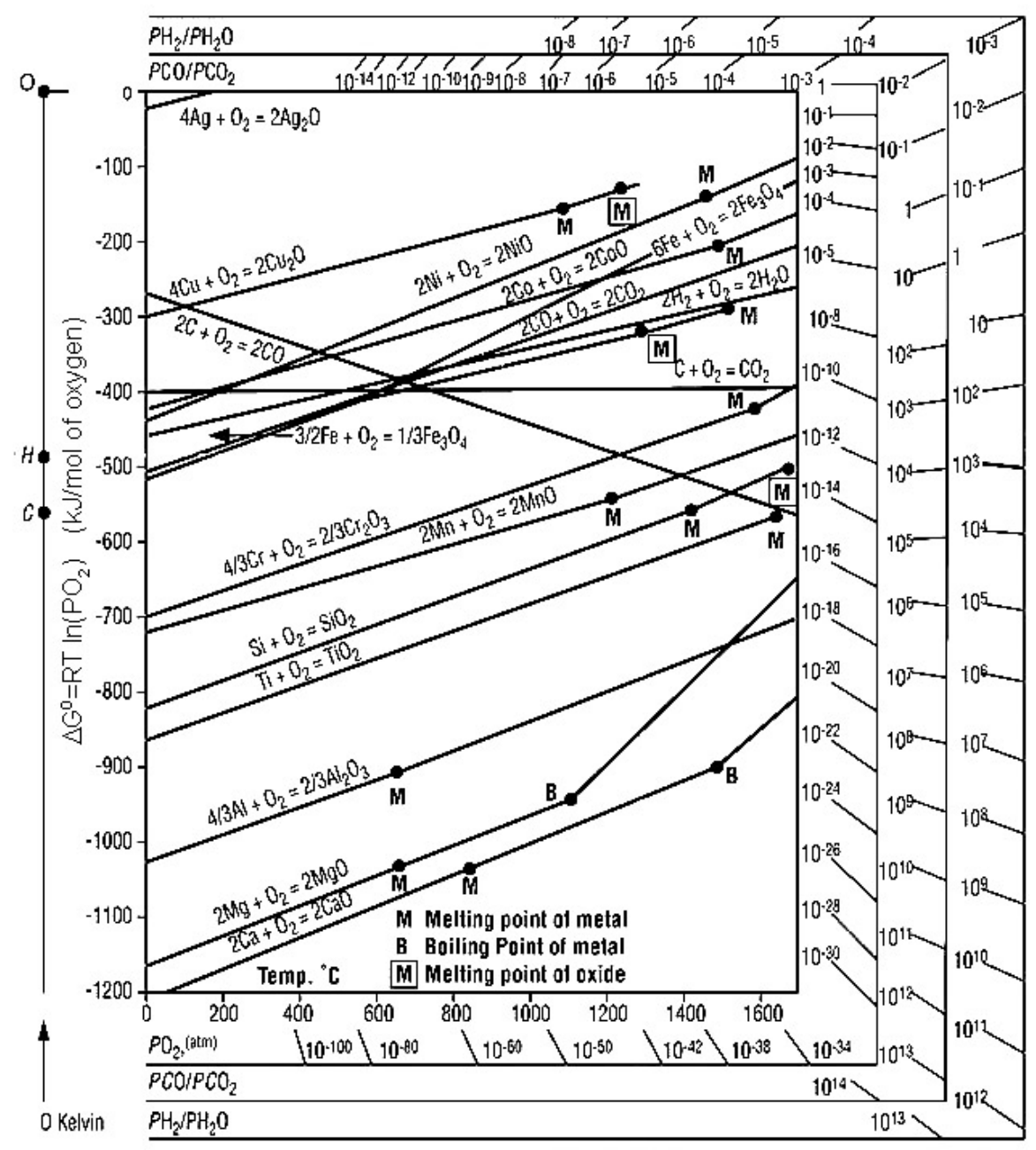

Figure 5. Ellingham diagram for oxides. After [158].

\subsubsection{Interactions of metal nanoparticles with oxide supports}

The chemisorption behaviour of a metal cluster not only depends on its size and surface structure but also on its interaction with the substrate [150]. For example, gold clusters are found to be catalytically active when deposited on $\mathrm{Fe}_{3} \mathrm{O}_{4}, \mathrm{FeO}$ or $\mathrm{TiO}_{2}$ but inactive when 
deposited on $\mathrm{Al}_{2} \mathrm{O}_{3}[146,148,150]$. Strong metal-support interactions (SMSI) is the term commonly used to refer to the reduction of catalytic activity of metal particles on certain supports. SMSI are commonly attributed to two different effects: i) the modification of the electronic structure of the catalyst particle by the oxide support (notably by charge transfer) and ii) the physical encapsulation of the particles by a thin layer of oxide support. Generally speaking, two aspects should be considered when dealing with the interactions of metal nanoparticles with oxide supports: (i) the electronic interaction corresponding to the charge redistribution at the metal-oxide interface and (ii) the chemical interaction corresponding to atom diffusion at the metal-oxide interface [159]. As described hereafter, the difference of electronegativities and the conduction properties of the oxide support strongly influence the phenomena at the metal-oxide interface.

\subsubsection{Electronic interaction: charge redistribution}

Contact between a metal particle and an oxide surface results in charge redistribution at the interface [159]. Local charge redistribution occurs within the first few atomic layers at the interface. This local electronic interaction is the dominant effect in the case of insulating oxide supports such as $\mathrm{Al}_{2} \mathrm{O}_{3}, \mathrm{MgO}$ and $\mathrm{SiO}_{2}$ since electrons are strongly localized and the production and diffusion of ionic defects are limited. Local charge redistribution is driven by the difference of electronegativities between the metal and the oxide but is also affected by the surface properties of the oxide (surface stoichiometry, defects and terminations). The electronic interaction affects the catalytic properties of the particles. For instance, Yoon et al. [160] observed that, due to charge transfer, $\mathrm{Au}_{8}$ clusters are catalytically active when supported on defect-rich $\mathrm{MgO}(100)$ surfaces but inert when deposited on a virtually defectfree $\mathrm{MgO}$ surface. The modification of the electronic properties and reactivity of the metal particles by the support is only significant for particles smaller than $2 \mathrm{~nm}$ [150]. In the case of conducting oxides such as $\mathrm{TiO}_{2}, \mathrm{ZrO}_{2}$ and $\mathrm{ZnO}$, charge redistribution is long ranged and 
driven by the difference of Fermi energies similarly to metal-semiconductor junctions [159]. In this case, the electric fields generated at the interface can significantly enhance the diffusion of ionic defects and promote long-range chemical interactions (see 2.5.2.2 and 2.5.2.3)

\subsubsection{Atomic diffusion: wetting, coarsening and encapsulation}

From Bauer's criterion [161], a thin metal layer deposited on a substrate will preferentially form 3D islands rather than a 2D layer if $\gamma_{\text {metal }}+\gamma_{\text {metal-substrate }}>\gamma_{\text {substrate }}$ where $\gamma_{i}$ denote surface free energies. Metal oxides generally have lower surface energies than metals which favors the growth of 3D metal islands on oxide surfaces. Conversely, oxidizing metal particles generally leads to a flattening of the particles on the oxide support [162]. The interface term $\gamma_{\text {metal-oxide }}$ has also to be taken into account. Because $\gamma_{\text {metal }}$ and $\gamma_{\text {metal-oxide }}$ are usually difficult to estimate directly, $\gamma_{\text {metal }}$ is usually approximated by the heat of sublimation $\gamma_{\text {metal }}$ which also reflects the strength of metal/metal lateral interactions while $\gamma_{\text {metal-oxide }}$ is approximated by heat of formation of the most stable oxide of the metal since it reflects the strength of the metal-oxide interaction. Figure 6 displays the wetting behavior of different metals on $\mathrm{TiO}_{2}$ as a function of their heat of sublimation and of oxide formation. It is apparent that transition metals with high electronegativity and high cohesion to dewet oxide surfaces while the more electropositive and lower cohesion metals tend to wet them [163]. 


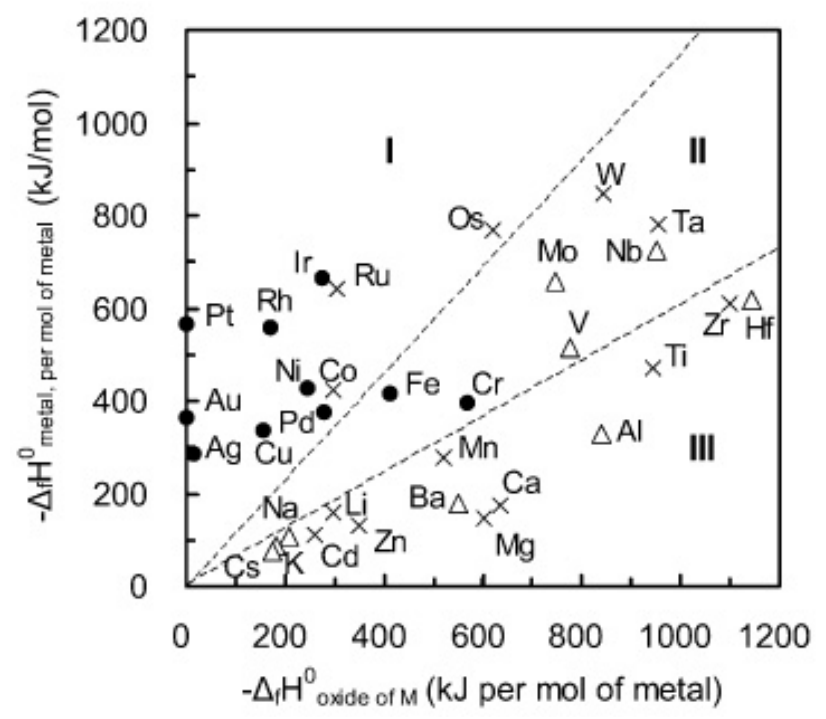

Figure 6. Description of the growth mode of metals on $\mathrm{TiO}_{2}(110)$ versus the heat of formation of the most stable metal oxide $\left(\Delta_{\mathrm{f}} \mathrm{H}_{0}{ }^{\text {oxide }}\right)$ and the heat of sublimation $\left(\Delta_{\mathrm{f}} \mathrm{H}_{0}{ }^{\text {metal }}\right)$, in which $\bullet$ and $\Delta$ represent experimentally observed 3D island and 2D layer growth modes, respectively; and $X$ represents the positions of metals whose growth modes have not been determined. In Zone I, metal/metal lateral interactions are stronger than metal/ $\mathrm{TiO}_{2}$ interfacial interactions so that metals tend to grow in the $3 \mathrm{D}$ island mode. In Zone III, metal/metal lateral interactions are weaker than metal/TiO ${ }_{2}$ interfacial interactions so that metals tend to grow in the 2D layer mode. Zone II is a transition domain where metals show either 3D island or 2D layer growth, depending on secondary factors. From [164].

Surface energies can also be dramatically modified by adsorption of molecular compounds present in the gas phase [165]. In general, adsorbates increase the anisotropy of surface energy between crystal planes, resulting in strong faceting. Encapsulation (or decoration) is another way to minimize surface energy. It involves mass transport from the oxide support onto the surface of the metal particle and results in the covering of the particle by a thin layer of reduced oxide support or even its immersion into the oxide support [159]. It preferentially impacts metals with high surface energy deposited on oxide surfaces of low surface energy. Typical examples are $\mathrm{Pt}$ and $\mathrm{Pd}$ particles on $\mathrm{TiO}_{2}$ and $\mathrm{CeO}_{2}$ supports. From a kinetic point of view, encapsulation is also favored when the outward diffusion of oxide 
cations is promoted by the surface electric field, which is the case when the Fermi energy of the metal is lower than that of the oxide.

If one now considers an ensemble of interacting particles on an oxide support, coarsening (or sintering) is another possibility to minimize the energy of the system [166] [167]. Coarsening of supported metal particles can occur in essentially two ways: either by the diffusion of single metal atoms (or metal-bearing molecules) from small particles to large ones (which is termed Ostwald ripening or interparticle transport), or by the migration and coalescence of whole particles (which is sometimes referred to as Smoluchowski ripening). Ostwald ripening is driven by the fact that vapour pressure varies inversely with particle size (see §2.2.2). It follows that metal atoms escape more quickly from small particles than from larger ones, resulting in a net flow of matter from the former to the latter. The nature of the diffusion process (surface, gas phase) and of the diffusing species (individual atoms, molecular species) can vary from one system to another. In numerous cases, it was found that the presence of oxygen greatly enhanced particle coarsening possibly due to the formation of more mobile metal oxide compounds [168]. The likelihood of particle coarsening by the migration-coalescence mechanism increases with the surface density of particles and their migration coefficients which increase with temperature, but also depend on the diameter, shape and nature of the particles. In practice, the different coarsening modes are characterized by different kinetic laws of the type:

$$
\bar{d}^{n}-\bar{d}_{0}^{n}=K t
$$

where $\bar{d}^{n}$ is the mean diameter after time $t, \bar{d}_{0}^{n}$ the initial mean diameter, $K$ a temperaturedependent constant and $n$ an integer which is characteristic of the type of coarsening mechanism. Such studies on $\mathrm{SiO}_{2}$-supported Ni particles [169], $\mathrm{Al}_{2} \mathrm{O}_{3}$-supported Ni particles [170] and $\mathrm{Al}_{2} \mathrm{O}_{3}$-supported $\mathrm{Pt}$ particles [171] indicated a change in the predominant 
coarsening mechanism from migration-coalescence at low temperatures (i.e. typically less than $700^{\circ} \mathrm{C}$ ) and short times (i.e. typically less than $1 \mathrm{~h}$ ) to Ostwald ripening at higher temperatures and longer times.

\subsubsection{Chemical reactions: redox, alloy formation}

Silicon wafers are standard substrates for nanotube growth. However, metals tend to diffuse into silicon and to form metal silicides which have much lower surface reactivity. For instance, for nickel, cobalt or iron deposited on silicon, formation of silicides were observed to occur at temperatures as low as $225^{\circ} \mathrm{C}$ for nickel $[172,173], 450^{\circ} \mathrm{C}$ for cobalt [174] and $800-850^{\circ} \mathrm{C}$ for iron $[175,176]$. The propensity of a given metal to form silicides is apparent in the silicide formation enthalpies as those shown in Figure 7. In first approximation, such bulk thermodynamic data are useful to predict interface reactions. For instance, the Ellingham diagram for oxides in Figure 5 predicts that a silicon substrate tends to reduce the particles of most transition metal oxides deposited on its surface. However, in the case of nanoparticles, it should be kept in mind that the contribution of the surface energy to the total free energy of the system can be dominant.

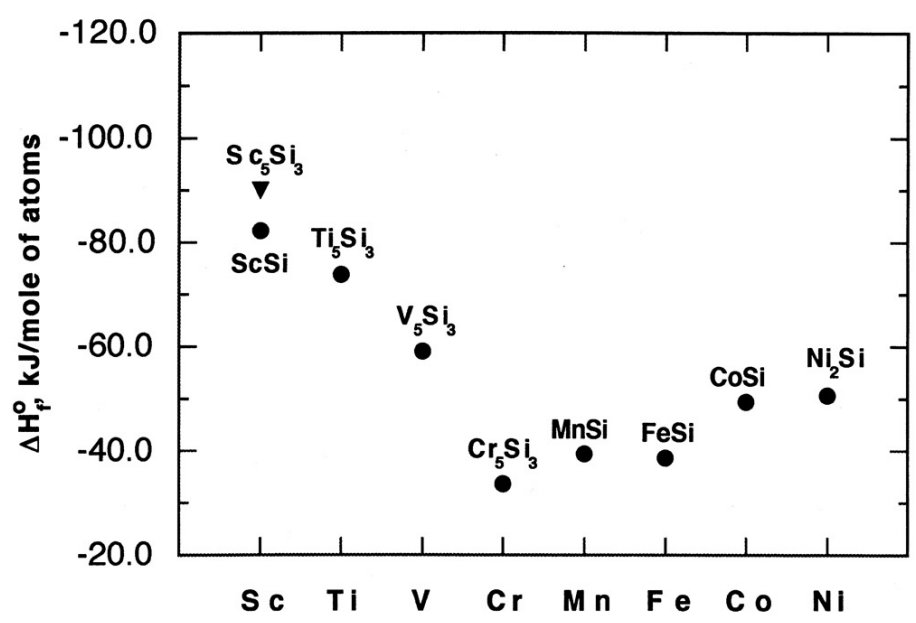

Figure 7. Standard enthalpies of formation of some 3d transition metal silicides (from [177]).

This explains why pure silicon supports are rarely used for the growth of CNTs. To circumvent the problem of silicide formation, a diffusion barrier of $\mathrm{SiO}_{2}$ or $\mathrm{Al}_{2} \mathrm{O}_{3}$ is 
commonly employed. Simmons et al. reported that a 4-nm silicon dioxide layer is the minimum diffusion barrier thickness to prevent iron silicide formation below $900^{\circ} \mathrm{C}$ [175]. The efficiency of the diffusion barrier depends not only on its thickness and structural quality, but also on the nature of the metal, the processing time and the gas ambient. For instance, silicide formation at metal/ $\mathrm{SiO}_{2}$ interface was reported for many metals after prolonged heating under hydrogen atmosphere (e.g. $\mathrm{Ni}_{3} \mathrm{Si}$ formation at $\mathrm{Ni} / \mathrm{SiO}_{2}$ interface [178]). At elevated temperatures, even low reactivity metals (such as $\mathrm{Pt}, \mathrm{Pd}, \mathrm{Rh}, \mathrm{Cu}$ and $\mathrm{Ni}$ ) deposited on $\mathrm{SiO}_{2}$ and $\mathrm{Al}_{2} \mathrm{O}_{3}$ can form silicide and aluminide layers $[179,180]$ while highly reactive metals (such as $\mathrm{Ti}, \mathrm{Zr}, \mathrm{Hf}$ ) tend to form a thin layer of aluminide or silicide sandwiched between a top layer of metal oxide and the oxide substrate [181,182].

Pauling electronegativity is a good indicator to predict the chemical affinity of transition metals for oxide surfaces. Metals with electronegativity lower than 1.5 tend to form strong chemical bonds with $\mathrm{SiO}_{2}$ [159]. The more electronegative metals do not reduce a $\mathrm{TiO}_{2}$ surface whereas the more electropositive metals can reduce one or more $\mathrm{TiO}_{2}$ layers, thereby forming an interfacial bond that increases their adhesion energy [163]. Mattevi et al. [183] observed that metallic $\mathrm{Fe}$ on $\mathrm{Al}_{2} \mathrm{O}_{3}$ formed $\mathrm{Fe}(\mathrm{II})$ and $\mathrm{Fe}(\mathrm{III})$ interface states making the interaction of $\mathrm{Fe}$ with $\mathrm{Al}_{2} \mathrm{O}_{3}$ much stronger than with $\mathrm{SiO}_{2}$ in agreement with the lower electronegativity of $\mathrm{Al}$ compared to $\mathrm{Si}$. They proposed that these interface states anchor $\mathrm{Fe}$ particles to the oxide surface and limit their coarsening.

Finally, metal thin films on silica/alumina can also form surface silicates/aluminates when heat-treated [184-189]. In presence of oxygen, a mixed oxide interlayer of $\mathrm{NiAl}_{2} \mathrm{O}_{4}$ can form by interdiffusion between $\mathrm{Ni}$ and $\mathrm{Al}_{2} \mathrm{O}_{3}$ [190]. A Mössbauer study by Oshima et al. [191] showed that a quarter of $\alpha$-Fe deposited on $\mathrm{SiO}_{2} / \mathrm{Si}$ changed to $\mathrm{Fe}_{2} \mathrm{SiO}_{4}$ when heat-treated at $840^{\circ} \mathrm{C}$ for $10 \mathrm{~min}$ under an hydrogen/argon/water atmosphere. Upon ethylene exposure at high temperature, $\mathrm{Fe}_{2} \mathrm{SiO}_{4}$ was observed to be predominantly carbonized into $\mathrm{Fe}_{3} \mathrm{C}$. At least 
for cobalt, silicate formation is activated by water vapor [192,193] and was observed to occur at temperatures as low as $220^{\circ} \mathrm{C}$ [192]. In Fischer-Tropsch synthesis, silicate formation during catalyst ageing is a major cause of catalyst deactivation [193]. Following silicate formation, the catalytic activity can be partially recovered by a reducing treatment. For instance, cobalt silicates and aluminates can be partially reconverted into cobalt using hydrogen, but this requires higher reduction temperatures $\left(\sim 700-900^{\circ} \mathrm{C}\right)$ than $\mathrm{Co}_{3} \mathrm{O}_{4}$ and $\mathrm{CoO}\left(\sim 300-400^{\circ} \mathrm{C}\right.$ under $\mathrm{H}_{2}$ ). Accordingly, Li et al. [184] reported that following a high-temperature reduction treatment, surface cobalt silicates can form well-dispersed Co nanoparticles highly efficient for SWCNT growth.

\subsection{Summary}

CNTs can be grown using a large variety of carbon sources and catalyst nanoparticles. When going from the right to the left of the periodic table, transition metals display a stronger affinity for carbon as explained by the d-band model of Nørskov. This results in higher carbon solubility, higher propensity to form stable carbides and higher adsorption energy. Because a good catalyst forms adsorbate-substrate bonds of intermediate strength, the catalytic activity of transition metals for a given reaction generally displays a volcano-shaped pattern across the periodic table. Compared to the corresponding metals, metal carbides and metal oxides generally have lower but non negligible catalytic activities for hydrocarbon dissociation. The thermodynamic stability of gaseous precursors and solid compounds at a given temperature and in a given environment can be estimated by using Ellingham diagrams.

Bulk diffusion of carbon through metals proceeds interstitially, making it much faster than the bulk diffusion of metal atoms but still slower than the surface diffusion of carbon on the metal. Bulk diffusion of carbon through metal carbides is always slower than through the corresponding metals. Qualitatively, the interaction of carbon atoms with a metallic surface is 
stronger for isolated atoms and decreases with the number of $\mathrm{C}-\mathrm{C}$ bonds formed with neighboring carbon atoms. The ultimate limit is the formation of a full graphene layer of a flat metal surface which has weak adhesion energy.

Due to the large number of interfacial atoms, nanoparticles have size-dependent properties that can significantly differ from their bulk counterparts: increased vapor pressure, depressed melting point, modified carbon solubility, increased catalytic activity, and increased sensitivity to the environment.

The reactivity of supported metal nanoparticles is strongly influenced by the electronic and chemical interactions with the oxide support. For insulating oxides, the electronic interaction is localized at the interface and driven by the difference of electronegativities. For conducting oxides, charge redistribution is long range and driven by the difference of Fermi energies. For insulating oxide supports such as $\mathrm{Al}_{2} \mathrm{O}_{3}, \mathrm{MgO}$ and $\mathrm{SiO}_{2}$, chemical reactions (redox, alloy formation) are confined at the interface and are notably driven by the differences of electronegativity between metals. For conducting oxides such as $\mathrm{TiO}_{2}, \mathrm{ZrO}_{2}$ and $\mathrm{ZnO}$, the spatial extent of the interfacial reaction can be strongly increased by the electric field created at the metal/oxide interface.

Since metal oxides generally have lower surface energy than metals, the growth of 3D metal islands is favored on oxide supports. The more electronegative transition metals tend to dewet oxide surfaces while the more electropositive metals tend to wet them. The oxidation of metal particles generally leads to a flattening of the particles. Particles can coarsen by Oswald ripening or migration-coalescence, which are both dependent on the particle sizes, the nature of the support and of the gas phase. Experimentally, the different coarsening mechanisms can be differentiated by their kinetic behaviors. Metal particles can also get encapsulated by a thin support oxide layer, a phenomenon which preferentially impacts metals with high surface energy deposited on oxide surfaces of low surface energy. 


\section{Synthesis-structure relationship in carbon nanotubes}

\section{grown by catalytic chemical vapour deposition}

The structural features of carbon nanotubes grown by CCVD strongly depend on the experimental conditions which include the preparation and pre-treatment of the catalyst and the synthesis conditions (Figure 8). This part aims at summarizing the synthesis-structure relationship in CNTs grown by CCVD as reported in the current literature. Considering the huge amount of articles published in the field since the mid-90s, an exhaustive summary is a nearly impossible task, and probably a useless one considering the diversity of experimental systems. Instead, this summary focuses on the most significant studies with respect to a particular experimental dependence. For each structural feature, the experimental dependence is summarized trying to highlight the most influential parameters and the dominant trends.

Experimental parameters

Catalyst particles: nature, size, density
Support: nature, surface features
Catalyst history: aging, pretreatment
Carbon precursor: nature, concentration
Additives: nature, concentration
Synthesis temperature
Time
...

Nanotube features

Outer diameter

Inner diameter / wall number

Chiral angle

Metallic / semiconducting ratio

Defect density

Length

Nanotube yield per particle

Figure 8. Input parameters and output features of carbon nanotube growth by CCVD

\subsection{Nanotube outer diameter}

A correlation between the size of the catalyst particles used in CCVD and the diameter of the resulting nanotubes is often observed. For instance, Cheung et al. [194] reported that iron nanoparticles of average diameters $\mathrm{d}_{\mathrm{NP}}$ of 3,9 , and $13 \mathrm{~nm}$ produced multi-wall carbon nanotubes with average diameters $\mathrm{d}_{\mathrm{NT}}$ of 3,7 , and $12 \mathrm{~nm}$, respectively, which corresponds to a ratio $\mathrm{d}_{\mathrm{NT}} / \mathrm{d}_{\mathrm{NP}}$ close to 1 . Schäffel et al. [195] obtained a similar ratio $\mathrm{d}_{\mathrm{NT}} / \mathrm{d}_{\mathrm{NP}}$ using iron 
particles of 3 to $18 \mathrm{~nm}$. Chen et al. [196] reported that the diameter distribution of SWCNTs was correlated with the size of the used $\mathrm{SiO}_{2}$ particles with a ratio $\mathrm{d}_{\mathrm{NT}} / \mathrm{d}_{\mathrm{NP}} \sim 0.8-0.9$.

Such correlations based on the initial and overall size distribution of catalyst particles raise the concern of certain particles being inactive for CNT growth. An improved approach is based on the direct observation of particle-tube connections by post-growth HRTEM analyses. In the case of Fe particles of 1.3-2.0 nm, Nasibulin et al. [197] measured a consistent $\mathrm{d}_{\mathrm{NT}} / \mathrm{d}_{\mathrm{NP}}$ ratio of $~ 0.6-0.7$ within a given batch. Using a similar approach, Hiraoka et al. [198] measured a $\mathrm{d}_{\mathrm{NT}} / \mathrm{d}_{\mathrm{NP}}$ ratio of ca. 0.3-0.5 in the case of Fe particles of 2-3 nm and Zhang et al. a $d_{N T} / d_{N P}$ ratio close to 1 in the case of Fe particles of 1-3 nm [199]. In the case of Co particles of 1-10 nm, Fiawoo et al. [200] actually observed that two configurations of nanotubenanoparticle junctions coexisted: a perpendicular configuration corresponding to $\mathrm{d}_{\mathrm{NT}} / \mathrm{d}_{\mathrm{NP}}$ ratio lower than 0.75 and a tangential configuration for $\mathrm{d}_{\mathrm{NT}} / \mathrm{d}_{\mathrm{NP}}$ ratio higher than 0.75 . Interestingly, they observed that the perpendicular configuration is dominant at short synthesis times (typically less than $2 \mathrm{~min}$ ) and the tangential one at longer times.

The direct observation of CNT growth by in situ TEM [201-207] is probably the best approach to address the question of the size relationship between a nanotube and its catalyst particle. A first result of in situ TEM studies is that active particles are rarely spherical during CNT growth: a dynamic reshaping of the particle occurs, at least in the case of the standard Fe, Co and Ni catalysts. In many cases (in particular for MWCNT growth on large particles), the catalyst particle displays a pear-like shape, the top of which top fits the inner diameter of the tube and bottom fits the outer one (Figure 9). To date, all in situ TEM observations on MWCNTs showed a direct correlation between the nanotube outer diameter and the largest diameter of the catalyst particle. In the case of SWCNTs, this conclusion has to be somehow tempered by the small number of in situ TEM observations. In the case of SWCNT growth on a Ni particle, growth simulations performed by W. Zhu et al. [208] support that the $\mathrm{d}_{\mathrm{NT}} / \mathrm{d}_{\mathrm{NP}}$ 
ratio must be lower than $0.8-0.9$ to prevent the nanotube rim to spontaneously close and to support continued growth.
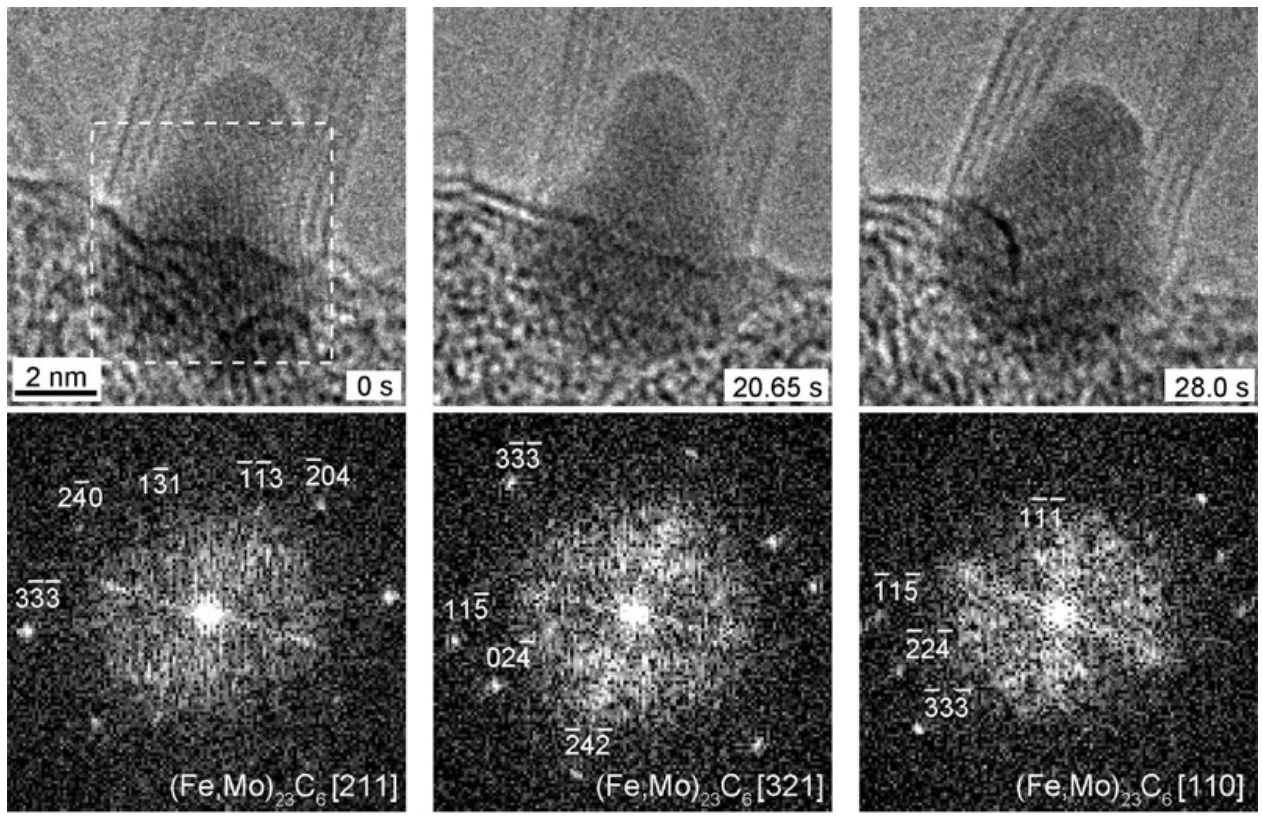

Figure 9. In situ ETEM observation of the growth of a four-wall CNT from a fluctuating catalyst nanoparticle of $(\mathrm{Fe}, \mathrm{Mo})_{23} \mathrm{C}_{6}$-type structure. From [205].

Based on the observed relationship between the nanotube outer diameter and the particle size, controlling the size distribution of catalyst particles is the most standard way to tune the nanotube diameter distribution. This is commonly achieved by controlling the thickness of the deposited catalyst [209,210], its coarsening [154,211] or its evaporation [212215] during the thermal pre-treatment preceding the growth. However, the observations of Fiawoo et al. [200] of two coexisting configurations of nanotube-particle junctions and the in situ observations that catalyst particles rapidly rearrange during the growth and adopt an equilibrium shape by interaction with the growing nanotube [201-207] suggest that parameters other than the particle size influence the size relationship between the particle and the nanotube. Growth parameters such as the growth temperature and the carbon precursor supply notably influence the final CNT diameter distribution. 
In general, increasing the growth temperature is reported to shift the CNT diameter distribution toward larger diameters [216-221]. By analogy with the influence of the thermal pretreatment, such results are often explained by an increased catalyst coarsening when increasing the growth temperature [217]. Yet, a study of Yao et al. [222] showed an opposite effect of temperature at the level of individual SWCNTs. Following the same nanotube, Yao et al. found that changing the temperature during growth resulted in a change of the nanotube diameter even though the catalyst particle remained the same: the SWCNT diameter increased when decreasing the growth temperature and inversely. A similar trend was reported by Mahjouri-Samani et al. [223]. Yao et al. [224] found that the diameter change was highly related to the initial nanotube diameter and that the range of variation mediated by the temperature was limited. As an example, for an initial nanotube diameter of $1.6 \mathrm{~nm}$, the maximum diameter variation was found to be $0.4 \mathrm{~nm}$.

The dependence of the diameter distribution on the carbon supply is the subject of even more controversy. Lu et al. [225] initially reported that small-diameter SWCNTs are preferentially grown at low carbon feeding rates even when highly polydisperse nanoparticles are used as catalyst. Tanioku et al. [218] and Geohegan et al. [226] also reported that the proportion of small-diameter SWCNTs increased as the feedstock pressure or flux were reduced. At the opposite, Saito et al. [227] and Wang et al. [228] reported that increasing the flow rate of ethylene or the pressure of carbon monoxide resulted in SWCNTs of smaller diameter. At least in the case of nickel, Picher et al. [229] found that the diameter dependence varied with the studied range of precursor supply and that, for each growth temperature, there was an optimal precursor pressure for the growth of small-diameter SWCNTs.

Gaseous additives can also influence the diameter distribution of SWCNT samples. For instance, Tian et al. reported that the mean diameters of SWCNTs grown from CO can be 
shifted from 1.2 to $1.9 \mathrm{~nm}$ by increasing the $\mathrm{CO}_{2}$ concentration [230]. They attributed this effect to the selective etching of small-diameter tubes by $\mathrm{CO}_{2}$.

\subsection{Nanotube inner diameter}

In 1983, Gary Tibbetts [231] studied a sample of tubular carbon filaments grown by CCVD and reported a linear relationship between the inner and outer diameters of the filaments. For the sample studied by Tibbetts, the proportionality coefficient $d_{i} / d_{o}$ was $\sim 0.6$. More recently, a statistical analysis by Chiodarelli et al. [232] of MWCNT samples grown in different CVD conditions also yielded a linear trend between the average number of walls $N_{\text {Walls }}$ and the average outer diameter $d_{o}$ of each MWCNT sample: $N_{\text {Walls }} \cong d_{o}(n m)-2$, which corresponds to $\mathrm{d}_{\mathrm{i}} / \mathrm{d}_{\mathrm{o}} \sim 0.3-0.4$. This explains why adjusting the size of the catalyst particles (or the catalyst thickness) is among the most popular methods to tune the outer diameter and hence the walls number of CNTs. As an example, using catalyst nanoparticles of controlled sizes, Schäffel et al. [195] and Chiang et al. [233] showed that increased catalyst sizes lead to increased wall numbers. Zhao et al. [210] reported that CNTs of larger outer diameters and larger wall numbers were obtained by increasing the catalyst thickness. Yamada et al. [234] even showed that high selectivity for double-walled CNTs could be achieved by precisely controlling the thickness of the catalyst film. However, the statistical analysis of Chiodarelli et al. [232] yields a quite large standard deviation $\sigma_{\mathrm{N}}$ which increases with the average outer diameter: $\sigma_{\mathrm{N}} \cong 0.17 \mathrm{~d}_{\mathrm{o}}$. This suggests that the inner diameter is not only related to the outer diameter, but is also influenced by other growth parameters.

The precursor supply notably influences the inner diameter. Sharma et al. [235] observed that the number of walls decreased at lower precursor supply. Zhang et al. [236] reported that low ethylene supply leads to CNTs with small diameters and few walls and that selective synthesis of single- and double-walled CNTs could be achieved by tuning the flow 
rates. These results suggest that a decreased carbon concentration of the catalyst particle (i.e. lower carbon chemical potential) leads to a decreased number of walls, as can be deduced from the model originally proposed by Tibbetts [231]. In situ TEM observations during CNT growth of Gamalski et al. [206] showed that, in certain cases, the number of walls of a nanotube could decrease during its growth. In the experiments of Gamalski et al., the thinning of the wall finally led to the detachment of the nanotube from the catalyst particle and the nucleation of another CNT displaying the same behaviour. Similarly, studying the growth of MWCNTs displaying periodic fluctuation of their inner diameter and periodic inclusion of catalyst material, Jourdain et al. [237] found that the size evolution of the carbon units along the MWCNT could be quantitatively accounted for by periodic fluctuations of the carbon concentration of the catalyst particle. Together, these results support that the inner diameter is influenced by the instantaneous carbon concentration of the catalyst particle which depends on both the carbon supply and consumption.

Concerning the temperature dependence of the inner diameter, there is no general agreement in the literature. For instance, Mudimela et al. [238] reported larger wall numbers (and larger outer diameters) with increasing growth temperature, while Sharma et al. [235] reported that both the number of walls and the outer diameter decreased with increasing temperature. The lack of agreement on the temperature dependence of nanotube structural features is a quite general trend; this maybe explained by the variety of catalyst systems and growth conditions experimentally studied and by the large number of thermally-activated processes involved at the different CCVD stages.

Additives were also reported to influence the nanotube inner diameter. Adding sulphur to the catalyst particles has been reported by several authors to reduce the inner diameter and increase the wall number [239-241]. For instance, Ci et al. [240,241] reported that the addition of sulphur favoured the formation of DWCNTs with small inner diameters at the 
expense of SWCNTs. At the opposite, Pan et al. [242] reported an enlargement of the inner diameter of CNTs by adding boric acid $\left(\mathrm{HBO}_{3}\right)$ to the catalyst.

\subsection{Nanotube chiral angle}

Many authors reported a higher occurrence of high-chiral-angle CNTs (i.e. neararmchair) in nanotube samples [243-250]. The fact that both indirect (i.e. photoluminescence excitation) and direct methods (i.e. electron diffraction) of structural determination led to the same result strengthens this conclusion. In more detail, all authors agree on the higher occurrence of near-armchairs among relatively small-diameter CNTs (i.e. diameter ca. less than $3 \mathrm{~nm}$ ). However, Hirahara et al. [248] observed that this preferential occurrence disappeared for CNTs larger than $3 \mathrm{~nm}$ while Arenal et al. [250] reported a preferential occurrence of near-armchairs even for few-walled CNTs of diameters between 3 and $8 \mathrm{~nm}$.

Beyond this general trend, highly-selective synthesis of SWCNTs of high chiral angles were reported using specific catalyst systems such as Co-MCM41 [251], , $\mathrm{CoSO}_{4} / \mathrm{SiO}_{2}$ [252], Co-Mo [253,254], Fe-Ru [255], Fe-Co [245], Fe-Cu [256] or Al-Cu-Fe [257] (Figure 10). He et al. [256] notably reported the predominant growth of $(6,5)$ SWCNTs using $\mathrm{Fe}-\mathrm{Cu}$ nanoparticles at low synthesis temperature. Using $\mathrm{Ni}_{\mathrm{x}} \mathrm{F}_{\mathrm{e} 1-\mathrm{x}}$ catalyst nanoparticles of controlled sizes, Chiang and Sankaran showed that the chirality distribution could be influenced at constant particle size by varying the $\mathrm{Ni} / \mathrm{Fe}$ ratio of the particles [56]. Lolli et al. [258] reported that changing the catalyst support from $\mathrm{SiO}_{2}$ to $\mathrm{MgO}$ resulted in nanotubes with comparable diameters but different chiral angles.

Optimized gaseous feed are usually required to achieve SWCNT synthesis with high chiral selectivity. Lolli et al. reported that increasing the synthesis temperature resulted in an increase in nanotube diameter without a change in the chiral angle while varying the composition of the gaseous feed modified the (n,m) distribution [258]. Wang et al. confirmed 
the influence of the gaseous feed by reporting that high-chiral-angle SWCNTs were preferentially obtained at high pressure of CO [228] (or under vacuumed ethanol or methanol [254]. Similarly, M. He et al [259,260] found that using $\mathrm{CO}$ instead of $\mathrm{CH}_{4}$ as carbon precursor led much smaller diameter SWCNTs with a higher occurrence of large chiral angles. Ghorannevis et al. [261] reported that an appropriate hydrogen concentration was the critical factor in achieving a narrow chirality distribution of $(6,5)$ tubes when using a gold catalyst in plasma-enhanced CVD. Despite this general trend, there is no satisfying explanation for it.

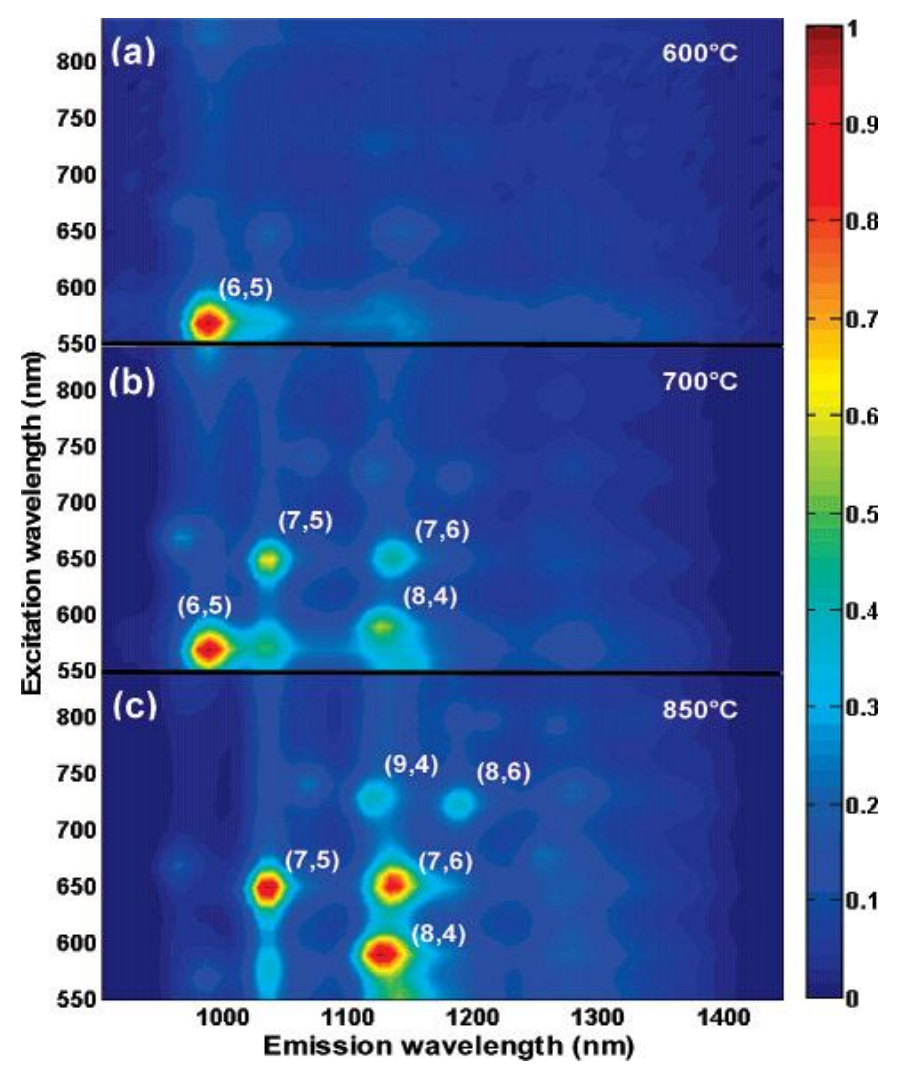

Figure 10. Contour plots of normalized photoluminescence emission intensities under various excitations for the Fe-Ru SWNTs grown at various temperatures. From [255].

Additional factors were reported to affect the chirality distribution. For instance, Koziol et al. [262] observed that the addition of a nitrogen-containing compound in the hydrocarbon feedstock leads to the growth of large MWCNTs in which all the walls are either of the armchair or zigzag structure. Recently, the same authors showed that nitrogen interacted with the catalyst in the form of ammonia, causing a restructuring of the catalyst 
surface and stabilizing the iron catalyst in its $\mathrm{Fe}_{3} \mathrm{C}$ carbide phase [263]. Such a restructured catalyst is proposed to be at the origin of the epitaxial growth of MWCNT with only armchair and zigzag walls. The growth support may also be influential: using monocrystal sapphire as growth substrate, Ishigami et al. [219] reported the preferential growth of near-zigzag tubes on the A-plane and of near-armchair tubes on the R-plane.

\subsection{Metallic / semiconducting nanotube ratio}

Structurally, two-thirds of SWCNTs are semiconducting and one-third is metallic. In the absence of selectivity, a nanotube sample would be expected to present such proportions. Actually, there are several reports of synthesis conditions yielding SWCNT samples enriched in semiconducting or metallic tubes.

Several examples of semiconductor-enriched SWCNT samples were notably reported using plasma-enhanced CVD (PECVD). Based on electrical measurements, Y. Li et al. reported a percentage of semiconducting tubes of $89 \%$. Later, they found that higher percentages of semiconducting SWCNTs are especially obtained when the growth parameters are adjusted to produce SWCNTs of small diameters, i.e. of the order of $1.1 \mathrm{~nm}$ [264]. Electrical measurements preformed by Mizutani et al. [265] confirmed that most CNTs grown by PECVD display a semiconducting behaviour. However, their Raman characterization also revealed several radial breathing modes corresponding to metallic SWCNTs. Scanning gate microscopy measurements suggested that the semiconducting behaviour observed for CNTs fabricated by PECVD process may actually result from the opening of a band gap due to defects caused by irradiation damage during the PECVD growth. Also using Raman spectroscopic assessments, L. Qu et al. [266] found at the opposite that arrays of SWCNTs grown by PECVD combined with fast heating, contained $~ 96 \%$ of semiconducting tubes. 
These results support a higher reactivity of metallic SWCNTs in plasma conditions leading to a modification of their electrical properties or even to their selective removal.

Other examples of selective removal of metallic tubes in reactive environments can be found in the literature. Hong et al. [267] found that applying a UV irradiation during the CVD growth of SWCNTs on quartz increased the proportion of semiconducting tubes up to $95 \%$ (as assessed by Raman and electrical measurements). Similarly, Yu et al. [268] reported that introducing a small amount of oxygen during the CVD synthesis of SWCNTs by the floating catalyst method led to the selective removal of metallic SWCNTs (based on Raman characterization). Parker et al. [269] found that the semiconducting SWCNT percentage peaked at $85 \%$ using isopropanol as carbon source while 2-butanol and methane yielded $70 \%$ and $32 \%$ of semiconducting SWCNTs, respectively. Using different alcohols as carbon precursors, Wang et al. [270] observed that the proportion of semiconducting tubes grown from an $\mathrm{Fe}-\mathrm{Co} / \mathrm{MgO}$ catalyst increased when decreasing the ratio of carbon atoms to oxygen atoms in the precursor composition. Similarly, L. Ding et al. [271] observed that increasing the proportion of methanol in the ethanol precursor increases the proportion of semiconducting tubes grown on quartz. Both groups proposed a selective etching of metallic tubes by hydroxyl radicals to explain the semiconductor enrichment. However, Che et al. [272] reported that isopropanol yielded a much higher fraction of semiconducting tubes (up to 97\%) than ethanol suggesting that a too high amount of water may be detrimental to semiconducting tubes. Recently, W. Zhou et al. confirmed the higher chemical reactivity of metallic tubes to water etching and detailed rules for choosing the appropriate water concentration for selectively removing metallic tubes during CCVD [273].

Harutyunyan et al. [274] also reported that the M/SC ratio was highly sensitive to the composition of the atmosphere used during the annealing stage preceding the introduction of the carbon source and notably to the presence of water: the presence of water in Ar ambient 
favoured the growth of semiconducting tubes whereas the same amount of water in $\mathrm{He}$ ambient promoted the growth of metallic tubes. Using an optimized atmosphere, these authors could increase the proportion of metallic tubes up to $91 \%$, as shown by both Raman and electrical measurements.

Finally, the nature of the catalyst was also reported to affect the M/SC ratio. Using NiFe catalyst particles of controlled size and composition, Chiang et al. [275] showed that the semiconducting content (assessed by optical absorption and Raman spectroscopy) significantly changed with the $\mathrm{Ni}-\mathrm{Fe}$ ratio and could reach $90 \%$ for $\mathrm{Ni}_{0.27} \mathrm{Fe}_{0.73}$ nanoparticles of $2.0 \mathrm{~nm}$ mean diameter. Using europium oxide $\left(\mathrm{Eu}_{2} \mathrm{O}_{3}\right)$ catalyst particles, Qian et al. [276] found that $80 \%$ of the as-grown SWCNTs were semiconducting based on Raman measurements.

\subsection{Defect density and carbonaceous impurities}

Several methods exist to quantify the defect density of CNTs, including microscopic observations (HR-TEM [277], STM [278]) and electrochemical labelling [279]. Most usually, the crystalline quality of CNT samples is assessed by Raman spectroscopy which provides a rapid and statistical assessment of the defect density based on the intensity ratio of the defectinduced D-band to the graphitic G-band [280-285]. A difficulty of this approach is the potential contribution of carbonaceous impurities to the D-band, even though these contributions can often be distinguished by their positions and linewidths [286-293] or by their deposition kinetics [294]. For instance, Yasuda et al. [294] performed Raman measurements of the G/D ratio at different synthesis times showing that the level of carbonaceous impurities solely depends on the cumulated time of exposure to the carbon source (i.e. ethylene). 
(a)

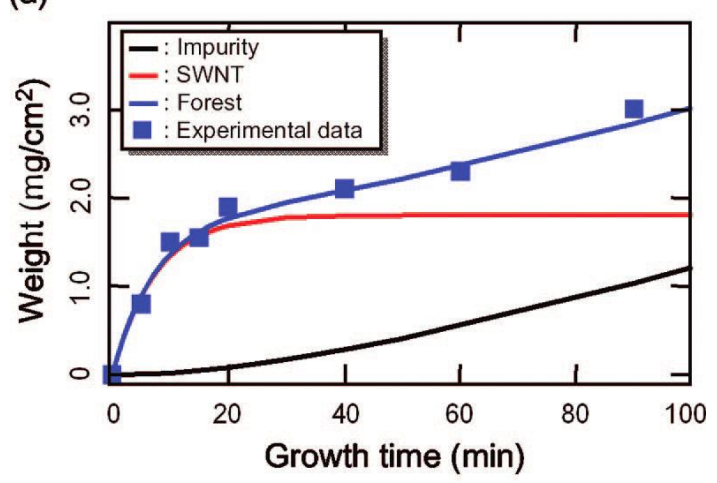

(b)

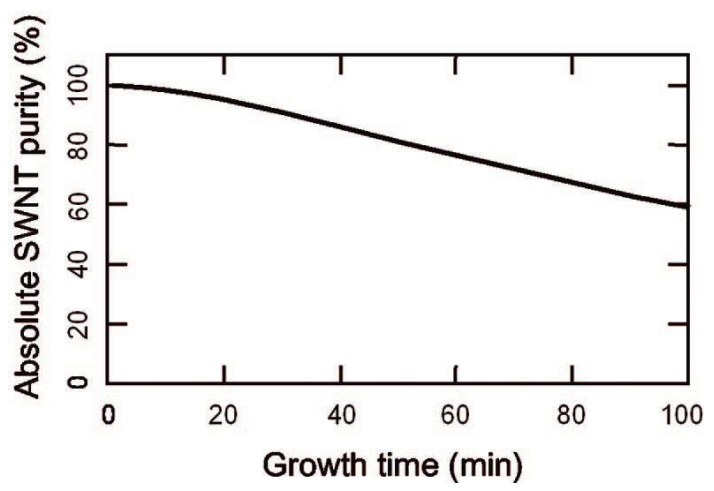

Figure 11. (a) Time evolution of the calculated weights of SWCNTs (red line), carbonaceous impurities (black line), and forest (blue line and squares). (b) Time evolution of the absolute purity in SWCNT. From [294].

By analogy with standard crystal growth, the crystalline quality of CNTs is expected to increase with decreasing supply and increasing mobility of the elementary building blocks. Qualitatively, in situ TEM observations of Sharma et al. [235] confirm that straight nanotubes tend to form at high temperatures and low precursor pressures while bent and defective nanotubes form at low temperatures and high precursor pressures. More quantitatively, the Raman measurements of the D/G ratio reported by Picher et al. indicate that the defect density that the defect density of CNT sample follows a power law with precursor pressure [295].

The dependence of $\mathrm{D} / \mathrm{G}$ on the growth temperature as reported in the literature is more complex. Studying CNT samples grown at increasing temperatures, Vinten et al. [296], Kwok et al. [297] and Picher et al. [295] observed three different regimes: with increasing growth temperatures: D/G first exponentially decreases, then decreases less markedly for an 
intermediate range of temperatures and finally increases strongly. Concerning the high temperature regime, Kwok et al [297] and Picher et al. [295] observed that the increase of D/G was proportional to the growth duration which they both attributed to the deposition of pyrolytic carbon activated at high temperatures in agreement with the conclusions of Yasuda et al. based on coupled TEM-Raman studies [294] and of Feng et al. based on coupled TEMthermal analyses [298]. Concerning the observation of two different regimes at low and intermediate temperatures, different explanations have been proposed (e.g. predominance of non-SWCNT carbon impurities at low temperature, change of the catalyst state) but there is still no agreement in the literature.

Certain molecular species were also reported to act as defect-promoters. Noda et al. notably reported that the addition of water to ethylene degrades the quality of CCVD-grown SWCNTs [299]. Similarly, Gao et al.[279] found that using an oxygen-containing precursor such as ethanol yielded a higher linear density of defects than using methane. Using a nitrogen-containing additive (acetonitrile), Thurakitsereea et al. [300] showed that the density of defects by nitrogen incorporation into the $\mathrm{sp}^{2}$ carbon network could reach one atomic percent.

A remaining question is the influence of the catalyst on the defect density of CNTs. Theoretical works [301] support that the catalyst may strongly influence the processes of defect creation and annealing, but dedicated experimental studies are still missing.

\subsection{Proportion of catalyst particles active for nanotube growth}

After growth, it is commonly observed that many catalyst particles did not yield nanotubes. Different denominations are used in the literature for the ratio of the number of synthesized nanotubes by the number of catalyst particles, such as "catalyst activity" or "synthesis yield". To avoid confusion with other features of the catalyst or of the synthesis 
process, we will use here the term proportion of active particles (PAP). The PAP is best evaluated when using well separated catalyst particles deposited on a support. For instance, using individual $\mathrm{Ni}$ particles of $4.7 \pm 1.5 \mathrm{~nm}$ in different growth conditions, Paillet et al. [302,303] measured PAP ranging between $0.5 \%$ and 20\%. Using spatially ordered Fe particles of $1.7 \pm 0.6 \mathrm{~nm}$, Ishida et al. [304] measured similarly low PAP of $\sim 10 \%$. Y. Li et al. [305] led post-growth HRTEM observations to understand the low PAP obtained with discrete Fe particles of 1-2 $\mathrm{nm}$ and 3-5 $\mathrm{nm}$. They observed that inactive particles yield only single spherical graphitic shells around them and that smaller nanoparticles $(<1.8 \mathrm{~nm})$ tend to be more active in producing SWCNTs with appreciable lengths. In agreement with the observations of the group of J. Liu that particle activity for nanotube growth was strongly size-dependent [225], Li et al. proposed that the disparity in particle size was the likely cause to the low PAP. The encapsulation of inactive particles by a graphitic shell is commonly observed during post-growth HRTEM analyses (Figure 12) and often invoked to explain the inactivity [306]. Rümmeli et al. [307] proposed that the nucleation of a carbon cap proceeds by precipitation of carbon from a supersaturated catalyst particle. They suggested that the biggest particles displaying a too large volume to surface area ratio would therefore be encapsulated by the precipitating carbon. Using the same argument and based on the observation that the ratio of the number of encapsulating graphitic layers, $\mathrm{N}_{\mathrm{L}}$, to the particle diameter, $D_{\mathrm{P}}$, is typically $0.2-0.3 \mathrm{~nm}^{-1}$, Ding et al. [308] even suggested that encapsulating layers were formed by precipitation of carbon from a carbide particle of composition $\mathrm{M}_{3} \mathrm{C}$ (e.g. $\mathrm{Fe}_{3} \mathrm{C}$ ). Experimentally remains the question of whether these encapsulating shells were formed during the exposure to the carbon precursor (therefore causing the inactivity) or at a later stage (e.g. during cooling). In situ TEM observations frequently reveal inactive particles larger or smaller than some active neighbours [206] but, up to now, the origin of their inactive could not be directly assessed. 
When considering a possible encapsulation of the catalyst particle by carbon, the exact nature of the carbonaceous material has to be considered since their reactivity can greatly vary with their composition (e.g. H or O contents) and structural disorder. For instance, Davis et al. [309] showed that the dissociation of ethylene on a $\mathrm{Pt}(111)$ surface leads to the formation of a carbonaceous overlayer containing a large fraction of hydrogen. With increasing time, increasing temperature or decreasing hydrogen partial pressure, the hydrogen concentration of the overlayer decreases, finally leading to a graphitic layer that is irreversibly adsorbed and displays no catalytic activity [310]. In the case of propylene conversion on $\mathrm{Mo}$ at $600^{\circ} \mathrm{C}, \mathrm{Wu}$ et al. [311] also confirmed the slow transformation of an easily removed hydrogen-rich overlayer into an inactive and irreversibly adsorbed graphitic layer. In the case of nanotube growth, Schünemann et al. [312] observed that the carbonaceous layer deposited by pyrolytic decomposition of cyclo-hexane did not prevent the growth of CNTs, but acted indeed as a carbon source. Interestingly, after monitoring the growth of an individual tube by in situ field emission imaging, Marchand et al. [313] found that increasing the temperature by a few tens of degrees reactivated the nanotube growth. This observation suggests that at low temperatures, deactivation is mainly caused by the encapsulation of the catalyst particle by a disordered carbonaceous layer whose structure is temperature-dependent.

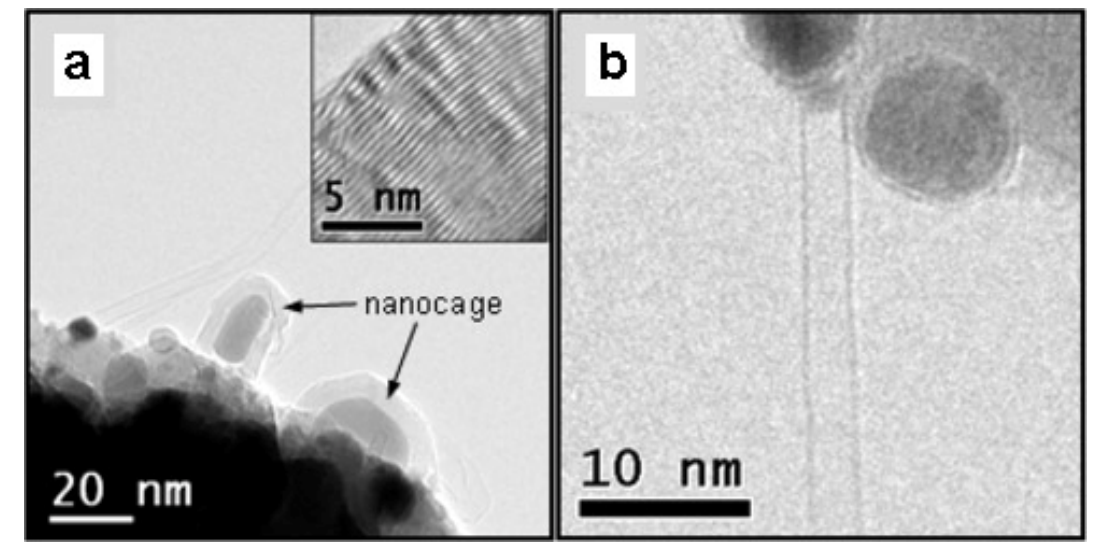

Figure 12. Nickel particles encapsulated by a thick (a) or single-layer (b) graphitic observed after nanotube growth together with active catalyst particles. From [306]. 
Accordingly, preventing the particle encapsulation and reducing the catalyst coarsening are the two main ways used in the literature to grow high-density CNT samples. The vertically aligned CNT (VACNT) forests prepared by the so-called "super-growth" reported by Futaba et al. [314] are among the best examples of high-density samples. Using iron on alumina as catalyst and a controlled addition of water vapour to the ethylene precursor, they obtained PAP of up to $84 \%$ [315]. Later, they showed that other oxygen-containing compounds such as $\mathrm{CO}_{2}$, ethanol or acetone, also act as growth enhancers [316]. They concluded that a controlled amount of oxygen supplied by the growth enhancer activates the catalysts by cleaning off the carbon coating that deactivates them. In another example of highdensity growth, the growth of aligned CNT arrays on quartz, Zhou et al. [317] reported that the nucleation efficiency can be enhanced by a factor 3-4 by performing multiple cycles of growths separated by a short argon exposure. A similar observation was reported by Bin $\mathrm{Wu}$ et al. [318]. Based on the observation of nanotube etching with increasing the number of cycles, they postulated that oxygen-containing functions (e.g. $-\mathrm{OH})$ reacted with the most reactive forms of carbon (amorphous carbon, small-diameter SWCNTs). Using $\mathrm{Fe} / \mathrm{Al}_{2} \mathrm{O}_{3}$ catalysts presenting a gradient of iron thickness, Hasegawa et al. [319] evidenced that millimetre-tall VACNT forests can be grown without addition of water if the carbon precursor supply is set below a certain limit in order to retain an active catalyst; water only extends the catalyst lifetime when an excess precursor supply is used. They also found water addition to widen the window of catalyst thickness for VACNT growth toward higher thicknesses and to suppress nanotube growth from the smallest catalyst particles [299].

The carbon etching effect of oxygen-bearing enhancers may not be the only reason for the high nucleation yield of the super-growth. Zhu et al. [320] and Noda et al. [321] reported that replacing $\mathrm{Al}_{2} \mathrm{O}_{3}$ support beneath the $\mathrm{Fe}$ catalyst by $\mathrm{SiO}_{2}$ decreases the nanotube yield by nearly two orders of magnitude under the same growth conditions. Studying Fe catalysts 
supported on different types of alumina, Amama et al. [322] observed that SWCNT forest growth was strongly dependent on the type of alumina. Highest nanotube yields were obtained using alumina of high porosity (e.g. sputtered $\mathrm{Al}_{2} \mathrm{O}_{3}$ ) which was correlated with low Ostwald ripening rates and mild subsurface diffusion rates. Burt et al. [323] also observed that the VACNT yield was strongly dependent on the grain size of the sputtered alumina layer. From Noda et al., using cobalt as catalyst instead of iron had little effect, but using nickel instead of iron reduced the CNT forest height by 2-3 orders of magnitude [321]. These results highlight the importance of the catalyst and the support for growing high-density CNT samples. Mattevi et al. [183] proposed that interaction of $\mathrm{Fe}$ on $\mathrm{Al}_{2} \mathrm{O}_{3}$ is much stronger than that on $\mathrm{SiO}_{2}$, and restricts $\mathrm{Fe}$ surface mobility. The resulting much narrower $\mathrm{Fe}$ catalyst particle size distribution on $\mathrm{Al}_{2} \mathrm{O}_{3}$ would lead to a higher CNT nucleation density. This is in line with the report of Esconjauregui et al. [324] that plasma-assisted thermal pretreatment of catalyst films of $\mathrm{Ni}$, Co or Fe on TiN greatly facilitates the direct growth of high-density arrays of CNTs by promoting a stronger catalyst-support interaction and hence stabilizes smaller catalyst particles with a higher number density. Amama et al. [325] reported that the addition of water contributed to reduce the migration of iron catalysts on alumina and proposed that the formation of hydroxyl groups at the surface of alumina by water was at the origin of the reduced surface diffusivity of catalyst atoms. At the opposite, Hasegawa et al. observed no influence of water addition to the rate of catalyst coarsening inferred from the evolution of the average CNT diameter from the top to the bottom of CNT forests [319]. After exploring a large range of growth condition, Hasegawa and Noda [326] concluded that both a moderate carbon supply and a suppressed catalyst restructuring are key requirements in order to grow dense millimetre-tall SWCNT forests. As a consequence of those, they observed that the optimal growth domain for high-density SWCNT growth followed a diagonal in the temperature-carbon supply diagram [326]. 


\subsection{Nanotube length}

Experimentally, the elongation rate (or growth rate) of nanotubes is observed to decrease with time until complete termination of the growth (Figure 13). In Figure 13, one can observe that nanotube kinetics is characterized by an initial growth rate and a lifetime corresponding to the saturation of the nanotube length. This general behavior was observed at the level of individual nanotubes [235,306,313], of thin nanotube carpets [327,328] and of thick nanotube forests [329-332]. The final length of a nanotube depends not only on the nature of the growth limiting step but also on the nature of the deactivation process(es) limiting the lifetime. Obviously, the nature of the rate-limiting step and of the dominating deactivation process may vary with the experimental conditions. Hereafter, we describe the parameter dependence of the growth rate and lifetime and discuss the particular case of the kite growth method which produces the longest nanotubes to date.

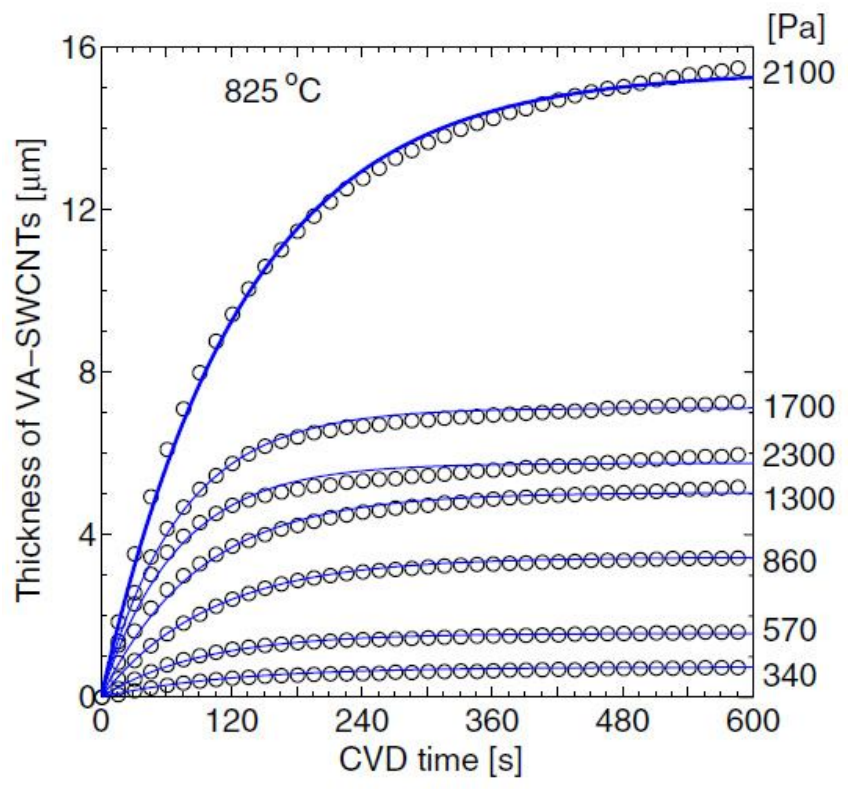

Figure 13. Time evolution of the thickness of a forest of VACNT measured by in situ optical absorbance for different partial pressures of carbon precursor (ethanol). $\mathrm{T}=825^{\circ} \mathrm{C}$. From $[331]$. 


\subsubsection{Growth rate}

Growing carbon filaments from acetylene at low temperatures $\left(350-600^{\circ} \mathrm{C}\right)$, Baker et al. measured growth activation energies that were remarkably correlated with the activation energy for solid-state carbon diffusion through the corresponding bulk metals $[6,333,334]$. This supported that, in these conditions, bulk diffusion through a solid-state catalyst particle was the rate-determining step. A similar correlation was noted by other authors [335-337] usually when using low temperatures $\left(400-600^{\circ} \mathrm{C}\right)$ and relatively reactive carbon sources $(e . g$. acetylene, propylene, butadiene).

However, many authors did not observe this correlation in their experimental conditions. Using acetylene in microwave plasma-assisted CVD, Bartsch et al. [337] measured an activation energy of 1.4-1.6 eV (in agreement with values for carbon diffusion in solid-state metals) for the formation of bamboo-like CNTs at $800-900^{\circ} \mathrm{C}$ but an activation energy of $0.3-0.6 \mathrm{eV}$ for the growth of MWCNTs at $900-1100^{\circ} \mathrm{C}$. They inferred that bulk diffusion was the rate-determining step in both cases, but through a solid or a liquid particle depending on the temperature range. Other authors reported high activation energies of the order of 2-2.8 eV at low temperatures [327,330,338,339] which may be compatible with gasphase conversion of the carbon or bulk diffusion of carbon through carbide metals, but not with bulk diffusion through pure metals (see 2.3.2).

In contradiction with the hypothesis that growth kinetics is simply determined by the diffusion rate of carbon, the growth activation energy is often reported to be influenced by the reactivity of the gas phase. For instance, using plasma-assisted growth from acetylene at 150$500^{\circ} \mathrm{C}$, Hofmann et al. [105] reported activation energies of $0.23-0.4 \mathrm{eV}$ much lower than the value of $1.2 \mathrm{eV}$ that Ducati et al. measured for thermal growth [340] or the value of $1.5 \mathrm{eV}$ measured by Baker et al.. They concluded that the rate-limiting step in plasma-assisted conditions was the surface diffusion of carbon on the catalyst particle and that precursor 
decomposition was the limiting step in purely thermal conditions. Meshot et al. [341] also showed that the growth activation energy was dependent on the pre-treatment of the gas mixture and increased from 1.02 to $1.88 \mathrm{eV}$ when increasing the preheating temperature of the gas mixture from 980 to $1120^{\circ} \mathrm{C}$.

In addition, the growth rate is often reported to increase with increasing precursor pressure. The reaction orders were reported to be close to unity by most authors [298,327,331,338,342] except by Wirth et al. [332] who measured a reaction order of 0.6 for low-pressure acetylene growth on $\mathrm{Fe} / \mathrm{Al}_{2} \mathrm{O}_{3}$. Noteworthy, several authors reported that above a critical precursor pressure, the growth rate is independent of the precursor pressure [298,327,331] which was interpreted by Picher et al. [327] and Feng et al. [298] as the transition from a kinetic regime controlled by gas diffusion to a surface-controlled regime.

Many growth models predict that the nanotube growth rate will either increase $[343,344]$ or decrease [330] with diminishing size of the catalyst particle. For instance, the model proposed by Puretzky et al. [330] stipulates that the larger diameter nanotubes should grow faster than the smaller diameter ones due to their higher surface area to circumference ratio. They later refined this model by including a size-dependent activation energy for feedstock dissociation to account for the experimental bell-like distribution of nanotube diameters [226]. Experimentally, however, there is no general agreement on the variation of the nanotube growth rate with the particle size or nanotube diameter. Growing arrays of aligned MWCNT by PECVD, Huang et al. [345] observed that the CNT growth rate was diminished when reducing the catalyst thickness from $35 \mathrm{~nm}$ to $10 \mathrm{~nm}$. A similar observation was reported by Lee et al. [346] using a lower range of catalyst thicknesses $(0.7-10 \mathrm{~nm})$. Using a gradient of catalyst thickness, Zhang et al. [33] reported that the growth rate increased with increasing catalyst thicknesses, while Hasegawa et al. [347] found that the initial growth rate of thick CNT forests was rather constant for catalyst thicknesses of 0.4-3.0 
nm. Contrary to Zhang et al., Patole et al. [348] observed that the CNT growth rate increased when decreasing the catalyst thickness from 3.0 to $0.5 \mathrm{~nm}$. They also noted that the growth rate decreased with time as $\mathrm{t}^{1 / 2}$, which supported that the rate was controlled by the diffusion through a barrier of increasing thickness (i.e. CNT or amorphous carbon mat) rather than by a catalyst size-related effect. This illustrates the difficulty to use CNT arrays to address this question because of the possible combination with other effects: diffusion through the stack, competitive/synergetic effects between neighbouring particles $[349,350]$. In this context, it is worth mentioning the in situ study of CNT length by aerosol size classification of Chiang et al. [351] who reported that reducing the catalyst size from $2.6 \mathrm{~nm}$ to $2.2 \mathrm{~nm}$ increased the CNT growth rate by a factor 3 .

Since the nature of the catalyst strongly affects the physical and chemical properties of the particles, it may significantly influence the CNT growth rate. For instance, growth simulations performed by Page et al. [352] predict that the growth rate on Ni particles would be $69 \%$ larger than on $\mathrm{Fe}$ particles due to a faster integration of carbon chains into the nanotube. However, experimental comparisons of CNT growth rates for different natures of catalyst are quite few. Comparing the efficiency of $\mathrm{Ni}$, Co and Fe catalyst films in the same PECVD conditions, Huang et al. [345] found that Ni yielded the highest growth rate, largest diameter and thickest wall, whereas Co results in the lowest growth rate, smallest diameter and thinnest wall. The CNT growth rates with $\mathrm{SiO}_{2}$ [353] and $\mathrm{Al}_{2} \mathrm{O}_{3}$ [354] nanoparticles are usually of the order of $10 \mathrm{~nm} / \mathrm{s}$, which is much lower than with standard iron-group catalysts. Motta et al. [355] also reported that the presence of sulphur facilitates the formation of nanotubes. They found that sulphur forms a layer on the surface of the catalyst particles which may play a role in encouraging nanotube growth by surface diffusion.

Other factors may influence the nanotube growth kinetics. For instance, Louchev proposed a kinetic model where the growth rate is controlled by the surface diffusion of 
carbon atoms over the surfaces of the carbon nanotube and of the underlying support [356]. This is in tune with the proposition of Magrez et al. [147] that the support contributes to the conversion and supply of carbon-containing intermediates to the nanotube root. Quantitative assessments of these effects on the growth kinetics of CNTs are however still missing.

\subsubsection{Lifetime}

Several authors reported on the temperature dependence of the lifetime. Studying the growth kinetics of thin CNT carpets on silica-supported catalysts as a function of temperature, Picher et al. [327] found that the evolution of the lifetime was inversely correlated with that of the initial growth rate: the lifetime first decreases with increasing temperature until a critical temperature above which it increases with temperature. However, they observed that the correlation ceased at too high temperature or too low precursor pressure [156]. Studying the growth of CNT forest from ethylene at $600-700^{\circ} \mathrm{C}$, Bronikowski [339] found that the lifetime decreases with increasing temperature with an apparent activation energy of $3.4 \mathrm{eV}$ for an alumina underlayer and $2.1 \mathrm{eV}$ for a silica underlayer. Studying the growth kinetics of thick CNT forests at higher temperatures $\left(650-1000^{\circ} \mathrm{C}\right)$, Vinten et al. [296] also observed that the lifetime generally decreased with increasing temperature. In addition, they identified a critical temperature above which the initial growth rate started to plateau and the lifetime decreased even more abruptly. Monitoring the mass uptake of a $\mathrm{Fe}-\mathrm{Mo} / \mathrm{Al}_{2} \mathrm{O}_{3}$ catalyst during $\mathrm{CNT}$ growth, Feng et al. [298] observed that, with increasing temperature, the catalyst lifetime first slightly decreased, then increased and finally declined.

Several studies also showed the dependence of the lifetime on the gas phase. Using ethylene as carbon source and an $\mathrm{Fe} / \mathrm{Al}_{2} \mathrm{O}_{3}$ catalyst, Futaba et al [329] reported that the lifetime tended to decrease with increasing precursor supply. Using other types of catalysts $\left(\mathrm{Ni} / \mathrm{SiO}_{2}, \mathrm{Fe}-\mathrm{Mo} / \mathrm{Al}_{2} \mathrm{O}_{3}\right)$ and carbon sources (acetylene, ethanol), Feng et al. [298] and Picher et al. [327] also found that the lifetime generally decreases with increasing precursor pressure. 
When applying a separate preheating of the process gas for the growth of CNT forests, [341], Meshot et al. observed that the lifetime strongly varied with the preheating temperature and peaked for a certain value. As already highlighted, Futaba et al. showed that the addition of water at an appropriate concentration could increase the growth lifetime [329]. Using ultrapure process gases free of oxygen and water contaminations, In et al. [338] found that the lifetime was significantly lower with purified gases than with unpurified ones, but was strikingly insensitive to variations in ethylene or hydrogen pressures. Generally speaking, these results support that different deactivation processes are at play during nanotube growth and that the predominance of each depends on the growth conditions.

Finally, in the case of thick base-grown CNT forests, the diffusion of gaseous species through the growing mat of CNTs may become limiting. Observing that the growth rate decreases with time as $\mathrm{t}^{1 / 2}$, Zhu et al. attributed the decrease to the growing diffusion resistance of the mat to gaseous species [357]. Based on diffusion modeling, Xiang et al.[358] argued that this explanation could only hold for highly dense millimetre-tall SWNT arrays, but not for other types of CNT samples.

\subsubsection{Ultralong carbon nanotubes obtained by kite growth}

To understand the processes controlling the nanotube length, it may be useful to learn from the syntheses yielding the longest CNTs. At the time of writing, the longest reported nanotubes were obtained by kite growth, a particular mode of CCVD growth where one extremity of the CNT floats in the gas phase while the other one remains attached to the support [359,360]. Such CNTs can reach lengths of 4-20 cm [361]. Their growth rates extrapolated from the synthesis duration and the CNT length can reach 10-90 $\mu \mathrm{m} / \mathrm{s}$ [361]. Ethanol, carbon monoxide and methane are the main carbon sources used for the growth of such ultralong CNTs by kite growth. It is worth noting that the addition of an appropriate amount of water to methane [361] or ethanol [362,363] significantly enhances the growth rate 
of such ultralong CNTs. The nature of the catalyst is varied: $\mathrm{Co}, \mathrm{Cu}, \mathrm{Fe}, \mathrm{Fe}-\mathrm{Mo}$. The growth temperatures are relatively high $\left(850-1000^{\circ} \mathrm{C}\right)$ compared to standard CCVD conditions. In kite growth, ultralong CNTs are believed to grow by the tip-growth mechanism, i.e. with the catalyst particle attached at the floating end of the nanotube. This supports that substraterelated deactivation processes are major causes of nanotube length limitation.

\subsection{Summary}

The structural features of carbon nanotubes grown by CCVD strongly depend on the support-catalyst system and on the synthesis conditions. From in situ TEM observations, the catalyst particle undergoes a dynamic reshaping to accommodate the growing carbon structure. In many cases, the reshaping leads to a pear-shaped catalyst particle. In first approach, the outer diameter of the nanotube is observed to correlate with the lateral dimension of the catalyst particle. However, for a given particle, the nanotube diameter is also found to vary with the growth temperature although the operating mechanism is still unclear. Carbon supply strongly influences the overall nanotube diameter distribution, but the reported trends are often contradictory, which suggests that its influence is strongly dependent on the growth conditions and of the studied systems. The nanotube inner diameter is often found proportional to the outer diameter with a proportionality coefficient which varies with the growth conditions. Consequently, adjusting the size of the catalyst particles is a common way to obtain CNTs of controlled wall numbers. Other parameters are also found influential. A decreased carbon supply generally reduces the number of walls, as expected from the initial model of Tibbetts for a reduced carbon chemical potential. The temperature dependence of the inner diameter is still unclear and gives rise to contradictory reports. The addition of sulphur is reported to reduce the inner diameter of CNTs. 
Concerning the chiral angle, a higher occurrence of near-armchair CNTs in as-grown samples is frequently reported. Obtaining such chirality-enriched samples usually requires special (often binary) catalyst systems, low synthesis temperatures and optimized gaseous feeds. The origin of this chiral selectivity is the subject of an intense debate and of different hypotheses as detailed in $\$ 4.4$. The addition of nitrogen and certain crystal substrates were also reported to promote the growth of specific chiralities. The growths of semiconducting- or metallic-enriched samples were reported by several groups. Most preferential growths of semiconducting SWCNTs can be attributed to a higher sensitivity of metallic SWCNTs to reactive environments (plasma, UV irradiation, oxygen-containing atmosphere) leading to a modification of their electrical properties or to their selective removal. The growth of samples highly enriched in metallic SWCNTs was also reported by an optimization of the annealing of the catalyst under a water-containing helium atmosphere. At the time of writing, this preferential growth of metallic SWCNTs remains is not explained.

The defect density of CNT samples is most commonly assessed by Raman measurements of the D band. However, these measurements can also be influenced by the presence of defective carbonaceous by-products (e.g. pyrolytic carbon). In first approximation, the resultant defect density of CNTs simply increases with increasing carbon supply and decreasing synthesis temperature as expected from classical crystal growth theory. In-depth studies actually showed different regimes of defect integration or of by-product formation when varying the growth temperature. Different hypotheses were proposed to explain the occurrence of these different regimes (e.g. change of state of the catalyst, reaction with contaminants, formation of defective carbon by-products), but the matter is still not closed. The use of oxygen- or nitrogen-containing precursors and the addition of water were shown to increase the defect density of CCVD-grown CNTs. In most CCVD syntheses, the percentage of particles yielding a nanotube is low (typically less than 10\%). Particle inactivity is usually 
attributed to the stochastic nature of nanotube nucleation or to its dependence on the particle size. Water and diverse oxygen-containing precursors were found to increase the percentage of active particles and to promote the growth of highly dense CNT forests. Their effect is usually attributed to the prevention of particle encapsulation by cleaning off carbon species at the surface of the particle. $\mathrm{Fe} / \mathrm{Al}_{2} \mathrm{O}_{3}$ used with ethylene and water traces is a popular catalyst for growing high-density CNT forests whose efficiency is attributed to both the etching effect of water and the low coarsening of iron particles on alumina.

For given conditions, the final length of a nanotube depends on the growth limiting step, on the main deactivation process, and on their respective parameter dependences. Growth activation energies are commonly used to infer the nature of the limiting step. However, the reported values $(0.2-3 \mathrm{eV})$ greatly vary from one catalyst system to another and with the growth conditions. The good correlation between the values measured by Baker (0.7$1.5 \mathrm{eV}$ ) and the values corresponding to bulk diffusion through solid metals supported this latter stage to be limiting. Other groups measured lower values $(0.2-0.6 \mathrm{eV})$, which led them to assign the limiting step to surface diffusion or to bulk diffusion through a liquid particle. Higher values $(1.5-3 \mathrm{eV})$ were also reported which were usually attributed to the surface or gas-phase conversion of carbon precursors. This latter proposition is additionally supported by the dependence of the activation energies on the gas phase reactivity (plasma activation, preheating, precursor pressure). From these reports, it is reasonable to conclude that the nature of the limiting step depends on the nature of the catalyst and the growth conditions although what actually fixes the limiting step is still not rationalized. The growth lifetime generally decreases with increasing precursor supply. This can be counteracted by a controlled addition of an appropriate oxygen-containing additive such as water. In a large range of precursor pressure and temperature, the lifetime is observed to be inversely correlated with growth rate. These results support that carbon encapsulation is a major cause of catalyst deactivation. 
However, the complex temperature dependence of the lifetime supports that other deactivation processes, such as catalyst coarsening, may be at play, especially at high temperature and low carbon supply. It is apparent that the same phenomena (catalyst coarsening, particle encapsulation) are invoked for both the growth deactivation and the catalyst inactivity, supporting that, in many cases, particles inactivity may be considered as early deactivation. It is worth mentioning that the longest tubes to date, which were grown by kite growth, were obtained using both catalyst particles detached from the support (i.e. tip growth) and a controlled addition of water.

\section{Open questions and current hypotheses}

This part addresses a few selected questions that are considered as important in the field of nanotube growth and are the subjects of intense investigations. These questions directly impact on the experimental dependence of the nanotube features described in the preceding chapter. For each question, the associated hypotheses are described together with the pros and cons from experimental results and in silico simulations.

\subsection{State of the particle}

\subsubsection{Physical state}

The physical state of the particle (liquid or solid) is a subject of controversy. As described in $\S 2.2 .2$, the melting point of a metal particle can be significantly lowered by the size effects or the incorporation of carbon atoms or increased by interaction with the substrate. Simulations performed by Diarra et al. [364] show that, at the standard temperatures of CNT growth and in the absence of carbon, nickel nanoparticles down to 147 atoms $(\sim 1 \mathrm{~nm})$ are solid. However, they observed that the incorporation of carbon tend to amorphize or melt the outer layer of the nanoparticle, eventually leading to a complete melting for smaller nanoparticles and large carbon fractions (i.e. larger than $10 \%$ at.). 
In the $70 \mathrm{~s}$, Baker $[5,6,365]$ proposed that the growth of carbon filaments proceeded via the vapour-liquid-solid (VLS) model developed by Wagner and Ellis for the growth of silicon whiskers [366]. In the original VLS model of Wagner and Ellis, the role of the particle is to form a liquid alloy droplet which acts as a preferred site for deposition from the vapour; once the liquid particle is supersaturated, the filament starts growing by precipitation of silicon atoms from the droplet. There are therefore two main and different hypotheses in the VLS model of Wagner and Ellis: i) the particle is liquid and ii) reactant atoms diffuse through the bulk of the particle. Actually, the proposition of Baker et al found massive support because the growth activation energies they measured were in excellent agreement with the values corresponding to the bulk diffusion of carbon through the corresponding metals. The results of Baker not only supported that bulk diffusion was a required step, but also that it was the rate determining step of carbon filament growth. However, it is often forgotten that the activation energies measured by Baker were in excellent agreement with those of bulk diffusion through the metals in the solid state and not in the liquid state. The results of Baker therefore provided a strong support for the second hypothesis of the VLS model (the bulk diffusion hypothesis), but were in contradiction with its first hypothesis (the liquid particle hypothesis). The use of the VLS term by opposition to a model where the particle would be solid is therefore often misleading. Preferably, one should specify which hypothesis of the VLS model one considers.

Experimentally, the rounded and elongated shapes of nickel catalyst particles observed after nanotube growth led Kukovitsky et al [367] to conclude that the particles were liquid during the growth process. However, in situ TEM observations by Helveg et al. [201] and other groups [202-205] demonstrated that, although highly deformable, nickel and iron catalyst particles remained crystalline during CNT growth. It is worth mentioning that, to date, all in situ TEM observations of crystalline particles correspond to rather large particles 
(typically larger than $4 \mathrm{~nm}$ ). Experimentally, the physical state of transition metal catalyst particles of a few nanometres that are active for SWCNT growth is still an open question.

If one considers the current list of active catalysts for SWCNT growth (see §2.2.1), the melting temperature of the bulk phase ranges from $327^{\circ} \mathrm{C}(\mathrm{Pb})$ to $3550^{\circ} \mathrm{C}$ (diamond) for individual elements and up to $2830^{\circ} \mathrm{C}$ ( $\mathrm{SiC}$ ) for mixed compounds. Even by taking into account the influence of the particle size, carbon content and support, one must conclude that at standard growth temperatures $\left(600^{\circ} \mathrm{C}-1000^{\circ} \mathrm{C}\right)$, some catalyst particles are probably liquid (e.g. $\mathrm{Pb}$ ) while other ones are solid (e.g. diamond). For instance, the quantum-based molecular dynamics simulations reported by Page et al. [368] support that, during CNT growth, the surface of $\mathrm{SiO}_{2}$ nanoparticles is converted to an amorphous $\mathrm{SiC}$ layer while the core of the $\mathrm{SiO}_{2}$ nanoparticle remains oxygen-rich and solid. From all these results, one must conclude that both liquid and solid particles can support the growth of a CNT. However, the physical state would modify several properties of the particle that influence the efficiency and features of CNT nucleation, growth or deactivation (i.e. carbon solubility and diffusivity, deformability). For a given element, a solid or liquid state may be preferred to assist the growth of CNTs.

\subsubsection{Chemical state}

The chemical state of transition metal particles during CNT growth is also a controversial subject, especially in the case of iron. Essentially, the question is how much carburized is the metal particle during the growth: is it still metallic or carbidic? Is carbon dissolved in the bulk, only in subsurface sites, or does it remain at the surface of the particle? Obviously, one may expect from the content of $\S 2.3$ that the answer varies with the considered metal, its carbon affinity and its propensity to form carbides. 
Esconjauregui et al [38] performed in situ X-Ray diffraction (XRD) studies of CNT growth from a large range of elements as catalyst. They observed that all transition metal particles undergo carburization during the induction phase. At the onset of CNT growth, higher transition metal carbides such as $\mathrm{Ni}_{3} \mathrm{C}$ tended to decompose while lower transition metal carbides, such as WC, remained stable during CNT growth. Other metal carbides, such as $\mathrm{Mo}_{2} \mathrm{C}$, were found stable but inactive for CNT growth. They also reported that MWCNTs could be grown by using pre-carburized $\mathrm{Ni}_{3} \mathrm{C}$ particles as catalyst. The in situ TEM studies reported by Lin et al. [306] confirmed that $\mathrm{Ni}$ particles of 1-10 $\mathrm{nm}$ remain metallic during CNT growth and do not transform into $\mathrm{Ni}_{3} \mathrm{C}$ carbide. [369] In situ XPS studies of Wirth et al. also showed that $\mathrm{Ni}, \mathrm{Co}$ and Fe catalyst particles are in the metallic state during CNT growth.

The case of iron requires special attention. As can be seen in Figure 3, the stability of $\mathrm{Fe}_{3} \mathrm{C}$ at the considered temperatures is close to that of graphite. Therefore, one should expect the stability of $\mathrm{Fe}_{3} \mathrm{C}$ to strongly depend on the experimental conditions (i.e. temperature and carbon activity of the gas phase). Hofmann et al. observed the presence of additional carbide peaks in XPS in the case of iron, but not in the case of nickel and cobalt catalysts [370]. In line with the results of Esconjauregui et al, Emmeneger et al [371] reported in situ XRD data showing that, when exposed to $\mathrm{C}_{2} \mathrm{H}_{2}, \mathrm{Fe}_{2} \mathrm{O}_{3}$ was progressively converted into $\mathrm{Fe}_{3} \mathrm{C}$ which decomposed after 20-30 min into Fe and graphite, this process coinciding with the onset of CNT growth. This result supports that Fe is in the metallic state during CNT growth and in the carbidic state before CNT nucleation. In contrast with these results, in situ TEM observations [21,204,372] and XRD measurements [373] of different groups showed that CNTs nucleate and grow from $\mathrm{Fe}_{3} \mathrm{C}$ particles. To complete this description, it is also worth mentioning the post-growth analysis by TEM reported by Z. He et al. [374]. These authors observed that, in the same sample, both $\mathrm{Fe}$ and $\mathrm{Fe}_{3} \mathrm{C}$ particles could be found at nanotube ends. Interestingly, the ratio of $\mathrm{Fe}$ and $\mathrm{Fe}_{3} \mathrm{C}$ particles was found to vary with the synthesis 
temperature, $\mathrm{Fe}_{3} \mathrm{C}$ particles being more abundant at low temperature. In addition, $\mathrm{CNTs}$ connected to $\mathrm{Fe}_{3} \mathrm{C}$ particle were all bamboo-like and were much shorter than the CNTs connected to Fe particles. Similarly, in situ TEM and XRD data from Wirth et al [375] showed that both metallic $\mathrm{Fe}$ and carbidic $\mathrm{Fe}_{3} \mathrm{C}$ can be the active catalyst phase. Interestingly, they found that the nature of the main catalyst phase strongly depended on the $\alpha / \gamma-\mathrm{Fe}$ proportion following catalyst reduction: they observed that metallic Fe was the main active catalyst phase for $\gamma$-rich catalyst mixtures while $\mathrm{Fe}_{3} \mathrm{C}$ was the main catalyst phase in the case of $\alpha$-rich catalyst mixtures, which could be accounted for by considering the metastable Fe-C phase diagram.

\subsection{Reaction intermediates}

A still open question concerns the nature of the reaction intermediates incorporated at the nanotube edge. This is important since the nature of the intermediates affects the mechanism of carbon incorporation in the nanotube and, hence, the growth rate, the defect density and the chiral selectivity. Simulations reported by Wang et al. [376] notably predict that changes of chirality would be more frequent in the case of the addition of carbon adatoms than in the case of carbon dimers.

Many studies were devoted to study the dissociation mechanism of carbon precursor molecules on a metal surface. Studying the dissociation of $\mathrm{C}_{2} \mathrm{H}_{2}$ on $\mathrm{Fe}(001)$ by first-principles calculations, Lee et al. [377] observed C-C bond breaking, leading to the formation of $\mathrm{CH}$ fragments. Molecular dynamics simulations performed by Vasenkov et al [378] also supported a $\mathrm{C}-\mathrm{C}$ bond scission of $\mathrm{C}_{2} \mathrm{H}_{2}$, but highlighted that surface contamination by oxygen could impede the dissociation. Experimentally, Moors et al. [122] studied the surface products of acetylene decomposition on a nickel nanocrystal using field-assisted desorption coupled with mass spectrometry. They found that, for short reaction times $(\mathrm{t}<10 \mathrm{~ms})$, the carbon 
spectrum is dominated by $\mathrm{C}_{1}$ species, demonstrating rapid $\mathrm{C}-\mathrm{C}$ bond scission during acetylene decomposition. Only at longer reaction times $(t>10 \mathrm{~ms})$ were higher $C_{n}$ carbon oligomers ( $\mathrm{n}=2-4)$ observed to form from $\mathrm{C}_{1}$. Using $\mathrm{C}^{13}$-marked ethanol as carbon source, Maruyama $e t$ al. [379] demonstrated that a smaller amount of site-1 carbon atom (i.e. next to $\mathrm{OH}$ ) was incorporated into the CNTs, also supporting a prior scission of C-C bond in ethanol. Studying ethanol dissociation on $\mathrm{Rh}(111)$ by $\mathrm{X}$-ray photoelectron spectroscopy and temperatureprogrammed desorption, Vesselli et al. [380] confirmed that C-C bond cleavage is the preferential dissociation channel, while $\mathrm{C}-\mathrm{O}$ bond scission was not observed.

Other works support that chains of a few carbon atoms may be the intermediates of carbon incorporation in the CNT. For instance, growth simulations performed by Irle et al. [381] support that carbon incorporation proceeds via carbon chains that are covalently attached to the nanotube edge. The image of an octopus on a rock was used by the Irle group to popularize this hypothesis. Simulations of nanotube nucleation and growth by Amara et al. [200,382] and Neyts et al. [383] also support that both processes proceed via carbon chains. Additional support was provided by the calculations of graphene nucleation and growth on a $\mathrm{Cu}(111)$ surface (Wesep et al. [384]) showing that the formation of carbon chains of 3-13 atoms was preferred compared to two-dimensional compact islands of equal sizes. Experimentally, the afore mentioned study of Moors et al. [122] support a rapid aggregation of $\mathrm{C}_{1}$ into carbon oligomers of 2-4 units. Studying graphene growth on $\mathrm{Ru}$ by low-energy electron microscopy, Loginova et al. [385] found that graphene growth essentially occurs through addition of carbon clusters of about five atoms. Obviously, if the octopus hypothesis can account for SWCNT and graphene growth, it does not seem applicable in the case of the inner walls of MWCNTs.

Some reports support the possibility of a direct polymerization of carbon precursors, such as alkynes and benzene, without $\mathrm{C}-\mathrm{C}$ bond scission. When monitoring the decomposition 
products of benzene by mass spectrometry during the CCVD growth of MWCNTs, Tian et al [20] surprisingly observed no possible hydrocarbon species derived from benzene. Concluding that the carbon-hydrogen bonds of benzene were dissociated but not the carboncarbon bonds, they proposed that CNT growth proceeded by direct integration of sixmembered rings. Their conclusion was supported by density functional theory calculations [386] showing the formation of biphenyl from two benzene molecules on a Ni(111) surface. The calculations indicated that the $\mathrm{C}-\mathrm{H}$ bond of benzene could be selectively dissociated while the C-C bond was still retained. Observing that the growth kinetics of CNT forests were characteristic of heterogeneous chain reactions, Eres et al. [387] proposed that acetylene could self-assemble without $\mathrm{C}-\mathrm{C}$ bond dissociation into larger carbon structures such as chains and nanotubes. Using different alkyne additives for the growth of MWCNT forests in a cold-wall reactor, Plata et al. [388] observed that multiple alkynes reacted with ethylene to accelerate MWCNT growth, suggesting a polymerization-like formation mechanism without full dissociation of the carbon precursors into $\mathrm{C}_{1}$ or $\mathrm{C}_{2}$ units.

\subsection{Mechanism of nanotube nucleation and growth}

Numerous works have been devoted to understand the requirements for nucleating a nanotube. In situ TEM studies have now unambiguously demonstrated that nanotube growth in CCVD is initiated by the formation of a carbon cap at the surface of the particle. These results validated the yarmulke hypothesis originally proposed by Hongjie Dai et al [389]. The experimental conditions favoring a high density of nucleation have already been described in §3.6. Here, we will describe the different theoretical approaches that have been reported to rationalize the nucleation process. 


\subsubsection{Thermodynamic models}

Analytical models based on thermodynamic arguments are an interesting first approach to identify the processes at play during nucleation and evaluate their respective contributions. Kuznetsov et al. [390] considered the probability of formation of a carbon nucleus at the surface of a metal/carbon particle and the corresponding critical radius. They hypothesized that the carbon nucleus has the form of a flat saucer whose edges are bent in order to bond to the metal surface. The change in Gibbs free energy for the formation of the nucleus includes four contributions: the free energy of precipitation of the carbon atoms from the particle, the free energy associated with the surfaces of the nucleus, the free energy associated with the nucleus edges and the strain energy arising from bending the graphene layer. The model predicts that the critical radius of nucleus formation decreases with increasing temperature, increasing saturation of the metal-carbon solution and decreasing specific edge free energy. The authors observed a good agreement between this critical diameter and the average diameter of CNTs formed by different methods as a function of the catalyst nature and synthesis temperature. Dijon et al. [391] used a similar approach to compare the probability of two models of nanotube nucleation leading to either base-growth or tip-growth as a function of the particle size and oxidation state of the catalyst.

The model developed by Kanzow et al. [392] addressed the thermodynamic conditions for a graphene sheet at the surface of a liquid metal/carbon particle to bend and form a fullerene-like cap. From the model, the formation of a cap will be preferred if the available thermal energy exceeds the work of adhesion at the graphene/particle interface and the strain energy associated with the cap formation: the work of adhesion depends on the metal and decreases with the carbon content while the strain energy per unit area decreases with increasing the size of the graphene sheet. Although simple, the model could also reproduce the general dependence of the nanotube diameter distribution on the catalyst type and the 
temperature observed in arc discharge and laser ablation. More recently, Schebarchov et al. [393] developed a model based on a flexible graphitic cap with its free edge constrained to the surface of a rigid spherical particle. They considered that the cap will lift if the curvature energy penalty in the collapsed state exceeds the work of adhesion. Their model provided a prediction of the catalyst-to-nanotube diameter ratio in good agreement with experimental observations for nickel and iron catalysts. However, a model based on a rigid catalyst particle may appear as too unrealistic with regard to the large particle deformability observed during in situ TEM observations.

\subsubsection{Computer simulations}

Such macroscopic models provide useful insights, but they generally lack reliable input data and their applicability at the nanoscale and the building hypotheses can often be questioned. For instance, all models consider a rigid particle which is contrary to most recent experimental observations. Contrary to thermodynamic models that consider idealized objects such as perfect cap structures on a spherical nanoparticle, but lack of reliable energy parameters, computer simulation approaches start, or should start, from a validated interatomic energy model and try and find conditions to nucleate a cap and/or grow a tube, that quite often incorporate a large number of defects. As described in $\$ 2.3 .3$, different atomic interaction models for metal and carbon have been proposed, ranging from simple empirical models to more sophisticated and more demanding in computer resources $a b$ initio calculations. The computer simulation methods used are generally "brute force" Molecular Dynamics (MD) or Monte Carlo (MC) methods. In the former, atoms are generally added randomly close to the nanoparticle surface, while the latter enables more sophisticated approaches controlling carbon chemical potential, via Grand Canonical Monte Carlo (GCMC) simulations [382] or using force biased method to accelerate the relaxation and favor a healing of defective structures [383]. Such a naive approach is probably correct for simulating 
the heterogeneous nucleation of a cap on a metal nanoparticle, but the question of whether the driving forces leading to the formation of a cap (e.g. carbon density in the vapor phase in the case of MD or the carbon chemical potential in GCMC) are realistic should be raised. In the case of homogenous nucleation, specific techniques have been devised to evaluate the nucleation barriers $[394,395]$. In the present instance, too short time scales and exceedingly large driving forces often lead to carbon structures that are highly disordered. There is however a lot to be gained from atomistic computer simulation since the nanotube nucleation is very difficult to study by any other experimental technique.

Not all models give the same carbon solubility in the metal nanoparticle, nor has this solubility been systematically evaluated, but when carbon solubility is non-vanishing, a general trend is that the cap nucleation takes place once the nanoparticle is saturated with carbon [382,396]. The very small Fe clusters used in DFT [397] or tight-binding DFT [398] calculations do not allow such an analysis. In many models [382,396,399], carbon chains appear on the surface before a cap is formed. Although no direct experimental evidence has been produced, the presence of carbon chains during the nucleation and growth has been suggested by Eres et al. [387] and by Loginova et al. [385] in the case of graphene. The length of the observed carbon chains depends on the model and the precise nucleation and growth conditions and lead to more or less disordered structures. Quite interestingly, Neyts et al. [400] observed that the almost defect-less carbon nucleus formed could change its chirality in the early stages of the growth, thus discarding a possible determination of the tube chirality at the nucleation stage (Figure 14). 
$(11,0)$

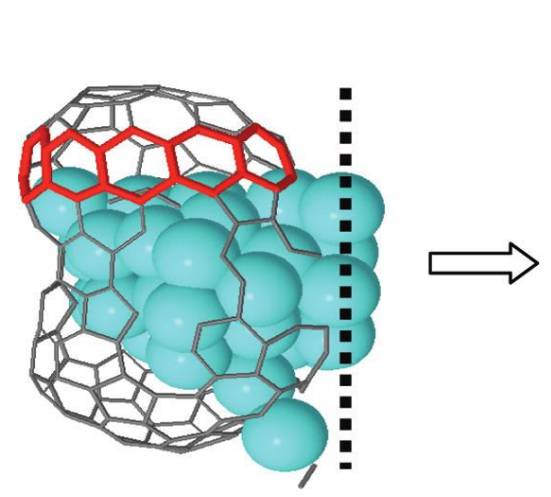

$(9,3)$

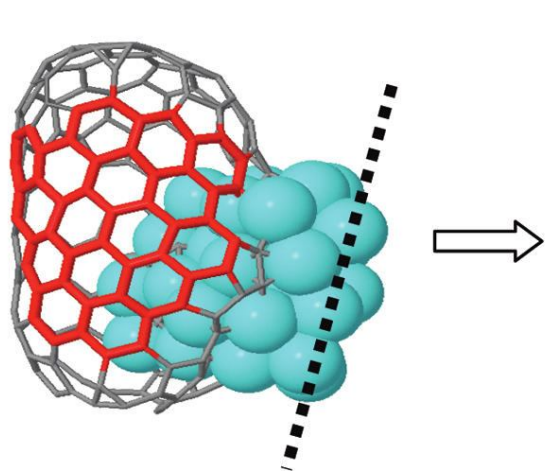

$(7,7)$

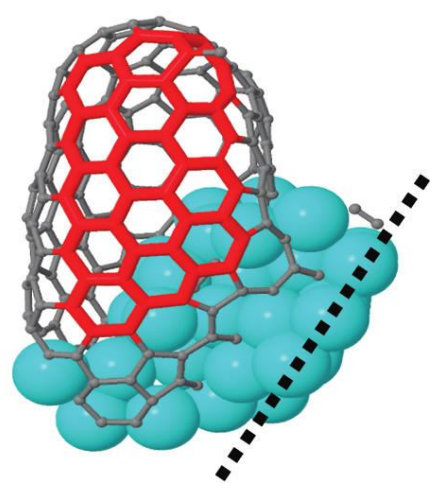

Figure 14. Coupled Monte Carlo / molecular dynamics study of the nucleation of a nanotube cap on a Ni nanoparticle. The local chirality of the cap appears to be changing at this stage of the nucleation process. After [400].

Once a cap is formed, it has to detach from the nanoparticle in order to avoid the encapsulation of the catalyst. Different explanations have been proposed to explain the cap detachment and lift-off. By systematically varying temperature and work of adhesion of the graphitic cap on the nanoparticle, Ribas et al. [401] could identify conditions leading either to a successful growth or to nanoparticle encapsulation. To explain the formation and lift-off of carbon domes observed by in-situ TEM during the formation of a multiwall nanotube on an Au doped Ni catalyst, Pigos et al. [402] identified two critical factors: the surface energy of the nanoparticle (that can be modified by chemisorbed carbon species) and the faceting of the nanoparticle. More recently, Diarra et al. [364] showed that the wetting properties of carbon $\mathrm{sp}^{2}$ walls on a Ni nanoparticle strongly depend on the fraction of carbon dissolved, and demonstrated that the cap lift-off takes place when the carbon concentration in the catalyst is within a critical window.

Computer simulation modeling of the nucleation and growth of carbon nanotubes has made significant progress by incorporating more efficient and realistic atomic interaction models, and by using more sophisticated computer simulation techniques and algorithms. The 
next challenge is a full understanding of the mechanisms leading to chiral selectivity that is discussed in the next paragraph.

\subsection{Chiral selectivity}

Chiral selectivity is an important issue in nanotube research due to the large number of applications requiring nanotubes with controlled electrical and optical properties. A higher proportion of high-chiral-angle CNTs (i.e. near-armchair) in nanotube samples is commonly reported as was already detailed in $\S 3.3$. The origin of this higher occurrence is still a matter of questioning. In the following, we review the theoretical works that have been devoted to this question and the hypotheses that have been proposed to explain the chiral selectivity of nanotube growth.

\subsubsection{Nucleation selectivity}

A first possibility is that chiral selectivity could be set at the nucleation stage. This hypothesis relies on the fact that the structure of a cap uniquely determines the chirality of the nanotube that will grow from it: in the absence of defects, the nanotube structure is an amplification of the edge structure of the cap. There is a statistical or entropic aspect to this question, i.e. how many different cap configurations exist for a given $(\mathrm{n}, \mathrm{m})$ tube. Brinkman et al. [403] established a census of the nanotube caps compatible with all tubes up to a diameter of $3 \mathrm{~nm}$. Considering either general caps or isolated-pentagon caps, they found that the number of compatible caps increases quasi-exponentially when increasing the nanotube diameter. Reich et al. [404] performed a detailed study of the geometry, structure, and energetics of nanotube caps. They observed that tubes with diameters smaller than $6.8 \AA$ have only caps that violate the isolated pentagon rule. The caps with isolated pentagons were found to have an average formation energy of $0.29 \mathrm{eV} /$ atom while a pair of adjacent pentagons required a formation energy of $1.5 \mathrm{eV}$. This much larger formation energy justifies the 
isolated pentagon rule and would explain the quasi-absence of SWCNTs of diameters less than $7 \AA$ in nanotube samples. The $(5,5)$ nanotube is the smallest diameter tube that has a cap obeying the isolated pentagon rule (a half $\mathrm{C}_{60}$ ). The other tubes with only one cap fulfilling the isolated pentagon rule are $(9,0),(9,1),(8,2)$, and $(6,5)$. Therefore, these results cannot account for the higher abundance of $(6,5)$ and high-chiral angle SWCNT in many samples. This statistical approach is interesting in the first place, but all cap sizes are not equally probable since caps progressively grow in size and are constrained by the catalyst particle. In addition, considering that pentagons are randomly formed neglects the chemistry of formation of carbon cycles and the influence of the catalyst surface.

Reich et al [405] performed ab initio calculations of the stability of different caps on a flat Ni surface. The results showed that certain caps are preferentially stabilized on a $\mathrm{Ni}(111)$ surface due to lattice matching with the catalyst surface. However, the energy differences were small (of the order of the thermal energy) and considering a flat and rigid catalyst surface now appears far from the experimentally encountered situation. The energy of graphene edges were calculated by Liu et al. [406] who found that the energy of an arbitrary graphene edge was significantly dependent on the orientation (from armchair to zigzag) and on the chemical functionnalization of the edge (i.e. $-\mathrm{H}$ or $-\mathrm{Ni}$ ). They proposed that this difference of edge energies may influence the chiral selectivity at the nucleation stage. At the opposite, Zhu et al. [208] calculated the formation energies of $(10,0)$ and $(5,5)$ SWCNT caps sitting on a $\mathrm{Ni}_{55}$ cluster and found the energy difference to be too small to expect a preferential nucleation of caps corresponding to either high or low chiral angles SWCNTs.

Most of these simulations were performed starting from pure Ni or Co catalysts but, in some cases, carbide particles may be more relevant. For instance, Koziol et al. [262] reported the preferential growth of achiral CNTs (zigzag and armchair) when nitrogen was added during the growth. They observed that the catalyst particles are iron carbide and are 
preferentially oriented with the [010] direction parallel to the nanotube axis and, more precisely, to either the [100] or [210] graphene direction [407]. Their studies support that the role of nitrogen is to stabilize iron carbide catalyst particles which act as epitaxial template for the selective nucleation of achiral CNTs.

\subsubsection{Growth-rate selectivity}

A second possibility is that the growth rate of nanotubes is chirality-dependent. Corresponding models assume that carbon integration, the last stage of the growth mechanism, is the rate-determining step and that its rate depends on the nanotube chirality. Experimentally, this is supported by several observations of higher reactivity of armchair edges compared to zigzag edges in the case of graphene [408-410]. Shu et al. [411] calculated that connecting a $\mathrm{Cu}$ atom to an armchair site lowers the barrier of incorporating carbon atoms onto graphene edge from $2.5 \mathrm{eV}$ to $0.8 \mathrm{eV}$, which would result in a much faster growth of armchair edges compared to zigzag edges. In the case of SWCNTs, Rao et al. reported in situ Raman measurements of the growth rates of individual index-identified tubes [412] showing a positive correlation between the nanotube growth rate and its chiral angle.

On the theoretical side, several works were devoted to the question of chiralitydependent kinetics. Zhao et al. [413] found that the energy of the frontier orbitals for $(5,5)$ and $(6,6)$ armchair carbon nanotubes bonded to $\mathrm{Ni}$ atoms exhibits a periodic behavior when increasing the number of carbon atoms in the nanotube. In contrast, the energy of the frontier orbitals of the $(6,5)$ tube was found constant as the number of $\mathrm{C}$ atoms increases. They proposed that the energetic smoothness of carbon addition in $(6,5)$ SWCNT may account for its experimentally high occurrence. Wang et al. [414] simulated the growth of armchair $(5,5)$, chiral $(6,5)$, and zigzag $(9,0)$ nanotubes on a relaxed $\mathrm{Ni}_{55}$ cluster and studied the reactivity caused by charge transfer between the metal particle and the tube. They notably found that the edge of a $(6,5)$ tube presents one particularly reactive site which could explain the preferential 
growth of chiral $(6,5)$ nanotubes over armchair $(5,5)$ and zigzag $(9,0)$ nanotubes. GomezGualdron et al. studied the energetics of frontier orbitals for different caps connected to a 9atom Co cluster during $\mathrm{C}_{2}$ addition [415]. The LUMO orbital expected to participate in the $\mathrm{C}_{2}$ addition reaction was found to be located in a more favorable part of the cap rim for neararmchair than for near-zigzag caps. They concluded that the carbon atoms in the neararmchair caps may have a better predisposition for continuation of the nanotube growth when the growth proceeds by $\mathrm{C}_{2}$ addition.

Also considering carbon addition to either armchair or zigzag nanotube edges connected to metal steps, Ding et al. [416] calculated that the addition of carbon to an armchair site has essentially no barrier while for a zigzag edge, the barrier energy is of the order of 1.1-1.5 eV. Building on that, they proposed that the lengthening rate of a nanotube is proportional to the linear density of armchair sites (kinks) at the nanotube edge, which is approximately proportional to the chiral angle of the tube (Figure 15). Dumlich and Reich [417] theoretically considered the geometric constraints for the addition of $\mathrm{C}_{2}$ dimers to armchair kinks at the edge of a nanotube. Observing that nanotube growth basically proceeds via the conversion of dangling bonds from armchair (a) to zigzag (z) and vice versa, they concluded that all armchair kinks are not equivalent and that a nanotube edge actually contains three types of armchair kinks $(\bullet)$ for $\mathrm{C}_{2}$ addition: aa $\bullet a a$, aa $\bullet \mathrm{z}$ and $\mathrm{z} \bullet \mathrm{z}$. In the case of a low energy difference between zigzag and armchair dangling bonds, the growth rate is proportional to the density of armchair kinks, that is a conclusion similar to Ding et al. In the case of a much larger energy for zigzag dangling bonds than for armchair ones, the model predicts that (n, n/2) chiral tubes would be kinetically favoured. 

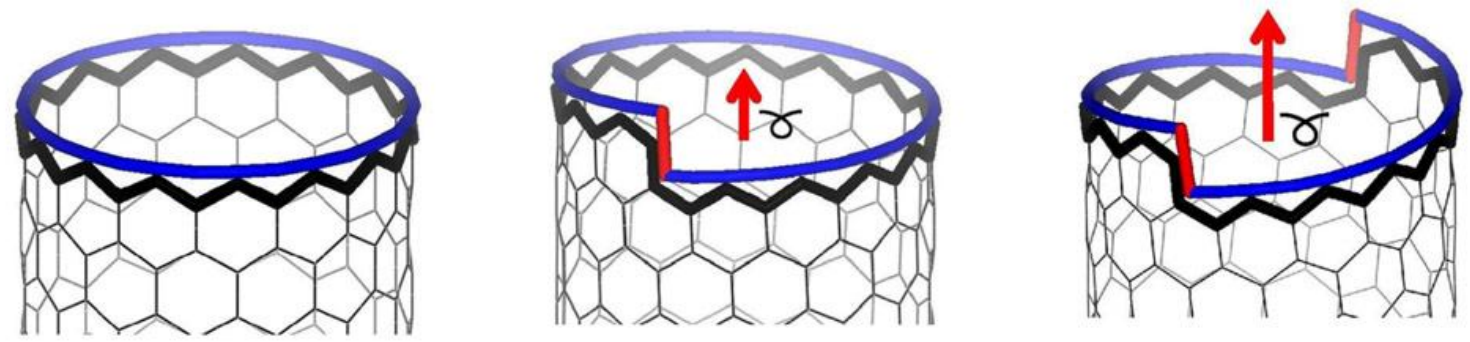

Figure 15. Schematic rim structures of $(n, 0),(n, 1)$ and $(n, 2)$ nanotubes showing that the number of kinks (armchair sites) is proportional to the chiral angle. Red arrows denote the Burgers vectors describing the axial screw dislocation associated with each tube. Adapted from [416].

\subsubsection{Lifetime selectivity}

A third possibility is that the resistance of a growing tube regarding growth termination or chiral change depends on its chiral structure. Actually, environmental TEM observations frequently show the introduction of defects and the creation of kinks during CNT growth [207]. Changes of chirality along as-grown CNTs were experimentally observed [418]. Yao et al. [222] showed that chiral changes could be induced by slight modifications of the growth conditions (i.e. temperature. Recently, Kim et al. [419] simulated the dynamics of SWCNT chirality during growth and observed that improper defect healing could lead to changes in the tube chirality. In this respect, zigzag SWCNTs were found significantly inferior in maintaining their chirality compared to armchair SWCNTs. Besides defect integration, a major cause of growth termination or of chirality change is the coarsening of the catalyst particles. Using first principles calculations, Börjesson et al. [420] studied the influence of the nanotube chirality on the Ostwald ripening of the attached particle. They found that the Ostwald ripening of metal particles attached to CNTs not only depends on the particle size, but also on the nanotube chirality. Particles attached to armchair and zigzag nanotubes of similar diameters were found to have different propensity to ripening. For both 
hypotheses (defect integration and catalyst coarsening), experimental studies of the chiral dependence are presently missing.

\subsection{Summary}

Concerning the state of the particle, in situ TEM studies show that catalyst particles of iron, nickel and cobalt are highly deformable, but still crystalline during growth. These observations were made on rather large particles (typically larger than $4 \mathrm{~nm}$ ), which leaves open the question of the physical state in the case of smaller nanoparticles. Considering the range of elements active for $\mathrm{CNT}$ growth, certain particles are likely to be liquid (e.g. $\mathrm{Pb})$ and other ones solid (e.g. diamond) in the standard conditions of nanotube growth. Having an either liquid or solid particle does not appear to be a requirement for growing a CNT, although the nanotube and growth features are likely to be modified. From in situ studies (TEM, XPS, XRD), nickel and cobalt particles are usually in a metallic state during nanotube growth while iron particles may either display a metallic or carbide structure.

The nature of the reaction intermediates (adatoms, dimers, chains, undissociated precursors) is still unsettled. Different in situ studies revealed the presence of $\mathrm{C}_{1}$ species at short synthesis times. At longer times, the conversion of carbon adatoms into higher $C_{n}$ oligomers $(\mathrm{n}=2-5)$ is reported both experimentally and in silico. In the case of alkynes and aromatic precursors, the hypothesis of a direct polymerization without $\mathrm{C}-\mathrm{C}$ bond scission has been proposed by certain groups to account for the abnormal kinetic behavior.

Concerning the mechanism of nanotube nucleation, the formation of a carbon cap at the surface of the particle (the yarmulke hypothesis) has now been validated by in situ TEM observations. Thermodynamic models support a strong influence of the carbon concentration, metal-carbon interaction and temperature on the formation of a carbon nucleus of critical size. Numerical simulations also confirm that surface carbon formation takes place once the 
nanoparticle is saturated with carbon. They highlight the critical importance of the carbon cap-metal surface adhesion in the process of cap lift-off and its dependence on the fraction of carbon dissolved in the particle.

To explain the chiral selectivity experimentally observed, three general hypotheses are considered: chiral-selective nucleation, chiral-dependent growth rate and chiral-dependent lifetime. The selective nucleation hypothesis is now somehow abandoned due to the small differences of formation energies calculated for caps of different chiralities. Growth-rate selectivity is currently preferred based on calculations showing a large difference of barrier energies for carbon integration at armchair and zigzag sites and on experimental measurements of the growth rate of individual SWCNTs of different chiral angles. The lifetime selectivity assuming a chiral-dependent propensity for growth termination or chiral change has found some support from simulation works, but is still to be experimentally validated.

Beside those questions, many other questions remain that could not be addressed in detail in this review either due to the limited space or to the limited number of reported studies. One may notably mention the mechanism leading to either base- or tip-growth, the influence of the substrate on the growth kinetics or the mechanisms of defect integration. The interested reader can also refer to the list of open questions established after each edition of the Guadalupe Workshop on the Nucleation and Growth Mechanisms of Single Wall Carbon Nanotubes ${ }^{1}$.

\section{Conclusion}

As apparent from this review, the growth mechanism of CNTs in CCVD is complex and still the subject of intense investigations. Its understanding is noticeably complicated by

\footnotetext{
${ }^{1}$ Guadalupe Workshop on Nucleation and Growth Mechanisms of Single Wall Carbon Nanotubes. Available from: http://swcnt.nano.rice.edu/.
} 
the variety of experimental systems in terms of catalyst, support, carbon precursor and growth conditions. Too different systems often lead to too different observations to allow unification and rationalization. In addition, the studied systems are still frequently insufficiently controlled and characterized. Learning from other fields of research such as heterogeneous catalysis or molecular biology, one may identify two successful approaches to work out complex mechanisms: the study of model systems and the development of numerical simulations. As evidenced in this review, numerical simulations have already been extremely beneficial for orienting experimental works and improving our understanding of CNT growth mechanism. With increasing calculating capacities, simulation will probably become an essential prediction tool for the phenomena that are still too difficult to study experimentally. On the experimental side, the field would probably benefit from the establishment and study of model systems, as was successfully demonstrated in the field of heterogeneous catalysis with the study of model surfaces and metal clusters. $\mathrm{Fe} / \mathrm{Al}_{2} \mathrm{O}_{3}$ used with ethylene as carbon source and water as additive is an example of such a model system which has self-established due to its high nanotube yield. Other model systems having characteristic features important for fundamental studies such as catalyst clusters of uniform size, no or negligible catalyst coarsening, known limiting step or known dissociation products, would also be highly desirable. Novel types of experiments may also help improving our understanding of the role of the catalyst nanoparticles in CCVD. For instance, the recent discovery that SWCNT seeds can be elongated by vapour-phase epitaxy without the need of a catalyst nanoparticle [421] will probably shine light on the exact role of the nanoparticle at each stage (precursor decomposition, cap nucleation, nanotube amplification) of the CCVD process.

In conclusion, we now have a qualitatively good description of many phenomena acting during CNT growth, but quantitative relations are often lacking (e.g. quantitative parameter dependences of the defect density, growth rate, number of walls, outer and inner 
diameters). More quantitative models would be extremely helpful for orienting experimental works and facilitating the analysis of experimental data. Growth kinetics or chiral selectivity are good examples of the valuable contribution of quantitative models to the rationalization of experimental data and to the orientation of experimental studies. For the future, we would clearly need more quantitative models that can be experimentally tested if we wish to build a more accurate and predictive theory of nanotube growth. Establish and study model systems and develop more quantitative and predictive theoretical tools should be particularly important goals for the young and creative minds entering the field. As apparent from this review, many exciting challenges are still awaiting them.

\section{Acknowledgements}

The authors thank the Agence Nationale de la Recherche for support (contract ANR09-Nano-028 “SOS_Nanotubes"), and all the consortium members for fruitful discussions. 


\section{References}

[1] Radushkevich LV, Lukyanovich VM. O strukture ugleroda, obrazujucegosja pri termiceskom razlozenii okisi ugleroda na zeleznom kontakte. Zurn Fisic Chim 1952; 26:8895.

[2] Hillert M, Lange N. The structure of graphite filaments. Z Kristallogr 1958; 111:24

34.

[3] Baird T, Fryer JR, Grant B. Structure of fibrous carbon. Nature 1971; 233(5318):329-

30 .

[4] Koyama T, Endo M, Onuma Y. Carbon fibers obtained by thermal decomposition of vaporized hydrocarbon. Jpn J Appl Phys 1972; 11(4):445-9.

[5] Baker RTK, Barber MA, Harris PS, Feates FS, Waite RJ. Nucleation and growth of carbon deposits from the nickel catalyzed decomposition of acetylene. J Catal 1972; 26:51-62.

[6] Baker RTK, Harris PS, Thomas RB, Waite RJ. Formation of filamentous carbon from iron, cobalt and chromium catalyzed decomposition of acetylene. J Catal 1973; 30:86-95.

[7] Oberlin A, Endo M, Koyama T. Filamentous growth of carbon through benzene decomposition. J Cryst Growth 1976; 32:335-49.

[8] Iijima S. Helical microtubules of graphitic carbon. Nature 1991; 354:56-8.

[9] Iijima S, Ichihashi T. Single-shell carbon nanotubes of 1-nm diameter. 1993.

[10] Moisala A, Nasibulin AG, Kauppinen EI. The role of metal nanoparticles in the catalytic production of single-walled carbon nanotubes - a review. J Phys: Condens Matter 2003; 15:S3011-S35.

[11] Dupuis AC. The catalyst in the CCVD of carbon nanotubes - a review. Prog Mater Sci 2005; 50(8):929-61.

[12] Irle S, Ohta Y, Okamoto Y, Page AJ, Wang Y, Morokuma K. Milestones in molecular dynamics simulations of single-walled carbon nanotube formation: A brief critical review.

Nano Research 2009; 2(10):755-67.

[13] Harutyunyan AR. The catalyst for growing single-walled carbon nanotubes by catalytic chemical vapor deposition method. J Nanosci Nanotechnol 2009; 9(4):2480-95.

[14] Nessim GD. Properties, synthesis, and growth mechanisms of carbon nanotubes with special focus on thermal chemical vapor deposition. Nanoscale 2010; 2(8):1306-23.

[15] Tessonnier JP, Su DS. Recent progress on the growth mechanism of carbon nanotubes: a review. Chemsuschem 2011; 4(7):824-47.

[16] Hong G, Chen YB, Li P, Zhang J. Controlling the growth of single-walled carbon nanotubes on surfaces using metal and non-metal catalysts. Carbon 2012; 50(6):2067-82.

[17] Kong J, Cassel AM, Dai H. Chemical vapor deposition of methane for single-walled carbon nanotubes. Chem Phys Lett 1998; 292:567-74.

[18] Mayne M, Grobert N, Terrones M, Kamalakaran R, Ruhle M, Kroto HW, et al. Pyrolytic production of aligned carbon nanotubes from homogeneously dispersed benzenebased aerosols. Chem Phys Lett 2001; 338(2-3):101-7.

[19] Maruyama S, Kojima R, Miyauchi Y, Chiashi S, Kohno M. Low-temperature synthesis of high-purity single-walled carbon nanotubes from alcohol. Chem Phys Lett 2002; 360(3-4):229-34.

[20] Tian Y, Hu Z, Yang Y, Wang X, Chen X, Xu H, et al. In situ TA-MS study of the sixmembered-ring-based growth of carbon nanotubes with benzene precursor. J Am Chem Soc $2003 ; 126(4): 1180-3$. 
[21] Rodríguez-Manzo JA, Terrones M, Terrones H, Kroto HW, Sun L, Banhart F. In situ nucleation of carbon nanotubes by the injection of carbon atoms into metal particles. Nature Nanotech 2007; 2(5):307-11.

[22] Tsui F, Ryan P. Self-organization of carbide superlattice and nucleation of carbon nanotubes. J Nanosci Nanotechnol 2003; 3(6):529-34.

[23] Journet C, Picher M, Jourdain V. Carbon nanotube synthesis: from large-scale production to atom-by-atom growth. Nanotechnology 2012; 23(142001).

[24] Thurakitseree T, Kramberger C, Zhao P, Aikawa S, Harish S, Chiashi S, et al. Diameter-controlled and nitrogen-doped vertically aligned single-walled carbon nanotubes. Carbon 2012; 50(7):2635-40.

[25] Maciel IO, Campos-Delgado J, Cruz-Silva E, Pimenta MA, Sumpter BG, Meunier V, et al. Synthesis, electronic structure, and Raman scattering of phosphorus-doped single-wall carbon nanotubes. Nano Lett 2009; 9(6):2267-72.

[26] Lyu SC, Han JH, Shin KW, Sok JH. Synthesis of boron-doped double-walled carbon nanotubes by the catalytic decomposition of tetrahydrofuran and triisopropyl borate. Carbon 2011; 49(5):1532-41.

[27] Haynes WM. CRC Handbook of Chemistry and Physics: CRC press Boca Raton, FL; 2011-2012.

[28] Couttenye RA, De Vila MH, Suib SL. Decomposition of methane with an autocatalytically reduced nickel catalyst. J Catal 2005; 233(2):317-26.

[29] Lee J, Oyama S. Oxidative coupling of methane to higher hydrocarbons. Cat Rev - Sci Eng 1988; 30(2):249-80.

[30] Lunsford JH. The catalytic oxidative coupling of methane. Angew Chem Int Ed Engl 1995; 34(9):970-80.

[31] Skukla B, Saito T, Ohmori S, Koshi M, Yumura M, Iijima S. Interdependency of gas phase intermediates and chemical vapor deposition growth of single wall carbon nanotubes. Chem Mater 2010; 22(22):6035-43.

[32] Plata DL, Hart AJ, Reddy CM, Gschwend PM. Early evaluation of potential environmental impacts of carbon nanotube synthesis by chemical vapor deposition. Environ Sci Technol 2009; 43(21):8367-73.

[33] Zhang Y, Gregoire JM, van Dover RB, Hart AJ. Ethanol-promoted high-yield growth of few-walled carbon nanotubes. J Phys Chem C 2010; 114(14):6389-95.

[34] Galvita V, Semin G, Belyaev V, Semikolenov V, Tsiakaras P, Sobyanin V. Synthesis gas production by steam reforming of ethanol. Appl Catal A 2001; 220(1-2):123-7.

[35] Geurts F, Sacco Jr A. The relative rates of the Boudouard reaction and hydrogenation of CO over Fe and Co foils. Carbon 1992; 30(3):415-8.

[36] Shatynski SR. The thermochemistry of transition metal carbides. Oxid Met 1979; 13(2):105-18.

[37] Busca G, Finocchio E, Ramis G, Ricchiardi G. On the role of acidity in catalytic oxidation. Catal Today 1996; 32(1-4):133-43.

[38] Esconjauregui S, Whelan CM, Maex K. The reasons why metals catalyze the nucleation and growth of carbon nanotubes and other carbon nanomorphologies. Carbon 2009; 47(3):659-69.

[39] Yamada M, Kawana M, Miyake M. Synthesis and diameter control of multi-walled carbon nanotubes over gold nanoparticle catalysts. Appl Catal A 2006; 302(2):201-7.

[40] Deck CP, Vecchio K. Prediction of carbon nanotube growth success by the analysis of carbon-catalyst binary phase diagrams. Carbon 2006; 44(2):267-75.

[41] Takagi D, Homma Y, Hibino H, Suzuki S, Kobayashi Y. Single-walled carbon nanotube growth from highly activated metal nanoparticles. Nano Lett 2006; 6(12):2642-5. 
[42] Qian Y, Wang C, Ren G, Huang B. Surface growth of single-walled carbon nanotubes from ruthenium nanoparticles. Appl Surf Sci 2010; 256(12):4038-41.

[43] Zhou WHZ, Wang JZY, Jin ZSX, Zhang YYC, Li Y. Copper catalyzing growth of single-walled carbon nanotubes on substrates. Nano Lett 2006; 6(12):2987-90.

[44] Bhaviripudi S, Mile E, Steiner III SA, Zare AT, Dresselhaus MS, Belcher AM, et al. CVD synthesis of single-walled carbon nanotubes from gold nanoparticle catalysts. J Am Chem Soc 2007; 129(6):1516-7.

[45] Liu B, Ren W, Gao L, Li S, Liu Q, Jiang C, et al. Manganese-catalyzed surface growth of single-walled carbon nanotubes with high efficiency. J Phys Chem C 2008; 112(49):192315 .

[46] Li Y, Cui R, Ding L, Liu Y, Zhou W, Zhang Y, et al. How catalysts affect the growth of single walled carbon nanotubes on substrates. Adv Mater 2010; 22(13):1508-15.

[47] Yuan D, Ding L, Chu H, Feng Y, McNicholas TP, Liu J. Horizontally aligned singlewalled carbon nanotube on quartz from a large variety of metal catalysts. Nano Lett 2008; 8(8):2576-9.

[48] Takagi D, Kobayashi Y, Homma Y. Carbon nanotube growth from diamond. J Am Chem Soc 2009; 131(20):6922-3.

[49] Takagi D, Hibino H, Suzuki S, Kobayashi Y, Homma Y. Carbon nanotube growth from semiconductor nanoparticles. Nano Lett 2007; 7(8):2272-5.

[50] Swierczewska M, Rusakova I, Sitharaman B. Gadolinium and europium catalyzed growth of single-walled carbon nanotubes. Carbon 2009; 47(13):3139-42.

[51] Qi H, Qian C, Liu J. Synthesis of uniform double-walled carbon nanotubes using iron disilicide as catalyst. Nano Lett 2007; 7(8):2417-21.

[52] Bachmatiuk A, Bo rrnert F, Grobosch M, Scha ffel F, Wolff U, Scott A, et al. Investigating the graphitization mechanism of $\mathrm{SiO} 2$ nanoparticles in chemical vapor deposition. ACS Nano 2009; 3(12):4098-104.

[53] Liu B, Ren W, Gao L, Li S, Pei S, Liu C, et al. Metal-catalyst-free growth of singlewalled carbon nanotubes. J Am Chem Soc 2009; 131(6):2082-3.

[54] Huang S, Cai Q, Chen J, Qian Y, Zhang L. Metal-catalyst-free growth of single-walled carbon nanotubes on substrates. J Am Chem Soc 2009; 131(6):2094-5.

[55] Gao F, Zhang L, Huang S. Zinc oxide catalyzed growth of single-walled carbon nanotubes. Appl Surf Sci 2010; 256(8):2323-6.

[56] Chiang WH, Sankaran RM. Linking catalyst composition to chirality distributions of as-grown single-walled carbon nanotubes by tuning NixFe1- x nanoparticles. Nature Mat 2009; 8(11):882-6.

[57] Li Y, Liu J, Wang Y, Wang ZL. Preparation of monodispersed Fe-Mo nanoparticles as the catalyst for CVD synthesis of carbon nanotubes. Chem Mater 2001; 13(3):1008-14.

[58] Alvarez W, Kitiyanan B, Borgna A, Resasco D. Synergism of Co and Mo in the catalytic production of single-wall carbon nanotubes by decomposition of CO. Carbon 2001; 39(4):547-58.

[59] Flahaut E, Govindaraj A, Peigney A, Laurent C, Rousset A, Rao C. Synthesis of single-walled carbon nanotubes using binary (Fe, $\mathrm{Co}, \mathrm{Ni}$ ) alloy nanoparticles prepared in situ by the reduction of oxide solid solutions. Chem Phys Lett 1999; 300(1-2):236-42.

[60] Shibuta Y, Maruyama S. A molecular dynamics study of the effect of a substrate on catalytic metal clusters in nucleation process of single-walled carbon nanotubes. Chem Phys Lett 2007; 437(4-6):218-23.

[61] Hoch M. Phase stability of carbon in FCC and BCC metals. Calphad 1988; 12(1):83-8.

[62] Yazyev OV, Pasquarello A. Effect of metal elements in catalytic growth of carbon nanotubes. Phys Rev Lett 2008; 100:156102. 
[63] Yang R, Goethel P, Schwartz J, Lund C. Solubility and diffusivity of carbon in metals. J Catal 1990; 122(1):206-10.

[64] Samsonov G. On the problem of the classification of carbides. Powder Metall Met Ceram 1965; 4(1):75-81.

[65] Sinfelt JH. Heterogeneous catalysis: some recent developments. Science 1977; 195(4279):641-6.

[66] Yasuda H, Mori H. Phase diagrams in nanometer-sized alloy systems. J Cryst Growth 2002; 237-239, Part 1(0):234-8.

[67] Andrievski R. Size-dependent effects in properties of nanostructured Materials. Rev Adv Mater Sci 2009; 21:107-33.

[68] Lee JG, Mori H. Direct evidence for reversible diffusional phase change in nanometersized alloy particles. Phys Rev Lett 2004; 93(23):235501.

[69] Straumal BB, Mazilkin AA, Protasova SG, Myatiev AA, Straumal PB, Baretzky B. Increase of Co solubility with decreasing grain size in ZnO. Acta Mater 2008; 56(20):6246-56. [70] Lee JG, Mori H, Yasuda H. Alloy phase formation in nanometer-sized particles in the In-Sn system. Phys Rev B 2002; 65(13):132106.

[71] Sutter EA, Sutter PW. Giant carbon solubility in Au nanoparticles. J Mater Sci 2011; 46:7090-7.

[72] Petropoulos J, Cristiani T, Dongmo P, Zide J. A simple thermodynamic model for the doping and alloying of nanoparticles. Nanotechnology 2011; 22:245704.

[73] L'vov P, Svetukhin V, Obukhov A. Thermodynamics of phase equilibrium of binary alloys containing nanprecipitates. Phys Solid State 2011; 53(2):421-7.

[74] Oksengendler B, Nikiforov V, Sredin V, Turaeva N, Maksimov S. Effect of abnormal high solubility of impurity in nanocrystals and its metrological aspects. J Phys Conf Ser 2011; 291:012010.

[75] Ouyang G, Tan X, Wang C, Yang G. Solid solubility limit in alloying nanoparticles. Nanotechnology 2006; 17:4257.

[76] Koshkin V, Slezov V. Doping nanoparticles. Tech Phys Lett 2004; 30(5):367-9.

[77] Diarra M, Amara H, Ducastelle F, Bichara C. Carbon solubility in nickel nanoparticles : a grand canonical Monte Carlo study. Phys Status Solidi B 2012; 249(12):2629-34.

[78] Barrer RM. Diffusion in and through solids: University Press Cambridge; 1951.

[79] Smithells CJ. Smithells metals reference book. Seventh edition ed. Brandes EA, Brook G, editors. Oxford: Butterworth-Heinemann; 1992.

[80] Le Claire AD. In: Mehrer H, editor. Landolt-Börnstein - Numerical data and functional relationships in science and technology. 26. Berlin: Springer-Verlag; 1992. p. 471.

[81] Sharma R, Chee SW, Herzing A, Miranda R, Rez P. Evaluation of the role of Au in improving catalytic activity of Ni nanoparticles for the formation of one-dimensional carbon nanostructures. Nano Lett 2011; 11(6):2464-671.

[82] Xu J, Saeys M. First principles study of the stability and the formation kinetics of subsurface and bulk carbon on a Ni catalyst. J Phys Chem C 2008; 112(26):9679-85.

[83] Lander J, Kern H, Beach A. Solubility and diffusion coefficient of carbon in nickel: reaction rates of nickel carbon alloys with barium oxide. J Appl Phys 1952; 23(12):1305-9.

[84] Massaro TA, Petersen EE. Bulk diffusion of carbon 14 through polycrystalline nickel foil between 350 and $700^{\circ}$ C. J Appl Phys 1971; 42(13):5534-9.

[85] Cermak J, Rollert F, Mehrer H. Diffusion of carbon-14 in fcc cobalt. Z Metallkd 1990; 81(2):81-3.

[86] Powers R, Doyle MV. The diffusion of carbon and oxygen in vanadium. Acta Metall 1958; 6(10):643-6. 
[87] Son P, Ihara S, Miyake M, Sano T. Diffusion of carbon in vanadium. J Japan Inst Metals 1969; 33(1):1-3.

[88] Yokoyama H, Numakura H, Koiwa M. The solubility and diffusion of carbon in palladium. Acta Mater 1998; 46(8):2823-30.

[89] Ling C, Sholl DS. First-principles evaluation of carbon diffusion in Pd and Pd-based alloys. Phys Rev B 2009; 80(21):214202.

[90] Fromm E, Gebhardt E. Gase und kohlenstoff in metallen. Berlin: Springer Verlag; 1976.

[91] Agarwala R, Paul A. Diffusion of carbon in zirconium and some of its alloys. J Nucl Mater 1975; 58(1):25-30.

[92] Krishtal M. Thermodynamics of carbon diffusion in iron. In: Ltd. APCP, editor. Protective Coatings on Metals. 61984. p. 96-106.

[93] Gegner J, editor Concentration-and temperature-dependent diffusion coefficient of carbon in FCC iron mathematically derived from literature data. . 4th Int Conf Mathematical Modeling and Computer Simulation of Materials Technologies 2006; Ariel, College of Judea and Samaria.

[94] Wells C, Batz W, Mehl RF. Trans AIME 1950; 188:553-60.

[95] Mittemeijer EJ. Fundamentals of materials science. Heidelberg: Springer Verlag; 2010.

[96] Andrievsky R, Gurov K. Self-diffusion in interstitial phases. Fiz Met Metalloved 1968; 26(5):818-22.

[97] Hillert M, Höglund L, Ågren J. Diffusion in interstitial compounds with thermal and stoichiometric defects. J Appl Phys 2005; 98:053511.

[98] Ozturk B, Fearing V, Ruth J. The diffusion coefficient of carbon in cementite, Fe 3C, at $450 \mathrm{deg}$ C. Solid State Ionics 1984; 12(1):145-51.

[99] Schneider A, Inden G. Carbon diffusion in cementite (Fe3C) and Hägg carbide (Fe5C2). Calphad 2007; 31(1):141-7.

[100] van Loo FJJ, Bastin G. On the diffusion of carbon in titanium carbide. Metall Mater Trans A 1989; 20(3):403-11.

[101] DePoorter GL, Wallace T. Diffusion in binary carbides. Adv High Temp Chem 1970; 4:107.

[102] Shovensin A, Shcherbedinskii G, Minkevich A. Some characteristics of the diffusion of carbon in molybdenum carbide. Powder Metall Met Ceram 1966; 5(11):880-4.

[103] Borisova A, Evtushenko O. Diffusional processes in the welding of some refractory carbides to metals. Powder Metall Met Ceram 1979; 18(7):481-7.

[104] Smoluchowski R. Diffusion rate of carbon in iron-cobalt alloys. Phys Rev 1942;

62(11-12):539.

[105] Hofmann S, Csányi G, Ferrari AC, Payne MC, Robertson J. Surface diffusion: the low activation energy path for nanotube growth. Phys Rev Lett 2005; 95(3):36101.

[106] Mojica JF, Levenson LL. Bulk-to-surface precipitation and surface diffusion of carbon on polycrystalline nickel. Surf Sci 1976; 59(2):447-60.

[107] Portavoce A, Chai G, Chow L, Bernardini J. Nanometric size effect on Ge diffusion in polycrystalline Si. J Appl Phys 2008; 104(10):104910-8.

[108] Siegel DJ, Hamilton J. First-principles study of the solubility, diffusion, and clustering of C in Ni. Phys Rev B 2003; 68(9):094105.

[109] Cinquini F, Delbecq F, Sautet P. A DFT comparative study of carbon adsorption and diffusion on the surface and subsurface of Ni and Ni3Pd alloy. Phys Chem Chem Phys 2009; 11(48):11546-56.

[110] Gracia L, Calatayud M, Andrés J, Minot C, Salmeron M. Migration of the subsurface C impurity in Pd (111). Phys Rev B 2005; 71(3):033407. 
[111] Kalibaeva G, Vuilleumier R, Meloni S, Alavi A, Ciccotti G, Rosei R. Ab initio simulation of carbon clustering on an $\mathrm{Ni}(111)$ surface: A model of the poisoning of nickelbased catalysts. J Phys Chem B 2006; 110(8):3638-46.

[112] Ramirez-Caballero GE, Burgos JC, Balbuena PB. Growth of carbon structures on stepped (211) Co surfaces. J Phys Chem C 2009; 113(35):15658-66.

[113] Klinke II DJ, Wilke S, Broadbelt LJ. A theoretical study of carbon chemisorption on Ni (111) and Co (0001) surfaces. J Catal 1998; 178(2):540-54.

[114] Klink C, Olesen L, Besenbacher F, Stensgaard I, Laegsgaard E, Lang N. Interaction of C with Ni (100): Atom-resolved studies of the “clock' reconstruction. Phys Rev Lett 1993; 71(26):4350-3.

[115] Stolbov S, Hong S, Kara A, Rahman TS. Origin of the C-induced p4g reconstruction of Ni (001). Phys Rev B 2005; 72(15):155423.

[116] Hong S. Surface energy anisotropy of iron surfaces by carbon adsorption. Curr Appl Phys 2003; 3(5):457-60.

[117] Begtrup GE, Gannett W, Meyer JC, Yuzvinsky TD, Ertekin E, Grossman JC, et al. Facets of nanotube synthesis: High-resolution transmission electron microscopy study and density functional theory calculations. Phys Rev B 2009; 79(20):205409.

[118] Riikonen S, Krasheninnikov A, Nieminen R. Submonolayers of carbon on $\alpha$-Fe facets: An ab initio study. Phys Rev B 2010; 82(12):125459.

[119] Fujii J, Panaccione G, Vobornik I, Rossi G, Trimarchi G, Binggeli N. C-Fe chains due to segregated carbon impurities on Fe (100). Surf Sci 2006; 600(18):3884-7.

[120] Panaccione G, Fujii J, Vobornik I, Trimarchi G, Binggeli N, Goldoni A, et al. Local and long-range order of carbon impurities on Fe (100): Analysis of self-organization at a nanometer scale. Phys Rev B 2006; 73(3):035431.

[121] Medlin JW, Allendorf MD. Theoretical study of the adsorption of acetylene on the (111) surfaces of Pd, Pt, Ni, and Rh. J Phys Chem B 2003; 107(1):217-23.

[122] Moors M, Amara H, Visart de Bocarmé T, Bichara C, Ducastelle F, Kruse N, et al. Early stages in the nucleation process of carbon nanotubes. ACS Nano 2009; 3(3):511-6.

[123] Zhang QM, Wells JC, Gong X, Zhang Z. Adsorption of a carbon atom on the Ni_ $\{38\}$ magic cluster and three low-index nickel surfaces: A comparative first-principles study. Phys

Rev B 2004; 69(20):205413.

[124] Wang Q, Lim KH, Yang SW, Yang Y, Chen Y. Atomic carbon adsorption on Ni nanoclusters: a DFT study. Theor Chim Acta 2011; 128(1):17-24.

[125] Ding F, Larsson P, Larsson JA, Ahuja R, Duan H, Rosén A, et al. The importance of strong carbon-metal adhesion for catalytic nucleation of single-walled carbon nanotubes.

Nano Lett 2008; 8(2):463-8.

[126] Larsson P, Larsson JA, Ahuja R, Ding F, Yakobson BI, Duan H, et al. Calculating carbon nanotube-catalyst adhesion strengths. Phys Rev B 2007; 75(11):115419.

[127] Reich S, Li L, Robertson J. Epitaxial growth of carbon caps on Ni for chiral selectivity. Phys Status Solidi B 2006; 243(13):3494-9.

[128] Fan X, Buczko R, Puretkzy A, Geohegan DB, Howe JY, Pantelides ST, et al. Nucleation of single-walled carbon nanotubes. Phys Rev Lett 2003; 90(14):145501.

[129] Lacovig P, Pozzo M, Alfè D, Vilmercati P, Baraldi A, Lizzit S. Growth of domeshaped carbon nanoislands on $\operatorname{Ir}(111)$ : the intermediate between carbidic clusters and quasifree-standing graphene. Phys Rev Lett 2009; 103(16):166101.

[130] Vanin M, Mortensen JJ, Kelkkanen A, Garcia-Lastra JM, Thygesen KS, Jacobsen KW. Graphene on metals: A van der Waals density functional study. Phys Rev B 2010; 81(8):081408.

[131] Mittendorfer F, Garhofer A, Redinger J, Klimeš J, Harl J, Kresse G. Graphene on Ni

(111): Strong interaction and weak adsorption. Phys Rev B 2011; 84(20):201401. 
[132] Olsen T, Yan J, Mortensen JJ, Thygesen KS. Dispersive and covalent interactions between graphene and metal surfaces from the random phase approximation. Phys Rev Lett 2011; 107(15):156401.

[133] Somorjai GA. Introduction to surface chemistry and catalysis. New York: Wiley; 1994. p. 347.

[134] Nørskov J. Covalent effects in the effective-medium theory of chemical binding: Hydrogen heats of solution in the 3d metals. Phys Rev B 1982; 26(6):2875.

[135] Sinfelt J. Catalytic hydrogenolysis on metals. Catal Lett 1991; 9(3):159-71.

[136] Teschner D, Borsodi J, Wootsch A, Révay Z, Hävecker M, Knop-Gericke A, et al. The roles of subsurface carbon and hydrogen in palladium-catalyzed alkyne hydrogenation. Science 2008; 320(5872):86-9.

[137] Bertolini J, Billy J, Massardier J, editors. Adsorption of CO on the face of monocrystalline nickel(III): the influence of surface carbides. IVth Colloquium on Solid Surface Physics and Chemistry, Gas/Solid and Liquid/Solid Interfaces; 1978 20-22 Sept. 1978; Antibes-Juan les Pins.

[138] Bridge ME, Prior KA, Lambert RM. The effects of surface carbide formation on the adsorption-desorption kinetics of CO on smooth and stepped cobalt surfaces. Surf Sci 1980; 97(1):L325-L9.

[139] Didziulis SV, Frantz P, Fernandez-Torres LC, Guenard RL, El-bjeirami O, Perry SS. Coordination chemistry of transition metal carbide surfaces: detailed spectroscopic and theoretical investigations of CO adsorption on TiC and VC (100) surfaces. J Phys Chem B 2001; 105(22):5196-209.

[140] Oyama S. Preparation and catalytic properties of transition metal carbides and nitrides. Catal Today 1992; 15(2):179-200.

[141] Kharlamov A, Kirillova N. Catalytic properties of powdered refractory compounds of transition elements. Carbides and nitrides-A review. Powder Metall Met Ceram 1983; 22(2):123-34.

[142] Yoshihara N, Ago H, Tsuji M. Growth mechanism of carbon nanotubes over goldsupported catalysts. Jpn J Appl Phys 1 2008; 47(4):1944-8.

[143] Solomon EI, Jones PM, May JA. Electronic structures of active sites on metal oxide surfaces: definition of the copper-zinc oxide methanol synthesis catalyst by photoelectron spectroscopy. Chem Rev 1993; 93(8):2623-44.

[144] Skurnik S, Steinberg M. Heat of adsorption of carbon monoxide on coprecipitated nickel oxide-silica catalyst. Ind Eng Chem Fundam 1967; 6(3):459-60.

[145] Bolis V, Cerrato G, Magnacca G, Morterra C. Surface acidity of metal oxides.

Combined microcalorimetric and IR-spectroscopic studies of variously dehydrated systems. Thermochim Acta 1998; 312(1-2):63-77.

[146] Meier DC, Goodman DW. The influence of metal cluster size on adsorption energies: CO adsorbed on Au clusters supported on TiO2. J Am Chem Soc 2004; 126(6):1892-9.

[147] Magrez A, Smajda R, Seo JW, Horvath E, Ribic PR, Andresen JC, et al. Striking influence of the catalyst support and its acid-base properties: new Insight into the growth mechanism of carbon nanotubes. ACS Nano 2011; 5(5):3428-37.

[148] Haruta M, Yamada N, Kobayashi T, Iijima S. Gold catalysts prepared by coprecipitation for low-temperature oxidation of hydrogen and of carbon monoxide. J Catal $1989 ; 115(2): 301-9$.

[149] Tsunoyama H, Sakurai H, Tsukuda T. Size effect on the catalysis of gold clusters dispersed in water for aerobic oxidation of alcohol. Chem Phys Lett 2006; 429(4-6):528-32. [150] Henry CR. Surface studies of supported model catalysts. Surf Sci Rep 1998; 31(78):231-325.

[151] Somorjai GA. Introduction to surface chemistry and catalysis: New York: Wiley; 1994. 
[152] Novotny V, Itnyre G, Homola A, Franco L. Corrosion of thin film cobalt based magnetic recording media. IEEE Trans Magn 1987; 23(5):3645-7.

[153] Flis-Kabulska I. Oxide growth on evaporated thin film and bulk iron exposed to humid air and $\mathrm{HCl}$ or $\mathrm{HNO} 3$ vapours. J Electroanal Chem 2001; 508(1-2):89-96.

[154] Nessim GD, Hart AJ, Kim JS, Acquaviva D, Oh J, Morgan CD, et al. Tuning of vertically-aligned carbon nanotube diameter and areal density through catalyst pre-treatment. Nano Lett 2008; 8(11):3587-93.

[155] Cantoro M, Hofmann S, Pisana S, Scardaci V, Parvez A, Ducati C, et al. Catalytic chemical vapor deposition of single-wall carbon nanotubes at low temperatures. Nano Lett 2006; 6(6):1107-12.

[156] Picher M, Anglaret E, Jourdain V. High temperature activation and deactivation of single-walled carbon nanotube growth investigated by in situ Raman measurements. Diamond Rel Mat 2010; 19(5-6):581-5.

[157] Lu JQ. Nanocatalysts with tunable properties derived from polystyrene-b-poly(vinyl pyridine) block copolymer templates for achieving controllable carbon nanotube synthesis. J Phys Chem C 2008; 112(28):10344-51.

[158] Stempo MJ. The Ellingham diagram: how to use it in heat-treat-process atmosphere troubleshooting. Ind Heating 2011; April 55-60.

[159] Fu Q, Wagner T. Interaction of nanostructured metal overlayers with oxide surfaces. Surf Sci Rep 2007; 62(11):431-98.

[160] Yoon B, Häkkinen H, Landman U, Wörz AS, Antonietti J-M, Abbet S, et al. Charging effects on bonding and catalyzed oxidation of CO on Au8 clusters on MgO. Science 2005; 307(5708):403-7.

[161] Bauer E. Phänomenologische theorie der kristallabscheidung an oberflächen. II. Z Kristallogr 1958; 110(1-6):395-431.

[162] Fu Q, Wagner T. Thermal stability of Cr clusters on SrTiO3 (1 0 0). Surf Sci 2002; 505:39-48.

[163] Diebold U, Pan JM, Madey TE. Ultrathin metal film growth on TiO2 (110): an overview. Surf Sci 1995; 331:845-54.

[164] Hu M, Noda S, Komiyama H. A new insight into the growth mode of metals on $\mathrm{TiO} 2$ (110). Surf Sci 2002; 513(3):530-8.

[165] Lee WH, Vanloon KR, Petrova V, Woodhouse JB, Loxton CM, Masel RI. The equilibrium shape and surface-energy anisotropy of clean platinum. J Catal 1990; 126(2):65870.

[166] Harris P. Growth and structure of supported metal catalyst particles. Int Mater Rev 1995; 40(3):97-115.

[167] Thiel PA, Shen M, Liu D-J, Evans JW. Coarsening of two-dimensional nanoclusters on metal surfaces. J Phys Chem C 2009; 113(13):5047-67.

[168] Layson AR, Evans JW, Thiel PA. Additive-enhanced coarsening and smoothening of metal films: Complex mass-flow dynamics underlying nanostructure evolution. Phys Rev B 2002; 65(19):193409.

[169] Kuo HK, Ganesan P, De Angelis RJ. The sintering of a silica-supported nickel catalyst. J Catal 1980; 64(2):303-19.

[170] Kim K-T, Ihm S-K. Sintering behavior of nickel particles supported on alumina model catalyst in hydrogen atmosphere. J Catal 1985; 96(1):12-22.

[171] Beck DD, Carr CJ. A study of thermal aging of PtAl2O3 using temperatureprogrammed desorption spectroscopy. J Catal 1988; 110(2):285-97.

[172] Sasaki T, Nishibe S, Harima H, Isshiki T, Yoshimoto M, Kisoda K, et al., editors.

Raman study of low-Temperature formation of nickel silicide layers. 14th IEEE International Conference on Advanced Thermal Processing of Semiconductors 2006: IEEE. 
[173] Teo K, Chhowalla M, Amaratunga G, Milne W, Pirio G, Legagneux P, et al. Characterization of plasma-enhanced chemical vapor deposition carbon nanotubes by Auger electron spectroscopy. J Vac Sci Technol, B 2002; 20:116-21.

[174] Malik IJ, Ouaknine M, Ueda T, Fukada T, Yoo WS, Erbetta D, et al., editors. Cobalt silicide formation characteristics in a single wafer rapid thermal furnace (SRTF) system. RTP Conference; 2006: IEEE.

[175] Simmons JM, Nichols BM, Marcus MS, Castellini OM, Hamers RJ, Eriksson MA. Critical oxide thickness for efficient single-walled carbon nanotube growth on silicon using thin $\mathrm{SiO} 2$ diffusion barriers. Small 2006; 2:902-9.

[176] De los Arcos T, Vonau F, Garnier M, Thommen V, Boyen HG, Oelhafen P, et al. Influence of iron-silicon interaction on the growth of carbon nanotubes produced by chemical vapor deposition. Appl Phys Lett 2002; 80:2383-5.

[177] Meschel S, Kleppa O. Standard enthalpies of formation of some 3d transition metal silicides by high temperature direct synthesis calorimetry. J Alloys Compd 1998; 267(12):128-35.

[178] Lamber R, Jaeger N, Schulz-Ekloff G. On the metal-support interaction in the Ni-SiO2 system. Surf Sci 1990; 227(3):268-72.

[179] Penner S, Wang D, Su DS, Rupprechter G, Podloucky R, Schlögl R, et al. Platinum nanocrystals supported by silica, alumina and ceria: metal-support interaction due to hightemperature reduction in hydrogen. Surf Sci 2003; 532:276-80.

[180] Wang D, Penner S, Su DS, Rupprechter G, Hayek K, Schlögl R. Silicide formation on a Pt/SiO2 model catalyst studied by TEM, EELS, and EDXS. J Catal 2003; 219(2):434-41.

[181] Pretorius R, Harris JM, Nicolet MA. Reaction of thin metal films with SiO2 substrates. Solid-State Electron 1978; 21(4):667-75.

[182] Zhao X-A, Kolawa E, Nicolet M-A. Reaction of thin metal films with crystalline and amorphous Al2O3. J Vac Sci Technol, A 1986; 4(6):3139-41.

[183] Mattevi C, Wirth C, Hofmann S, Blume R, Cantoro M, Ducati C, et al. In-situ X-ray photoelectron spectroscopy study of catalyst-support interactions and growth of carbon nanotube forests. J Phys Chem C 2008; 112(32):12207-13.

[184] Li N, Wang X, Derrouiche S, Haller GL, Pfefferle LD. Role of surface cobalt silicate in single-walled carbon nanotube synthesis from silica-supported cobalt catalysts. ACS Nano 2010; 4(3):1759-67.

[185] Lucas S, Colomer JF, Bittencourt C, Moskovkin P, Moreau N. Surface phenomena involved in the formation of Co nanoparticles on amorphous carbon and $\mathrm{SiO} 2$ deposited by magnetron sputtering. Appl Phys A 2010; 99(1):125-38.

[186] Oshima H, Shimazu T, Siry M, Mibu K. Analysis of Fe catalyst during carbon nanotube synthesis by Mossbauer spectroscopy. J Phys Chem C 2009; 113(43):18523-6.

[187] Murakami T, Hasebe Y, Kisoda K, Nishio K, Isshiki T, Harima H. Effective catalyst on $\mathrm{SiO} 2$ in ethanol CVD for growth of single-walled carbon nanotubes. Diamond Rel Mat 2008; 17(7-10):1467-70.

[188] Yu Z, Chen D, Totdal B, Holmen A. Effect of catalyst preparation on the carbon nanotube growth rate. Catal Today 2005; 100(3-4):261-7.

[189] Malesevic A, Chen H, Hauffman T, Vanhulsel A, Terryn H, Haesendonck CV. Study of the catalyst evolution during annealing preceding the growth of carbon nanotubes by microwave plasma-enhanced chemical vapour deposition. Nanotechnology 2007; 18:455602. [190] Zhong Q, Ohuchi F. Surface science studies on the Ni/A12O3 interface. J Vac Sci Technol, A 1990; 8(3):2107-12.

[191] Oshima H, Shimazu T, Siry M, Mibu K. Analysis of Fe Catalyst during Carbon Nanotube Synthesis by Mo ssbauer Spectroscopy. J Phys Chem C 2009; 113(43):18523-6. 
[192] Kogelbauer A, Weber JC, Goodwin JG. The formation of cobalt silicates on Co/SiO2 under hydrothermal conditions. Catal Lett 1995; 34(3):259-67.

[193] Huber GW, Guymon CG, Conrad TL, Stephenson BC, Bartholomew CH, editors. Hydrothermal stability of $\mathrm{CO} / \mathrm{SiO} 2$ Fischer-Tropsch synthesis catalysts. Proceedings of the 9th International Symposium on Catalyst Deactivation; 2001: Elsevier.

[194] Cheung CL, Kurtz A, Park H, Lieber CM. Diameter-controlled synthesis of carbon nanotubes. J Phys Chem B 2002; 106:2429-33.

[195] Schäffel F, Rümmeli MH, Kramberger C, Queitsch U, Mohn E, Kaltofen R, et al. Tailoring the diameter, density and number of walls of carbon nanotubes through predefined catalyst particles. Phys Status Solidi A 2008; 205(6):1382-5.

[196] Chen Y, Zhang J. Diameter controlled growth of single-walled carbon nanotubes from $\mathrm{SiO} 2$ nanoparticles. Carbon 2011; 49(10):3316-24.

[197] Nasibulin AG, Pikhitsa PV, Jiang H, Kauppinen EI. Correlation between catalyst particle and single-walled carbon nanotube diameters. Carbon 2005; 43(11):2251-7.

[198] Hiraoka T, Bandow S, Shinohara H, Iijima S. Control on the diameter of single-walled carbon nanotubes by changing the pressure in floating catalyst CVD. Carbon 2006; 44:1853-9. [199] Zhang Y, Li Y, Kim W, Wang D, Dai H. Imaging as-grown single-walled carbon nanotubes originated from isolated catalytic nanoparticles. Appl Phys A 2002; 74(3):325-8. [200] Fiawoo MFC, Bonnot AM, Amara H, Bichara C, Thibault-Pénisson J, Loiseau A. Evidence of correlation between catalyst particles and the single-wall carbon nanotube diameter: a first step towards chirality control. Phys Rev Lett 2012; 108(19):195503. [201] Helveg S, Lopez-Cartes C, Sehected J, Hansen PL, Clausen BS, Rostrup-Nielsen JR, et al. Atomic-scale imaging of carbon nanofibre growth. Nature 2004; 427:426-9.

[202] Hofmann S, Sharma R, Du G, Matteri C, Cepek C, Cantoro M, et al. In-situ observations of catalyst dynamics during surface-bound carbon nanotube nucleation. Nano Lett 2007; 7:602-8.

[203] Lin M, Tan JPY, Boothroyd C, Loh KP, Tok ES, Foo YL. Dynamical observation of bamboo-like carbon nanotube growth. Nano Lett 2007; 7(8):2234-8.

[204] Yoshida H, Takeda S, Uchiyama T, Kohno H, Homma Y. Atomic-scale in-situ observation of carbon nanotube growth from solid state iron carbide nanoparticles. Nano Lett 2008; 8(7):2082-6.

[205] Yoshida H, Shimizu T, Uchiyama T, Kohno H, Homma Y, Takeda S. Atomic-scale analysis on the role of molybdenum in iron-catalyzed carbon nanotube growth. Nano Lett 2009; 9(11):3810-5.

[206] Gamalski A, Moore ES, Treacy MMJ, Sharma R, Rez P. Diffusion-gradient-induced length instabilities in the catalytic growth of carbon nanotubes. Appl Phys Lett 2009; 95(23):233109-11.

[207] Yoshida H, Uchiyama T, Kohno H, Takeda S. Environmental transmission electron microscopy observations of the growth of carbon nanotubes under nanotube-nanotube and nanotube-substrate interactions. Appl Surf Sci 2008; 254(23):7586-90.

[208] Zhu W, Börjesson A, Bolton K. DFT and tight binding Monte Carlo calculations related to single-walled carbon nanotube nucleation and growth. Carbon 2010; 48(2):470-8.

[209] Noda S, Tsuji Y, Murakami Y, Maruyama S. Combinatorial method to prepare metal nanoparticles that catalyze the growth of single-walled carbon nanotubes. Appl Phys Lett 2005; 86:173106.

[210] Zhao B, Futaba DN, Yasuda S, Akoshima M, Yamada T, Hata K. Exploring advantages of diverse carbon nanotube forests with tailored structures synthesized by supergrowth from engineered catalysts. ACS Nano 2008; 3(1):108-14. 
[211] Pisana S, Cantoro M, Parvez A, Hofmann S, Ferrari A, Robertson J. The role of precursor gases on the surface restructuring of catalyst films during carbon nanotube growth. Physica E 2007; 37(1):1-5.

[212] Jin-Ju K, Byeong-Joo L, Seung-Hwan L, Goo-Hwan J. Size engineering of metal nanoparticles to diameter-specified growth of single-walled carbon nanotubes with horizontal alignment on quartz. Nanotechnology 2012; 23(10):105607.

[213] Song W, Jeon C, Kim YS, Kwon YT, Jung DS, Jang SW, et al. Synthesis of bandgapcontrolled semiconducting single-walled carbon nanotubes. ACS Nano 2010; 4(2):1012-8.

[214] Jeong GH, Suzuki S, Kobayashi Y, Yamazaki A, Yoshimura H, Homma Y. Size control of catalytic nanoparticles by thermal treatment and its application to diameter control of single-walled carbon nanotubes. Appl Phys Lett 2007; 90:043108.

[215] Kim SY, Song W, Jung MW, Kim M, Jeon C, Choi WC, et al. Heat-driven size manipulation of Fe catalytic nanoparticles for precise control of single-walled carbon nanotube diameter. J Phys D: Appl Phys 2012; 45(25):255302.

[216] Wang WL, Bai XD, Xu Z, Liu S, Wang EG. Low temperature growth of single-walled carbon nanotubes: Small diameters with narrow distribution. Chem Phys Lett 2006; 419(13):81-5.

[217] Li N, Wang X, Ren F, Haller GL, Pfefferle LD. Diameter tuning of single-walled carbon nanotubes with reaction temperature using a Co monometallic catalyst. J Phys Chem C 2009; 113(23):10070-8.

[218] Tanioku K, Maruyama T, Naritsuka S. Low temperature growth of carbon nanotubes on Si substrates in high vacuum. Diamond Rel Mat 2008; 17(4-5):589-93.

[219] Ishigami N, Ago H, Imamoto K, Tsuji M, Iakoubovskii K, Minami N. Crystal plane dependent growth of aligned single-walled carbon nanotubes on sapphire. J Am Chem Soc 2008; 130(30):9918-24.

[220] Zoican Loebick C, Podila R, Reppert J, Chudow J, Ren F, Haller GL, et al. Selective synthesis of subnanometer diameter semiconducting single-walled carbon nanotubes. J Am Chem Soc 2010; 132(32):11125-31.

[221] He M, Chernov AI, Obraztsova ED, Sainio J, Rikkinen E, Jiang H, et al. Low temperature growth of SWNTs on a nickel catalyst by thermal chemical vapor deposition.

Nano Research 2011; 4(4):334-42.

[222] Yao Y, Li Q, Zhang J, Liu R, Jiao L, Zhu YT, et al. Temperature-mediated growth of single-walled carbon-nanotube intramolecular junctions. Nature Mat 2007; 6(4):293-6.

[223] Mahjouri-Samani M, Zhou Y, Xiong W, Gao Y, Mitchell M, Jiang L, et al. Diameter modulation by fast temperature control in laser-assisted chemical vapor deposition of singlewalled carbon nanotubes. Nanotechnology 2010; 21:395601.

[224] Yao Y, Dai X, Liu R, Zhang J, Liu Z. Tuning the diameter of single-walled carbon nanotubes by temperature-mediated chemical vapor deposition. J Phys Chem C 2009; 113(30):13051-9.

[225] Lu C, Liu J. Controlling the diameter of carbon nanotubes in chemical vapor deposition method by carbon feeding. J Phys Chem B 2006; 110(41):20254-7.

[226] Geohegan DB, Puretzky AA, Jackson JJ, Rouleau CM, Eres G, More KL. Fluxdependent growth kinetics and diameter selectivity in single-wall carbon nanotube arrays. ACS Nano 2011; 5(10):8311-21.

[227] Saito T, Ohshima S, Okazaki T, Ohmori S, Yumura M, Iijima S. Selective diameter control of single-walled carbon nanotubes in the gas-phase synthesis. J Nanosci Nanotechnol 2008; 8(11):6153-7.

[228] Wang B, Wei L, Yao L, Li L-J, Yang Y, Chen Y. Pressure-induced single-walled carbon nanotube (n,m) selectivity on Co-Mo catalysts. J Phys Chem C 2007; 111:14612-6. 
[229] Picher M, Anglaret E, Arenal R, Jourdain V. Processes controlling the diameter distribution of single-walled carbon nanotubes during catalytic chemical vapor deposition. ACS Nano 2011; 5:2118-25.

[230] Tian Y, Timmermans M, Kivistö S, Nasibulin A, Zhu Z, Jiang H, et al. Tailoring the diameter of single-walled carbon nanotubes for optical applications. Nano Research 2011; 4(8):807-15.

[231] Tibbetts GG. Why are carbon filaments tubular? J Cryst Growth 1984; 66:632-8.

[232] Chiodarelli N, Richard O, Bender H, Heyns M, De Gendt S, Groeseneken G, et al. Correlation between number of walls and diameter in multiwall carbon nanotubes grown by chemical vapor deposition. Carbon 2012; 50(5):1748-52.

[233] Chiang WH, Sankaran RM. In-flight dimensional tuning of metal nanoparticles by microplasma synthesis for selective production of diameter-controlled carbon nanotubes. $\mathbf{J}$ Phys Chem C 2008; 112(46):17920-5.

[234] Yamada T, Namai T, Hata K, Futaba DN, Mizuno K, Fan J, et al. Size-selective growth of double-walled carbon nanotube forests from engineered iron catalysts. Nature Nanotech 2006; 1(2):131-6.

[235] Sharma R, Rez P, Brown M, Du G, Treacy MMJ. Dynamic observations of the effect of pressure and temperature conditions on the selective synthesis of carbon nanotubes.

Nanotechnology 2007; 18(12):125602.

[236] Zhang H, Cao G, Wang Z, Yang Y, Shi Z, Gu Z. Influence of ethylene and hydrogen flow rates on the wall number, crystallinity, and length of millimeter-long carbon nanotube array. J Phys Chem C 2008; 112(33):12706-9.

[237] Jourdain V, Stéphan O, Castignolles M, Loiseau A, Bernier P. Controlling the morphology of multiwall carbon nanotubes by sequential catalytic growth induced by phosphorus. Adv Mater 2004; 16(5):447-53.

[238] Mudimela P, Nasibulin A, Jiang H, Susi T, Chassaing D, Kauppinen E. Incremental variation in the number of carbon nanotube walls with growth temperature. J Phys Chem C 2009; 113(6):2212-8.

[239] Wei J, Zhu H, Jia Y, Shu Q, Li C, Wang K, et al. The effect of sulfur on the number of layers in a carbon nanotube. Carbon 2007; 45(11):2152-8.

[240] Ci L, Rao Z, Zhou Z, Tang D, Yan X, Liang Y, et al. Double wall carbon nanotubes promoted by sulfur in a floating iron catalyst CVD system. Chem Phys Lett 2002; 359(12):63-7.

[241] Ci L, Zhou Z, Tang D, Yan X, Liang Y, Liu D, et al. Double wall carbon nanotubes with an inner diameter of $0.4 \mathrm{~nm}$. Chem Vap Depos 2003; 9(3):119-21.

[242] Pan Y, Liu Y, Chi W, Shen Z. Inner-diameter enlargement of multi-walled carbon nanotubes by adding HBO3 in catalyst. Mater Lett 2011; 65(23-24):3362-4.

[243] Jorio A, Fantini C, Pimenta MA, Heller DA, Strano MS, Dresselhaus MS, et al. Carbon nanotube population analysis from Raman and photoluminescence intensities. Appl Phys Lett 2006; 88:023109.

[244] Tsyboulski DA, Rocha JDR, Bachilo SM, Cognet L, Weisman RB. Structuredependent fluorescence efficiencies of individual single-walled carbon nanotubes. Nano Lett 2007; 7(10):3080-5.

[245] Miyauchi Y, Chiashi S, Murakami Y, Hayashida Y, Maruyama S. Fluorescence spectroscopy of single-walled carbon nanotubes synthesized from alcohol. Chem Phys Lett 2004; 387(1): 198-203.

[246] Oyama Y, Saito R, Sato K, Jiang J, Samsonidze GG, Gruneis A, et al.

Photoluminescence intensity of single-wall carbon nanotubes. Carbon 2006; 44:873-9. 
[247] Wang H, Wang B, Quek XY, Wei L, Zhao J, Li LJ, et al. Selective synthesis of $(9,8)$ single walled carbon nanotubes on cobalt incorporated TUD-1 catalysts. J Am Chem Soc 2010; 132(47):16747-9.

[248] Hirahara K, Kociak M, Bandow S, Nakahira T, Itoh K, Saito Y, et al. Chirality correlation in double-wall carbon nanotubes as studied by electron diffraction. Phys Rev B 2006; 73(19): 195420.

[249] Paillet M, Meyer JC, Michel T, Jourdain V, Poncharal P, Sauvajol J-L, et al. Selective growth of large chiral angle single-walled carbon nanotubes. Diamond Rel Mat 2006;

15:1019-22.

[250] Arenal R, Löthman P, Picher M, Than XT, Paillet M, Jourdain V. Direct evidence of atomic structure conservation along individual ultralong carbon nanotubes. J Phys Chem $\mathrm{C}$ 2012; 116(26):14103-7.

[251] Ciuparu D, Chen Y, Lim S, Haller GL, Pfefferle L. Uniform-diameter single-walled carbon nanotubes catalytically grown in cobalt-incorporated MCM-41. J Phys Chem B 2004; 108(2):503-7.

[252] Wang H, Wei L, Ren F, Wang Q, Pfefferle LD, Haller GL, et al. Chiral-selective CoSO4/SiO2 catalyst for $(9,8)$ single-walled carbon nanotube growth. ACS Nano 2012; 7(1):614-26.

[253] Bachilo SM, Balzano L, Herrera JE, Pompeo F, Resasco DE, Weisman RB. Narrow (n, $\mathrm{m}$ )-distribution of single-walled carbon nanotubes grown using a solid supported catalyst. $\mathrm{J}$ Am Chem Soc 2003; 125(37):11186-7.

[254] Wang B, Poa CHP, Wei L, Li LJ, Yang Y, Chen Y. (n, m) Selectivity of single-walled carbon nanotubes by different carbon precursors on Co-Mo catalysts. J Am Chem Soc 2007; 129(29):9014-9.

[255] Li X, Tu X, Zaric S, Welsher K, Seo WS, Zhao W, et al. Selective synthesis combined with chemical separation of single-walled carbon nanotubes for chirality selection. J Am Chem Soc 2007; 129(51):15770-1.

[256] He M, Chernov AI, Fedotov PV, Obraztsova ED, Sainio J, Rikkinen E, et al. Predominant $(6,5)$ single-walled carbon nanotube growth on a copper-promoted iron catalyst. J Am Chem Soc 2010; 132(40):13994-6.

[257] Kajiwara K, Suzuki S, Sato H, Hata K. Chirality-selective synthesis of carbon nanotubes by catalytic-chemical vapor deposition using quasicrystal alloys as catalysts. Z Kristallogr 2009; 224(1-2):5-8.

[258] Lolli G, Zhang L, Balzano L, Sakulchaicharoen N, Tan Y, Resasco DE. Tailoring $(n, m)$ structure of single-walled carbon nanotubes by modifying reaction conditions and the nature of the support of CoMo catalysts. J Phys Chem B 2006; 110:2108-15.

[259] He M, Jiang H, Kauppinen EI, Lehtonen J. Diameter and chiral angle distribution dependencies on the carbon precursors in surface-grown single-walled carbon nanotubes. Nanoscale 2012; 4(23):7394-8.

[260] He MS, Fedotov PV, Obraztsova ED, Viitanen V, Sainio J, Jiang H, et al. Chiralselective growth of single-walled carbon nanotubes on stainless steel wires. Carbon 2012; 50(11):4294-7.

[261] Ghorannevis Z, Kato T, Kaneko T, Hatakeyama R. Narrow-chirality distributed single-walled carbon nanotube growth from nonmagnetic catalyst. J Am Chem Soc 2010; 132(28):9570-2.

[262] Koziol K, Shaffer M, Windle A. Three-dimensional internal order in multiwalled carbon nanotubes grown by chemical vapor deposition. Adv Mater 2005; 17(6):760-3. [263] Pattinson SW, Ranganathan V, Murakami HK, Koziol KKK, Windle AH. Nitrogeninduced catalyst restructuring for epitaxial growth of multiwall carbon nanotubes. ACS Nano 2012; 6(9):7723-30. 
[264] Li Y, Peng S, Mann D, Cao J, Tu R, Cho K, et al. On the origin of preferential growth of semiconducting single-walled carbon nanotubes. J Phys Chem B 2005; 109(15):6968-71.

[265] Mizutani T, Ohnaka H, Okigawa Y, Kishimoto S, Ohno Y. A study of preferential growth of carbon nanotubes with semiconducting behavior grown by plasma-enhanced chemical vapor deposition. J Appl Phys 2009; 106:073705.

[266] Qu L, Du F, Dai L. Preferential syntheses of semiconducting vertically aligned singlewalled carbon nanotubes for direct use in FETs. Nano Lett 2008; 8(9):2682-7.

[267] Hong G, Zhang B, Peng B, Zhang J, Choi WM, Choi JY, et al. Direct growth of semiconducting single-walled carbon nanotube array. J Am Chem Soc 2009; 131(41):14642-3.

[268] Yu B, Hou PX, Li F, Liu B, Liu C, Cheng HM. Selective removal of metallic singlewalled carbon nanotubes by combined in situ and post-synthesis oxidation. Carbon 2010; 48(10):2941-7.

[269] Parker J, Beasley C, Lin A, Chen H-Y, Philip Wong HS. Increasing the semiconducting fraction in ensembles of single-walled carbon nanotubes. Carbon 2012; 50(14):5093-8.

[270] Wang Y, Liu Y, Li X, Cao L, Wei D, Zhang H, et al. Direct enrichment of metallic single-walled carbon nanotubes induced by the different molecular composition of monohydroxy alcohol homologues. Small 2007; 3(9):1486-90.

[271] Ding L, Tselev A, Wang J, Yuan D, Chu H, McNicholas TP, et al. Selective growth of well-aligned semiconducting single-walled carbon nanotubes. Nano Lett 2009; 9(2):800-5.

[272] Che Y, Wang C, Liu J, Liu B, Lin X, Parker J, et al. Selective synthesis and device applications of semiconducting single-walled carbon nanotubes using isopropanol as feedstock. ACS Nano 2012; 6(8):7454-62.

[273] Zhou W, Zhan S, Ding L, Liu J. General rules for selective growth of enriched semiconducting single walled carbon nanotubes with water vapor as in situ etchant. J Am Chem Soc 2012; 134(34):14019-26.

[274] Harutyunyan AR, Chen G, Paronyan TM, Pigos EM, Kuznetsov OA, Hewaparakrama $\mathrm{K}$, et al. Preferential growth of single-walled carbon nanotubes with metallic conductivity. Science 2009; 326(5949):116-20.

[275] Chiang WH, Sakr M, Gao XPA, Sankaran RM. Nanoengineering Ni x Fe 1- x catalysts for gas-phase, selective synthesis of semiconducting single-walled carbon nanotubes. ACS Nano 2009; 3(12):4023-32.

[276] Qian Y, Huang B, Gao F, Wang C, Ren G. Preferential growth of semiconducting single-walled carbon nanotubes on substrate by europium oxide. Nanoscale Res Lett 2010; 5(10): $1578-84$.

[277] Suenaga K, Wakabayashi H, Koshino M, Sato Y, Urita K, Iijima S. Imaging active topological defects in carbon nanotubes. Nature Nanotech 2007; 2(6):358-60.

[278] Clauss W, Bergeron DJ, Freitag M, Kane CL, Mele EJ, Johnson AT. Electron backscattering on single-wall carbon nanotubes observed by scanning tunneling microscopy. Europhys Lett 1999; 47(5):601.

[279] Gao F, Zhang L, Yang Y, Huang S. Quality of horizontally aligned single-walled carbon nanotubes: Is methane as carbon source better than ethanol? Appl Surf Sci 2010; 256(11):3357-60.

[280] Tuinstra F, Koenig J. Raman spectrum of graphite. J Chem Phys 1970; 53:1126-30.

[281] Lucchese M, Stavale F, Ferreira E, Vilani C, Moutinho M, Capaz RB, et al.

Quantifying ion-induced defects and Raman relaxation length in graphene. Carbon 2010; 48(5):1592-7.

[282] Dresselhaus M, Jorio A, Souza Filho A, Saito R. Defect characterization in graphene and carbon nanotubes using Raman spectroscopy. Philos T R Soc A 2010; 368(1932):5355-77. 
[283] Pimenta M, Dresselhaus G, Dresselhaus MS, Cancado L, Jorio A, Saito R. Studying disorder in graphite-based systems by Raman spectroscopy. Phys Chem Chem Phys 2007; 9(11):1276-90.

[284] Dresselhaus MS, Dresselhaus G, Saito R, Jorio A. Raman spectroscopy of carbon nanotubes. Phys Rep 2005; 409(2):47-99.

[285] Reich S, Thomsen C, Maultzsch J. Carbon nanotubes: basic concepts and physical properties. 1st Edition ed. Berlin: Wiley-VCH; 2004.

[286] Souza Filho A, Jorio A, Samsonidze GG, Dresselhaus G, Pimenta M, Dresselhaus M, et al. Competing spring constant versus double resonance effects on the properties of dispersive modes in isolated single-wall carbon nanotubes. Phys Rev B 2003; 67(3):035427. [287] Gao B, Zhang Y, Zhang J, Kong J, Liu Z. Systematic comparison of the Raman spectra of metallic and semiconducting SWNTs. J Phys Chem C 2008; 112(22):8319-23. [288] Jorio A, Fantini C, Dantas M, Pimenta M, Souza Filho A, Samsonidze GG, et al. Linewidth of the Raman features of individual single-wall carbon nanotubes. Phys Rev B 2002; 66(11):115411.

[289] Tan PH, Dimovski S, Gogotsi Y. Raman scattering of non-planar graphite: arched edges, polyhedral crystals, whiskers and cones. Philos T R Soc A 2004; 362(1824):2289. [290] Xu Z, Chen L, Liu L, Wu X, Chen L. Structural changes in multi-walled carbon nanotubes caused by [gamma]-ray irradiation. Carbon 2011; 49(1):350-1.

[291] Matthews M, Pimenta M, Dresselhaus G, Dresselhaus M, Endo M. Origin of dispersive effects of the Raman D band in carbon materials. Phys Rev B 1999; 59(10):6585-8. [292] Pócsik I, Hundhausen M, Koós M, Ley L. Origin of the D peak in the Raman spectrum of microcrystalline graphite. J Non-Cryst Solids 1998; 227:1083-6.

[293] Ferrari AC, Robertson J. Raman spectroscopy of amorphous, nanostructured, diamond-like carbon, and nanodiamond. Philos T R Soc A 2004; 362(1824):2477-512. [294] Yasuda S, Hiraoka T, Futaba D, Yamada T, Yumura M, Hata K. Existence and kinetics of graphitic carbonaceous impurities in carbon nanotube forests to assess the absolute purity. Nano Lett 2009; 9(2):769-73.

[295] Picher M, Navas H, Arenal R, Quesnel E, Anglaret E, Jourdain V. Influence of the growth conditions on the defect density of single-walled carbon nanotubes. Carbon 2012; 50(7):2407-16.

[296] Vinten P, Lefebvre J, Finnie P. Kinetic critical temperature and optimized chemical vapor deposition growth of carbon nanotubes. Chem Phys Lett 2009; 469(4-6):293-7.

[297] Kwok C, Reizman BJ, Agnew DE, Sandhu GS, Weistroffer J, Strano MS, et al. Temperature and time dependence study of single-walled carbon nanotube growth by catalytic chemical vapor deposition. Carbon 2010; 48(4):1279-88.

[298] Feng X, Liu K, Xie X, Zhou R, Zhang L, Li Q, et al. Thermal analysis study of the growth kinetics of carbon nanotubes and epitaxial graphene layers on them. J Phys Chem C 2009; 113(22):9623-31.

[299] Noda S, Sugime H, Hasegawa K, Kakehi K, Shiratori Y. A simple combinatorial method aiding research on single-walled carbon nanotube growth on substrates. Jpn J Appl Phys 2010; 49(2).

[300] Thurakitsereea T, Krambergera C, Zhaoa P, Aikawaa S, Harisha S, Chiashia S, et al. Diameter-controlled and nitrogen-doped vertically aligned single-walled carbon nanotubes. Carbon 2012; 50:2635-40.

[301] Karoui S, Amara H, Bichara C, Ducastelle F. Nickel-assisted healing of defective graphene. ACS Nano 2010; 4(10):6114-20.

[302] Paillet M, Jourdain V, Poncharal P, Sauvajol JL, Zahab A, Meyer JC, et al. Versatile synthesis of individual single-walled carbon nanotubes from nickel nanoparticles for the study of their physical properties. J Phys Chem B 2004; 108(44):17112-8. 
[303] Paillet M, Jourdain V, Poncharal P, Sauvajol JL, Zahab A, Meyer JC, et al. Growth and physical properties of individual single-walled carbon nanotubes. Diamond Rel Mat 2005; 14(9):1426-31.

[304] Ishida M, Hongo H, Nihey F, Ochiai Y. Diameter-controlled carbon nanotubes grown from lithographically defined nanoparticles. Jpn J Appl Phys 2004; 43:1356.

[305] Li Y, Kim W, Zhang Y, Rolandi M, Wang D, Dai H. Growth of single-walled carbon nanotubes from discrete catalytic nanoparticles of various sizes. J Phys Chem B 2001; 105(46):11424-31.

[306] Lin M, Tan JPY, Boothroyd C, Loh KP, Tok ES, Foo YL. Direct observation of single-walled carbon nanotube growth at the atomistic scale. Nano Lett 2006; 6(3):449-52.

[307] Rümmeli M, Kramberger C, Löffler M, Jost O, Bystrzejewski M, Grüneis A, et al. Catalyst volume to surface area constraints for nucleating carbon nanotubes. J Phys Chem B 2007; 111(28):8234-41.

[308] Ding F, Rosen A, Campbell EEB, Falk LKL, Bolton K. Graphitic encapsulation of catalyst particles in carbon nanotube production. J Phys Chem B 2006; 110(15):7666-70. [309] Davis SM, Zaera F, Gordon BE, Somorjai GA. Radiotracer and thermal desorption studies of dehydrogenation and atmospheric hydrogenation of organic fragments obtained from [14C] ]ethylene chemisorbed over Pt(111) surfaces. J Catal 1985; 92(2):240-6.

[310] Somorjai G, Zaera F. Heterogeneous catalysis on the molecular scale. J Phys Chem 1982; 86(16):3070-8.

[311] Wu G, Bartlett B, Tysoe WT. The effect of hydrogen on the carbonaceous layer formed on molybdenum model catalysts during high temperature propylene metathesis. $\mathbf{J}$ Catal 1998; 173(1):172-6.

[312] Schünemann C, Schäffel F, Bachmatiuk A, Queitsch U, Sparing M, Rellinghaus B, et al. Catalyst poisoning by amorphous carbon during carbon nanotube growth: fact or fiction? ACS Nano 2011; 5(11):8928-34.

[313] Marchand M, Journet C, Guillot D, Benoit JM, Yakobson BI, Purcell ST. Growing a carbon nanotube atom by atom:“And yet it does turn”. Nano Lett 2009; 9(8):2961-6.

[314] Hata K, Futaba DN, Mizuno K, Namai T, Yumura M, Iijima S. Water-assisted highly efficient synthesis of impurity-free single-waited carbon nanotubes. Science 2004; 306:13624.

[315] Futaba DN, Hata K, Namai T, Yamaka T, Mizuno K, Hayamizu Y, et al. 84\% catalyst activity of water-assisted growth of single walled carbon nanotube forest characterization by a statistical and macroscopic approach. J Phys Chem B 2006; 110:8035-8.

[316] Futaba DN, Goto J, Yasuda S, Yamada T, Yumura M, Hata K. General rules governing the highly efficient growth of carbon nanotubes. Adv Mater 2009; 21(47):4811-5. [317] Zhou W, Ding L, Yang S, Liu J. Synthesis of high density, large-diameter and aligned single-walled carbon nanotubes by multiple-cycle growth methods. ACS Nano 2011;

5(5):3849-57.

[318] Wu B, Geng D, Guo Y, Huang L, Chen J, Xue Y, et al. Ultrahigh density modulation of aligned single-walled carbon nanotube arrays. Nano Research 2011:1-7.

[319] Hasegawa K, Noda S. Millimeter-tall single-walled carbon nanotubes rapidly grown with and without water. ACS Nano 2011; 5(2):975-84.

[320] Zhu L, Hess DW, Wong CP. Monitoring carbon nanotube growth by formation of nanotube stacks and investigation of the diffusion-controlled kinetics. J Phys Chem B 2006; 110(11):5445-9.

[321] Noda S, Hasegawa K, Sugime H, Kakehi K, Zhang Z, Maruyama S, et al. Millimeterthick single-walled carbon nanotube forests: Hidden role of catalyst support. Jpn J Appl Phys 2007; 46(17):L399-L401. 
[322] Amama PB, Pint CL, Kim SM, McJilton L, Eyink KG, Stach EA, et al. Influence of alumina type on the evolution and activity of alumina-supported Fe catalysts in single-walled carbon nanotube carpet growth. ACS Nano 2010; 4(2):895-904.

[323] Burt DP, Whyte WM, Weaver JMR, Glidle A, Edgeworth JP, Macpherson JV, et al. Effects of metal underlayer grain size on carbon nanotube growth. J Phys Chem C 2009; 113(34):15133-9.

[324] Esconjauregui S, Bayer B, Fouquet M, Wirth C, Ducati C, Hofmann S, et al. Growth of high-density vertically aligned arrays of carbon nanotubes by plasma-assisted catalyst pretreatment. Appl Phys Lett 2009; 95:173115.

[325] Amama PB, Pint CL, McJilton L, Kim SM, Stach EA, Murray PT, et al. Role of water in super growth of single-walled carbon nanotube carpets. Nano Lett 2008; 9(1):44-9.

[326] Hasegawa K, Noda S. Moderating carbon supply and suppressing Ostwald ripening of catalyst particles to produce 4.5-mm-tall single-walled carbon nanotube forests. Carbon 2011; 49(13):4497-504.

[327] Picher M, Anglaret E, Arenal R, Jourdain V. Self-deactivation of single-walled carbon nanotube growth studied by in situ Raman measurements. Nano Lett 2009; 9(2):542-7.

[328] Finnie P, Li-Pook-Than A, Lefebvre J. The dynamics of the nucleation, growth and termination of single-walled carbon nanotubes from in situ Raman spectroscopy during chemical vapor deposition. Nano Research 2009; 2:783-92.

[329] Futaba DN, Hata K, Yamada T, Mizuno K, Yumura M, Iijima S. Kinetics of waterassisted single-walled carbon nanotube synthesis revealed by a time-evolution analysis. Phys Rev Lett 2005; 95:056104.

[330] Puretzky AA, Geohegan DB, Jesse S, Ivanov IN, Eres G. In situ measurements and modeling of carbon nanotube array growth kinetics during chemical vapor deposition. Appl Phys A 2005; 81(2):223-40.

[331] Einarsson E, Murakami Y, Kadowaki M, Maruyama S. Growth dynamics of vertically aligned single-walled carbon nanotubes from in situ measurements. Carbon 2008; 46:923-30. [332] Wirth CT, Zhang C, Zhong G, Hofmann S, Robertson J. Diffusion-and reactionlimited growth of carbon nanotube forests. ACS Nano 2009; 3(11):3560-6.

[333] Baker RTK, Chludzinski Jr JJ, Dudash NS, Simoens AJ. The formation of filamentous carbon from decomposition of acetylene over vanadium and molybdenum. Carbon 1983; 21(5):463-8.

[334] Baker RTK, Chludzinski Jr JJ, Lund CRF. Further studies of the formation of filamentous carbon from the interaction of supported iron particles with acetylene. Carbon 1987; 25(2):295-303.

[335] Zaikovskii VI, Chesnokov VV, Buyanov RA. The relationship between the state of active species in a Ni/Al2O3 catalyst and the mechanism of growth of filamentous carbon. Kinet Catal 2001; 42(6):813-20.

[336] Cooper BJ, Trimm DL. Carbon deposition from propylene on polycrystalline and single crystal iron. J Catal 1980; 62(1):35-43.

[337] Bartsch K, Biedermann K, Gemming T, Leonhardt A. On the diffusion-controlled growth of multiwalled carbon nanotubes. J Appl Phys 2005; 97:114301.

[338] In JB, Grigoropoulos CP, Chernov AA, Noy A. Growth kinetics of vertically aligned carbon nanotube arrays in clean oxygen-free conditions. ACS Nano 2011; 5(12):9602-10. [339] Bronikowski MJ. Longer nanotubes at lower temperatures: the influence of effective activation energies on carbon nanotube growth by thermal chemical vapor deposition. J Phys Chem C 2007; 111(48):17705-12.

[340] Ducati C, Alexandrou I, Chhowalla M, Amaratunga GAJ, Robertson J. Temperature selective growth of carbon nanotubes by chemical vapor deposition. J Appl Phys 2002; 92:3299. 
[341] Meshot ER, Plata DL, Tawfick S, Zhang Y, Verploegen EA, Hart AJ. Engineering vertically aligned carbon nanotube growth by decoupled thermal treatment of precursor and catalyst. ACS Nano 2009; 3(9):2477-86.

[342] Ni L, Kuroda K, Zhou L-P, Kizuka T, Ohta K, Matsuishi K, et al. Kinetic study of carbon nanotube synthesis over $\mathrm{Mo} / \mathrm{Co} / \mathrm{MgO}$ catalysts. Carbon 2006; 44(11):2265-72.

[343] Cervantes-Sodi F, McNicholas TP, Simmons Jr JG, Liu J, Csanyi G, Ferrari AC, et al. Viscous state effect on the activity of Fe nanocatalysts. ACS Nano 2010; 4(11):6950-6. [344] Ma H, Pan L, Nakayama Y. Modelling the growth of carbon nanotubes produced by chemical vapor deposition. Carbon 2011; 49(3):854-61.

[345] Huang ZP, Wang DZ, Wen JG, Sennett M, Gibson H, Ren ZF. Effect of nickel, iron and cobalt on growth of aligned carbon nanotubes. Appl Phys A 2002; 74:387-91.

[346] Lee DH, Kim SO, Lee WJ. Growth kinetics of wall-number controlled carbon nanotube arrays. J Phys Chem C 2010; 114(8):3454-8.

[347] Hasegawa K, Noda S. Real-time monitoring of millimeter-tall vertically aligned single-walled carbon nanotube growth on combinatorial catalyst library. Jpn J Appl Phys 2010; 49(8):5104.

[348] Patole SP, Kim H, Choi J, Kim Y, Baik S, Yoo JB. Kinetics of catalyst size dependent carbon nanotube growth by growth interruption studies. Appl Phys Lett 2010; 96(9):094101.

[349] Borgström MT, Immink G, Ketelaars B, Algra R, Bakkers EPAM. Synergetic nanowire growth. Nature Nanotech 2007; 2(9):541-4.

[350] Jeong GH, Olofsson N, Falk LKL, Campbell EEB. Effect of catalyst pattern geometry on the growth of vertically aligned carbon nanotube arrays. Carbon 2009; 47(3):696-704.

[351] Chiang WH, Sankaran RM. Relating carbon nanotube growth parameters to the size and composition of nanocatalysts. Diamond Rel Mat 2009; 18(5-8):946-52.

[352] Page AJ, Minami S, Ohta Y, Irle S, Morokuma K. Comparison of single-walled carbon nanotube growth from $\mathrm{Fe}$ and $\mathrm{Ni}$ nanoparticles using quantum chemical molecular dynamics methods. Carbon 2010; 48(11):3014-26.

[353] Liu B, Ren W, Liu C, Sun CH, Gao L, Li S, et al. Growth velocity and direct lengthsorted growth of short single-walled carbon nanotubes by a metal-catalyst-free chemical vapor deposition process. ACS Nano 2009; 3(11):3421-30.

[354] Liu H, Takagi D, Chiashi S, Chokan T, Homma Y. Investigation of catalytic properties of $\mathrm{A} 12 \mathrm{O} 3$ particles in the growth of single-walled carbon nanotubes. J Nanosci Nanotechnol 2010; 10(6):4068-73.

[355] Motta MS, Moisala A, Kinloch IA, Windle AH. The role of sulphur in the synthesis of carbon nanotubes by chemical vapour deposition at high temperatures. J Nanosci Nanotechnol 2008; 8(5):2442-9.

[356] Louchev OA. Transport-kinetical phenomena in nanotube growth. J Cryst Growth 2002; 237-239:65-9.

[357] Zhu L, Hess DW, Wong C-P. Monitoring carbon nanotube growth by formation of nanotube stacks and investigation of the diffusion-controlled kinetics. J Phys Chem B 2006; 110(11):5445-9.

[358] Xiang R, Yang Z, Zhang Q, Luo G, Qian W, Wei F, et al. Growth deceleration of vertically aligned carbon nanotube arrays: catalyst deactivation or feedstock diffusion controlled? J Phys Chem C 2008; 112(13):4892-6.

[359] Zheng LX, O'Connell MJ, Doorn SK, Liao XZ, Zhao YH, Akhadov EA, et al. Ultralong single-wall carbon nanotubes. Nature Mat 2004; 3:673-6.

[360] Jin Z, Chu H, Wang J, Hong J, Tan W, Li Y. Ultralow feeding gas flow guiding growth of large-scale horizontally aligned single-walled carbon nanotube arrays. Nano Lett 2007; 7(7):2073-9. 
[361] Wen Q, Zhang R, Qian W, Wang Y, Tan P, Nie J, et al. Growing $20 \mathrm{~cm}$ long DWNTs/TWNTs at a rapid growth rate of 80- $90 \mu \mathrm{m} / \mathrm{s}$. Chem Mater 2010; 22(4):1294-6.

[362] Huang L, White B, Sfeir MY, Huang M, Huang HX, Wind S, et al. Cobalt ultrathin film catalyzed ethanol chemical vapor deposition of single-walled carbon nanotubes. J Phys Chem B 2006; 110(23):11103-9.

[363] Wang X, Li Q, Xie J, Jin Z, Wang J, Li Y, et al. Fabrication of ultralong and electrically uniform single-walled carbon nanotubes on clean substrates. Nano Lett 2009; 9(9):3137-41.

[364] Diarra M, Zappelli A, Amara H, Ducastelle F, Bichara C. Importance of carbon solubility and wetting properties of nickel nanoparticles for single wall nanotube growth. Phys Rev Lett 2012; 109(18):185501.

[365] Baker RTK, Harris PS. In: Jr. PLW, Thrower PA, editors. Chemistry and Physics of carbon, volume 14. New York: Marcel Dekker; 1978. p. 83.

[366] Wagner RS, Ellis WC. Vapor-liquid-solid mechanism of single crystal growth. Appl Phys Lett 1964; 4(5):89-90.

[367] Kukovitsky EF, L'vov SG, Sainov NA. VLS-growth of carbon nanotubes from the vapor. Chem Phys Lett 2000; 317:65-70.

[368] Page AJ, Chandrakumar KRS, Irle S, Morokuma K. SWNT nucleation from carboncoated $\mathrm{SiO} 2$ nanoparticles via a vapor-solid-solid mechanism. J Am Chem Soc 2010; 133(3):621-8.

[369] Wirth CT, Hofmann S, Robertson J. State of the catalyst during carbon nanotube growth. Diamond Rel Mat 2009; 18(5-8):940-5.

[370] Hofmann S, Blume R, Wirth CT, Cantoro M, Sharma R, Ducati C, et al. State of transition metal catalysts during carbon nanotube growth. J Phys Chem C 2009; 113(5):164856.

[371] Emmenegger C, Bonard J-M, Mauron P, Sudan P, Lepora A, Grobety B, et al. Synthesis of carbon nanotubes over Fe catalyst on aluminium and suggested growth mechanism. Carbon 2003; 41(3):539-47.

[372] Sharma R, Moore E, Rez P, Treacy MMJ. Site-specific fabrication of Fe particles for carbon nanotube growth. Nano Lett 2009; 9(2):689-94.

[373] Landois P, Rouziére S, Pinault M, Porterat D, Mocuta C, Elkaim E, et al. Growth of aligned multi-walled carbon nanotubes: First in situ and time-resolved X-ray diffraction analysis. Phys Status Solidi A 2011; 248(11):2449-53.

[374] He Z, Maurice J-L, Gohier A, Lee CS, Pribat D, Cojocaru CS. Iron catalysts for the growth of carbon nanofibers: Fe, Fe3C or both? Chem Mater 2011; 23(24):5379-87.

[375] Wirth CT, Bayer BC, Gamalski AD, Esconjauregui S, Weatherup RS, Ducati C, et al. The phase of iron catalyst nanoparticles during carbon nanotube growth. Chem Mater 2012; 24(24):4633-40.

[376] Wang Q, Ng MF, Yang SW, Yang Y, Chen Y. The mechanism of single-walled carbon nanotube growth and chirality selection induced by carbon atom and dimer addition. ACS Nano 2010; 4(2):939-46.

[377] Lee GD, Han S, Yu J, Ihm J. Catalytic decomposition of acetylene on Fe (001): A first-principles study. Phys Rev B 2002; 66(8):081403.

[378] Vasenkov A, Sengupta D, Frenklach M. Multiscale modeling catalytic decomposition of hydrocarbons during carbon nanotube growth. J Phys Chem B 2009; 113(7):1877-82.

[379] Maruyama S, Miyauchi Y, editors. ACCVD growth, Raman and photoluminescence spectroscopy of isotopically modified single-walled carbon nanotubes. AIP Conf Proc; 2005. [380] Vesselli E, Baraldi A, Comelli G, Lizzit S, Rosei R. Ethanol decomposition: C-C cleavage selectivity on $\mathrm{Rh}$ (111). ChemPhysChem 2004; 5(8):1133-40. 
[381] Page AJ, Ohta Y, Irle S, Morokuma K. Mechanisms of single-walled carbon nanotube nucleation, growth, and healing determined using QM/MD methods. Acc Chem Res 2010; 43:1375-85.

[382] Amara H, Bichara C, Ducastelle F. Understanding the nucleation mechanisms of carbon nanotubes in catalytic chemical vapor deposition. Phys Rev Lett 2008; 100:056105. [383] Neyts EC, Shibuta Y, van Duin ACT, Bogaerts A. Catalyzed growth of carbon nanotube with definable chirality by hybrid molecular dynamics-force biased Monte Carlo simulations. ACS Nano 2010; 4(11):6665-72.

[384] Wesep RGV, Chen H, Zhu W, Zhang Z. Stable carbon nanoarches in the initial stages of epitaxial growth of graphene on $\mathrm{Cu}(111)$. J Chem Phys 2011; 134(17):171105.

[385] Loginova E, Bartelt NC, Feibelman PJ, McCarty KF. Evidence for graphene growth by C cluster attachment. New J Phys 2008; 10:093026.

[386] Feng H, Ma J, Hu Z. Six-membered-ring-based radical mechanism for catalytic growth of carbon nanotubes with benzene precursor. J Phys Chem C 2009; 113(37):16495502.

[387] Eres G, Rouleau C, Yoon M, Puretzky A, Jackson J, Geohegan D. Model for selfassembly of carbon nanotubes from acetylene based on real-time studies of vertically aligned growth kinetics. J Phys Chem C 2009; 113(35):15484-91.

[388] Plata DL, Meshot ER, Reddy CM, Hart AJ, Gschwend PM. Multiple alkynes react with ethylene to enhance carbon nanotube synthesis, suggesting a polymerization-like formation mechanism. ACS Nano 2010; 4(12):7185-92.

[389] Dai H, Rinzler AG, Nikolaev P, Thess A, Colbert DT, Smalley RE. Single-wall nanotubes produced by metal-catalyzed disproportionation of carbon monoxide. Chem Phys Lett 1996; 260:471-5.

[390] Kuznetsov VL, Usoltseva AN, Chuvilin AL, Obraztsova ED, Bonard J-M. Thermodynamic analysis of nucleation of carbon deposits on metal particles and its implications for the growth of carbon nanotubes. Phys Rev B 2001; 64(23):235401. [391] Dijon J, Szkutnik P, Fournier A, Goislard de Monsabert T, Okuno H, Quesnel E, et al. How to switch from a tip to base growth mechanism in carbon nanotube growth by catalytic chemical vapour deposition. Carbon 2010; 48(13):3953-63.

[392] Kanzow H, Lenski C, Ding A. Single-wall carbon nanotube diameter distributions calculated from experimental parameters. Phys Rev B 2001; 63:125402.

[393] Schebarchov D, Hendy SC, Ertekin E, Grossman JC. Interplay of wetting and elasticity in the nucleation of carbon nanotubes. Phys Rev Lett 2011; 107(18):185503. [394] Vanduijneveldt JS, Frenkel D. Computer-simulation study of free-energy barriers in crystal nucleation. J Chem Phys 1992; 96(6):4655-68.

[395] Tenwolde PR, Ruizmontero MJ, Frenkel D. Numerical evidence for bcc ordering at the surface of a critical fcc nucleus. Phys Rev Lett 1995; 75(14):2714-7.

[396] Zhao J, Martinez-Limia A, Balbuena PB. Understanding catalysed growth of singlewall carbon nanotubes. Nanotechnology 2005; 16(7):S575-S81.

[397] Raty JY, Gygi F, Galli G. Growth of carbon nanotubes on metal nanoparticles: A microscopic mechanism from ab initio molecular dynamics simulations. Phys Rev Lett 2005; 95(9):096103.

[398] Ohta Y, Okamoto Y, Page AJ, Irle S, Morokuma K. Quantum chemical molecular dynamics simulation of single-walled carbon nanotube cap nucleation on an iron particle. ACS Nano 2009; 3(11):3413-20.

[399] Page AJ, Irle S, Morokuma K. Polyyne chain growth and ring collapse drives Nicatalyzed SWNT growth: a QM/MD investigation. J Phys Chem C 2010; 114(18):8206-11. 
[400] Neyts EC, van Duin ACT, Bogaerts A. Changing chirality during single-walled carbon nanotube growth: a reactive molecular dynamics/Monte Carlo study. J Am Chem Soc 2011; 133(43):17225-31.

[401] Ribas M, Ding F, Balbuena P, Yakobson B. Nanotube nucleation versus carboncatalyst adhesion-Probed by molecular dynamics simulations. J Chem Phys 2009; 131:224501.

[402] Pigos E, Penev ES, Ribas MA, Sharma R, Yakobson BI, Harutyunyan AR. Carbon nanotube nucleation driven by catalyst morphology dynamics. ACS Nano 2011; 5(12):10096101.

[403] Brinkmann G, Fowler P, Manolopoulos D, Palser A. A census of nanotube caps. Chem Phys Lett 1999; 315(5):335-47.

[404] Reich S, Li L, Robertson J. Structure and formation energy of carbon nanotube caps. Phys Rev B 2005; 72:165423.

[405] Reich S, Li L, Robertson J. Control the chirality of carbon nanotubes by epitaxial growth. Chem Phys Lett 2006; 421:469-72.

[406] Liu Y, Dobrinsky A, Yakobson BI. Graphene edge from armchair to zigzag: the origins of nanotube chirality? Phys Rev Lett 2010; 105(23):235502.

[407] Koziol KKK, Ducati C, Windle AH. Carbon nanotubes with catalyst controlled chiral angle. Chem Mater 2010; 22(17):4904-11.

[408] Luo Z, Kim S, Kawamoto N, Rappe AM, Johnson ATC. Growth mechanism of hexagonal shape graphene flakes with zigzag edges. ACS Nano 2011; 5(11):9154-60.

[409] Booth TJ, Pizzocchero F, Andersen H, Hansen TW, Wagner JB, Jinschek JR, et al. Discrete dynamics of nanoparticle channelling in suspended graphene. Nano Lett 2011;

11(7):2689-92.

[410] Zhang Y, Li Z, Kim P, Zhang L, Zhou C. Anisotropic hydrogen etching of chemical vapor deposited graphene. ACS Nano 2012; 6(1):126-32.

[411] Shu H, Chen XS, Taob XM, Dinga F. Edges structural stability and kinetics of graphene chemical vapor deposition (CVD) growth. ACS Nano 2012; 6(4):3243-50.

[412] Rao R, Liptak D, Cherukuri T, Yakobson BI, Maruyama B. In situ evidence for chirality-dependent growth rates of individual carbon nanotubes. Nature Mat 2012; 11(3):2136.

[413] Zhao J, Balbuena PB. Structural and reactivity properties of finite length cap-ended single-wall carbon nanotubes. J Phys Chem A 2006; 110(8):2771-5.

[414] Wang Q, Yang SW, Yang Y, Chan-Park MB, Chen Y. Charge transfer between metal clusters and growing carbon structures in chirality-controlled single-walled carbon nanotube growth. J Phys Chem Lett 2011; 2:1009-14.

[415] Gomez-Gualdron DA, Balbuena PB. Effect of metal cluster-cap interactions on the catalyzed growth of single-wall carbon nanotubes. J Phys Chem C 2008; 113(2):698-709.

[416] Ding F, Harutyunyan AR, Yakobson BI. Dislocation theory of chirality-controlled nanotube growth. Proc Natl Acad Sci U S A 2009; 106(8):2506.

[417] Dumlich H, Reich S. Chirality-dependent growth rate of carbon nanotubes: A theoretical study. Phys Rev B 2010; 82(8):085421.

[418] Chandra B, Bhattacharjee J, Purewal M, Son Y-W, Wu Y, Huang M, et al. Molecularscale quantum dots from carbon nanotube heterojunctions. Nano Lett 2009; 9(4):1544-8.

[419] Kim J, Page AJ, Irle S, Morokuma K. Dynamics of local chirality during SWCNT growth: armchair versus zigzag nanotubes. J Am Chem Soc 2012; 134(22):9311-9.

[420] Börjesson A, Bolton K. First principles studies of the effect of Ostwald ripening on carbon nanotube chirality distributions. ACS Nano 2011; 5(2):771-9. 
[421] Liu J, Wang C, Tu X, Liu B, Chen L, Zheng M, et al. Chirality-controlled synthesis of single-wall carbon nanotubes using vapour-phase epitaxy. Nature Communications 2012; 3:1199. 